JAQUELLINE MARIA JARDIM

\title{
AVALIAÇÃO DAS PRÁTICAS DE PREVENÇÃO E CONTROLE DA INFECÇÃO DA CORRENTE SANGUÍNEA ASSOCIADA AO CATETER VENOSO CENTRAL DE CURTA PERMANÊNCIA POR MEIO DE INDICADORES CLÍNICOS
}

\author{
Dissertação apresentada à escola de \\ Enfermagem da Universidade de São Paulo \\ para obtenção do título de Mestre em Ciências \\ Área de concentração: Enfermagem na Saúde \\ do Adulto
}

Orientador: Profa. Rúbia Aparecida Lacerda

SÃO PAULO

2011 


\section{AUTORIZO A REPRODUÇÃO E DIVULGAÇÃO TOTAL OU PARCIAL DESTE TRABALHO, POR QUALQUER MEIO CONVENCIONAL OU ELETRÔNICO, PARA FINS DE ESTUDO E PESQUISA, DESDE QUE CITADA A FONTE.}

Assinatura:

Data:

Jardim, Jaquelline Maria

Avaliação das práticas de prevenção e controle da infecção da corrente sanguínea associada ao cateter venoso central de curta permanência por meio de indicadores clínicos / Jaquelline Maria Jardim. -- São Paulo, 2011. $175 \mathrm{p}$.

Dissertação (Mestrado) - Escola de Enfermagem da Universidade de São Paulo.

Orientadora: Prof ${ }^{a}$ Dr $^{a}$ Rúbia Aparecida Lacerda

1. Infecção hospitalar 2. Cateterismo venoso central 3. Indicadores de qualidade I. Título. 
Nome: Jaquelline Maria Jardim

Título: Avaliação das práticas de prevenção e controle da infecção da corrente sanguínea associada ao cateter venoso central de curta permanência por meio de indicadores clínicos

Dissertação apresentada à Escola de Enfermagem da Universidade de São Paulo para obtenção do título de Mestre em Ciências.

Área de concentração: Enfermagem na Saúde do Adulto.

Aprovada em:

\section{Banca Examinadora}

Prof. Dr. Instituição:

Julgamento: Assinatura:

Prof. Dr. Instituição:

Julgamento: Assinatura:

Prof. Dr. Instituição: Julgamento: Assinatura: 
"Falar é completamente fácil, quando se tem palavras em mente que expressem sua opinião...

Difícil é expressar por gestos e atitudes o que realmente queremos dizer.

Fácil é julgar pessoas que estão sendo expostas pelas circunstâncias...

Difícil é encontrar e refletir sobre os seus próprios erros.

Fácil é fazer companhia a alguém, dizer o que ele deseja ouvir...

Difícil é ser amigo para todas as horas e dizer a verdade quando for preciso.

Fácil é analisar a situação alheia e poder aconselhar sobre a mesma...

Difícil é vivenciar esta situação e saber o que fazer.

Fácil é demonstrar raiva e impaciência quando algo o deixa irritado...

Difícil é expressar o seu amor a alguém que realmente o conhece.

Fácil é viver sem ter que se preocupar com o amanhã...

Difícil é questionar e tentar melhorar suas atitudes impulsivas e às vezes impetuosas, a cada dia que passa.

Fácil é mentir aos quatro ventos o que tentamos camuflar...

Difícil é mentir para o nosso coração.

$$
(\ldots) "
$$

Carlas Drummand de Andrade 


\section{DEDICATÓRIA}

Aos meus queridos e amados Pais José e Vera

Por compartilharem comigo todas as minhas dores e conquistas, amo vocês.

\section{Ao meu Marido Cléber,}

Companheiro de todos os momentos, obrigada pela compreensão e carinho ao longo do período de elaboração deste trabalho, você me faz a pessoa mais feliz do mundo.

\section{Ao meu Irmão Júlio César}

Que embora longe, está sempre ao meu lado em todos os desafios. 


\section{AGRADECIMENTOS}

A Deus, que todos ilumina e abençoa com paz serenidade e sabedoria os nossos caminhos.

À Prof ${ }^{a} r^{a}$ Rúbia Aparecida Lacerda, minha orientadora, pela idealização e incentivo para a realização desse estudo.

À Equipe de Enfermagem da UTI Cirúrgica- Adulto, por permitirem e colaborarem na realização do estudo.

À Enfermeira e Amiga Naury de Jesus Danzy, por sua disponibilidade e dedicação pelos ensinamentos quanto à análise estatística e acima de tudo pela generosidade em me auxiliar na fase final com tanto afinco, mesmo nas adversidades.

À Enfermeira Bruna Nunes, a minha gratidão pelo profissionalismo, ética e empenho em participarem da coleta de dados, fundamental para o desenvolvimento da pesquisa.

Ao Ricardo Luís Barbosa, pela valiosa participação, contribuição estatística e resistência, mesmo nos momentos de indecisão.

Aos amigos de trabalho e da vida, obrigada por torcerem por mim.

A todos os pacientes que no anonimato contribuíram para este estudo. 
Jardim JM. Avaliação das práticas de prevenção e controle da infeç̧ão da corrente sanguínea associada ao cateter venoso central de curta permanência por meio de indicadores clínicos [dissertação]. São Paulo (SP), Brasil: Escola de Enfermagem, Universidade de São Paulo; 2011.

\section{RESUMO}

Há praticamente consenso de que o processo de trabalho de prevenção e controle de infecção relacionada à assistência à saúde (IrAS), pautado em indicadores de resultados, são limitados para reconhecer as condições reais em que as práticas assistenciais são realizadas. Para tanto, avaliações processuais vêm sendo utilizadas, para conhecer o grau de conformidade dessas ocorrências de acordo com as recomendações dadas por evidências científicas atualmente disponíveis. Este estudo teve a finalidade de avaliar a conformidade de práticas de prevenção e controle de infecção da corrente sanguínea associada ao cateter venoso central (ICS-ACVC), por meio de indicadores clínicos processuais especificamente elaborados. Tais práticas corresponderam a: a) Avaliação das práticas de registro de indicação e tempo de permanência do cateter venoso central de curta permanência; b) Avaliação das práticas de inserção do cateter venoso central de curta permanência: inserção percutânea, paramentação completa para inserção de CVC, campo estéril ampliado no momento da instalação do cateter, uso de anti-séptico de veículo alcoólico para preparo da pele do paciente, presença de curativo oclusivo; c) Avaliação da prática de adesão aos cuidados e manutenção do curativo da inserção do CVC e seus dispositivos: registro de troca do curativo, periodicidade da troca do curativo, desinfecção de hubs e conectores com clorexidina alcoólica $0,5 \%$ antes da manipulação, troca de equipos e transdutores conforme orientação institucional; d) Avaliação da adesão à higiene das mãos em procedimentos de troca do sistema de infusão, administração de medicamentos, coleta de sangue, troca e realização de curativo. Tratou-se de uma pesquisa aplicada envolvendo achados sobre o desempenho de práticas e procedimentos, buscando acessar sua qualidade, com delineamentos prospectivo, transversal e analítico. O cenário foi a UTI cirúrgica-Adulto de um Hospital Público de Ensino. A casuística correspondeu às oportunidades de avaliação das práticas selecionadas, realizadas por médicos, enfermeiros, auxiliares e técnicos de enfermagem, nos três turnos de trabalho, quando pertinente, em pacientes que teriam um CVC inserido e/ou que já possuíam CVC. A amostra baseou-se na conformidade esperada de 80\%, com 5877 avaliações distribuídas entre as práticas selecionadas, realizadas por meio de observação direta ou registros em prontuários. Instrumentos e 
avaliadores foram submetidos a testes de aferição de concordância. A conformidade geral das práticas de registro de indicação e tempo de permanência do cateter venoso central de curta permanência foi de $91,6 \%$. A conformidade geral obtido na avaliação das práticas de inserção do cateter venoso central de curta permanência foi nula $(0,0 \%)$, que ocorreu devido à ausência do curativo oclusivo na inserção do $\operatorname{CVC}(0,0 \%)$, quanto às demais práticas avaliadas, todas obtiveram conformidade total (100,0\%). A conformidade da prática de adesão aos cuidados e manutenção do curativo da inserção do CVC e seus dispositivos: registro de troca do curativo, periodicidade da troca do curativo, desinfecção de hubs e conectores com clorexidina alcoólica $0,5 \%$ antes da manipulação foi de $51,5 \%$, com a manhã o período que apresentou a maior taxa de conformidade $(69,3 \%)$ e a tarde a menor $(31,1 \%)$. A conformidade geral da prática de higiene das mãos na realização dos procedimentos selecionados foi apenas $10,7 \%$, sendo que a Troca e realização de curativo $(21,1 \%)$, seguindo-se Coleta de Sangue $(10,2 \%)$ e administração de medicamentos $(9,6 \%)$. O turno da manhã obteve maior adesão $(12,7 \%)$ e o noturno a menor $(8,4 \%)$. Nesta prática, o maior índice de conformidade foi obtido entre os enfermeiros em todas as práticas avaliadas (troca do sistema de infusão-18\%, coleta de sangue- $21,4 \%$, administração de medicamento- $20,4 \%$, troca e realização do curativo $21,7 \%$ ). Concluiu-se que, embora a avaliação das práticas de registro de indicação e tempo de permanência do cateter venoso central de curta permanência tenha atingido a conformidade esperada de $80 \%$, as demais práticas necessitam de uma nova elaboração de estratégias que assegurem a adesão duradoura das práticas de controle e prevenção de ICS-ACVC, associado à análise contínua de infra-estrutura, disponibilidade de material e carga de trabalho.

PALAVRAS-CHAVE: Infecção da corrente sanguínea associada ao cateter venoso central. Infecção relacionada à assistência à saúde. Cateter venoso central. Observação direta. Indicadores de qualidade. 
Jardim JM. Evaluation of practices for prevention and control of bloodstream infection associated with central venous catheter of short stay by means clinical indicators [dissertation]. São Paulo (SP), Brasil: Escola de Enfermagem, Universidade de São Paulo; 2011.

\section{ABSTRACT}

There is a consensus that the process of prevention and control healthcare associated infection ( $\mathrm{HAl}$ ), based on result indicators is limited to recognize the real conditions in which assistance practices are performed. So, processual evaluations have been required to know the conformity level of these events in relation to recommendations given by the scientific evidence now available. The aim of this study was to evaluation the conformity of practices for prevention and bloodstream infection control associated with central venous catheter (BSI - ACVC) by means of specifically elaborated processual clinical indicators. These practices corresponded to: a) Evaluation the practices of registration statement evaluation and central venous catheter for short stay evaluation; b) Evaluation the practices of the insertion of central venous catheter for short stay, percutaneous insertion, complete items for insertion of CVC, enlarged sterile field at the time of catheter insertion, use of antiseptic alcohol vehicle for the patient skin cleaning and occlusive dressing presence; c) Evaluation of the adherence to care practice and maintenance of CVC insertion healing and it devices: report of dressing and frequency changes, the hubs and connectors disinfection with chlorhexidine $0,5 \%$ before handling, exchange of catheters and transducers as institutional orientation; d) Evaluation of compliance to hand hygiene procedures in trading system for infusion, medication administration, blood collection, exchange an healing completion. This was an applied research involving findings about practices performance and procedures, aiming to access its quality, through a prospective transversal and analytical design. It took place in an surgical Adult - ICU of a Public School Hospital. The casuistic corresponded to opportunities of selected practices evaluation, performed by physicians, nurses, nursing assistants and technicians, in three work shift, where relevant, in patients who had a CVC inserted and / or who had CVC. The sample was based on the expected conformity of $80 \%$, with 5,877 evaluations distributed among the selected practices, performed by means of direct observation or registers in patient records. Instruments and evaluators were submitted to tests for measuring compliance. The general conformity practices registration statement and permanence of central venous catheter for short stay was $91,6 \%$. The overall conformity achieved in the evaluation of central venous catheter insertion a short stay was zero 
$(0,0 \%)$, which was due to the absence of occlusive dressings on CVC insertion $(0,0 \%)$, and the other evaluated practices all achieved full compliance $(100,0 \%)$. The conformity adherence to care practice and maintenance of healing of the CVC insertion and their devices: dressing change report, dressing change frequency, the disinfection of hubs and connectors with chlorhexidine $0.5 \%$ before the manipulation was $51,5 \%$, being that morning shift has the highest compliance rate $(69,3 \%)$ and the afternoon shift the smallest $(31,1 \%)$. The overall conformity of hand hygiene practice in the performance of selected procedures was only $10,7 \%$, and the exchange and completion of healing $(21,1 \%)$, followed by blood collection $(10,2 \%)$ and administration drugs $(9,6 \%)$. The morning shift had better adherence $(12,7 \%)$ and the lowest night shift $(8,4 \%)$. In the practice, the highest rate of compliance among nurses was obtained in all evaluated practices (exchange of the infusion system $-18 \%$, blood collection $-21,4 \%$, drug delivery $-20,4 \%$, exchange and completion of dressing $21,7 \%$ ). We have concluded that although the registration statement evaluation and permanence of central venous catheter for short stay has reached $80 \%$ as expected, other practices have needed a new formulation of strategies that ensure lasting adhesion of control practices and prevention of ICS-ACVC, associated to a continuum analysis of infra-structure and work conditions.

KEYWORDS: Bloodstream infection-associated central venous catheter. Infection related to health care. Central venous catheter. Direct observation. Quality of indicators. 


\section{LISTA DE ABREVIATURAS E SIGLAS}

$\begin{array}{ll}\text { CaPPesq } & \text { Comissão de Ética para Análise de Projetos de Pesquisa } \\ \text { CC } & \text { Centro Cirúrgico } \\ \text { CCIH } & \text { Comissão de Controle de Infecção Hospitalar } \\ \text { CDC } & \text { Centro de controle e Prevenção de Doenças } \\ \text { CSIP } & \begin{array}{l}\text { Registros de indicação e tempo de permanência do CVC } \\ \text { de curta permanência }\end{array} \\ \text { CSQI } & \text { Qualidade de inserção do CVC de curta permanência } \\ \text { CSCM } & \text { Adesão aos cuidados e manutenção do curativo do CVC } \\ \text { CVC } & \text { de curta permanência e seus dispositivos } \\ \text { FAV } & \text { Cateter venoso central } \\ \text { HCFMUSP } & \text { Fístula arteriovenosa } \\ \text { HMSEL } & \text { Universidade de São Paulo } \\ \text { HM } & \text { Higiene das mãos em procedimentos selecionados } \\ \text { ICS } & \text { Higiene das mãos } \\ \text { ICS-ACVC } & \text { Infecção da corrente sanguínea } \\ \text { IH } & \text { Infecção da corrente sanguínea associada a cateter } \\ \text { InCor } & \text { venoso central } \\ \text { INICC } & \text { Infecção Hospitalar } \\ \text { ISC } & \text { Instituto do Coração } \\ \text { ITU } & \text { International Nosocomial Infection Control Consortium } \\ \text { JCAHO } & \text { Infecção relacionada à assistência à saúde } \\ & \text { Joint Comão do sítio cirúrgico } \\ \text { Infeccão do trato urinário }\end{array}$




$\begin{array}{ll}\text { k } & \text { Kappa } \\ \text { MS } & \text { Ministério da Saúde } \\ \text { NHSN } & \text { National Healthcare Safety Network } \\ \text { NPT } & \text { Nutrição parenteral total } \\ \text { OD } & \text { Observação direta } \\ \text { OMS } & \text { Organização Mundial da Saúde } \\ \text { PCIH } & \text { Programas de Controle de Infecção Hospitalar } \\ \text { PICC } & \text { Cateter central inserido perifericamente } \\ \text { PN } & \text { Pneumonia } \\ \text { PO } & \text { Pós-operatório } \\ \text { PVC } & \text { Pressão venosa central } \\ \text { SAE } & \text { Sistematização da Assistência de Enfermagem } \\ \text { SARM } & \text { Staphylococcus aureus resistente à meticilina } \\ \text { SC } & \text { Subclávia } \\ \text { SNE } & \text { Sonda Nasoentérica } \\ \text { SPSS } & \text { Statistical Package for the Social Science } \\ \text { SUS } & \text { Sistema Único de Saúde } \\ \text { TCLE } & \text { Termo de consentimento livre esclarecido } \\ \text { UCIH } & \text { Unidade de Controle de Infecção Hospitalar } \\ \text { UCO } & \text { Unidade Coronariana } \\ \text { UFC } & \text { Unidade Formadora de Colônia } \\ \text { UTI } & \text { Veia femoral jugular } \\ \text { VF } & \\ \text { VJ } & \end{array}$




\section{LISTA DE FIGURAS}

Figura 1 - Vias de acesso para contaminação de um dispositivo vascular ....34 


\section{LISTA DE QUADROS}

Quadro 1 - Distribuição da taxa de infecção da corrente sanguínea associada ao cateter venoso central entre hospitais participantes do NHSN, CDC, 2006-2007

Quadro 2 - Revisão integrativa de estudos sobre intervenção educacional e redução das taxas de infecção da corrente sanguínea associada ao cateter venoso central em Unidade de Terapia Intensiva adulto. São Paulo, 2010 


\section{LISTA DE TABELAS}

Tabela 1 - Distribuição da amostra para avaliação das práticas de Inserção e Registros de Indicação e Tempo de Permanência do Cateter Venoso Central de Curta Permanência. São Paulo, 2010

Tabela 2 - Distribuição da amostra para avaliação da prática de adesão aos cuidados e manutenção do curativo da inserção do CVC e seus dispositivos. São Paulo, 2010

Tabela 3 - Distribuição da amostra para avaliação da prática de adesão à higiene das mãos. São Paulo, 2010

Tabela 4 - Aferição da concordância obtida entre a dupla de avaliadores para os componentes do indicador CSIP. São Paulo, 2010 .....72

Tabela 5 - Aferição da concordância obtida entre a dupla de avaliadores para os componentes do indicador CSQI. São Paulo, 2010 .....72

Tabela 6 - Aferição de concordância obtida entre a dupla de avaliadores para o indicador HMSEL. São Paulo, 2010

Tabela 7 - Aferição de concordância obtida entre a dupla de avaliadores para os componentes do indicador HMSEL. São Paulo, 2010......74

Tabela 8 - Aferição da concordância obtida entre a dupla de avaliadores para os componentes do indicador CSCM. São Paulo, 2010 ...75

Tabela 9 - Conformidade geral da prática de registro de indicação e tempo de permanência do cateter venoso central de curta permanência (Indicador CSIP). São Paulo, 2010. 
Tabela 10 - Conformidade e não conformidade dos componentes da prática de registro de indicação e de tempo de permanência do cateter venoso central de curta permanência (Indicador CSPI). São Paulo, 2010

Tabela 11 - Conformidade e não conformidade dos componentes da prática de inserção do cateter venoso central de curta permanência (Indicador CSQI). São Paulo, 2010

Tabela 12 - Conformidade geral da prática de adesão aos cuidados e manutenção do curativo do cateter venoso central de curta permanência e seus dispositivos (Indicador CSCM), de acordo com o turno de trabalho. São Paulo, 2010

Tabela 13 - Conformidade e não conformidade dos componentes da prática de cuidados e manutenção do curativo do cateter venoso central de curta permanência e seus dispositivos, segundo o turno de trabalho. São Paulo, 2010

Tabela 14 - Causas de não conformidade dos componentes da prática de cuidados e manutenção do curativo do cateter venoso central de curta permanência e seus dispositivos, de acordo com o turno de trabalho. São Paulo, 2010

Tabela 15 - Conformidade e não conformidade do componente adesão à desinfecção de hubs e conectores com clorexidina alcoólica $0,5 \%$ antes da manipulação, segundo a categoria profissional e turno de trabalho. São Paulo, 2010

Tabela 16 - Conformidade e não conformidade do componente desinfecção de hubs e conectores com clorexidina alcoólica $0,5 \%$ antes da manipulação, de acordo com os turnos de trabalho. São Paulo, 2010 
Tabela 17 - Conformidade geral e por componentes da prática de higiene das mãos em situações selecionadas. São Paulo, 2010

Tabela 18 - Conformidade geral da prática de higiene das mãos de acordo com os turnos de trabalho. São Paulo, 2010

Tabela 19 - Oportunidades da prática de higiene das mãos segundo a categoria profissional, o tipo de procedimento observado e o turno de trabalho. São Paulo, 2010.

Tabela 20 - Conformidade e não conformidade em relação à prática de higiene das mãos de acordo com a categoria profissional e procedimentos selecionados. São Paulo, 2010

Tabela 21 - Conformidade e não conformidade na adesão à prática de higiene das mãos conforme procedimentos selecionados, categoria profissional e o turno de trabalho. São Paulo, 2010 .....94

Tabela 22 - Conformidade e não conformidade da prática de higiene das mãos de acordo com os procedimentos selecionados e turno de trabalho. São Paulo, 2010

Tabela 23 - Causas de não conformidades da prática de higiene das mãos, de acordo com os procedimentos selecionados e a categoria profissional. São Paulo, 2010 


\section{LISTA DE GRÁFICOS}

Gráfico 1 - Conformidade dos componentes da prática de registro de indicação e tempo de permanência do cateter venoso central de curta permanência (Indicador CSPI). São Paulo, 2010 .........78

Gráfico 2 - Conformidade de cada componente da prática de inserção do cateter venoso central de curta permanência (Indicador CSQI). São Paulo, 2010 


\section{SUMÁRIO}

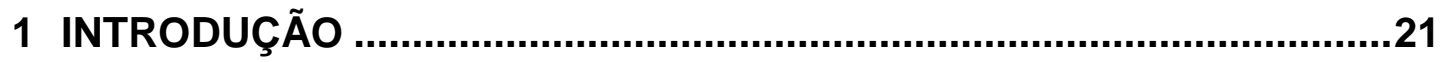

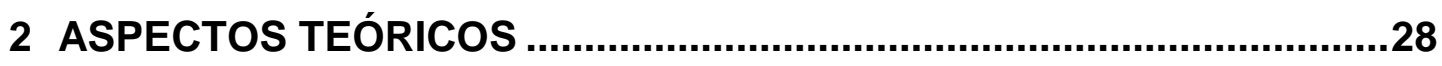

2.1 SOBRE A INFECÇÃO DA CORRENTE SANGUÍNEA ........................29

2.1.1 A diversidade de cateteres e sua relação com a infecção da corrente sanguínea .................................................................29

2.1.2 Infecção da Corrente Sanguínea Associada a Cateteres Venosos de Curta Permanência ..................................................................32

2.1.3 Patogênese da infecção da corrente sanguínea associada ao cateter venoso central de curta permanência...................................33

2.1.4 Fatores de risco para infecção da corrente sanguínea associada ao cateter venoso central de curta permanência................................35

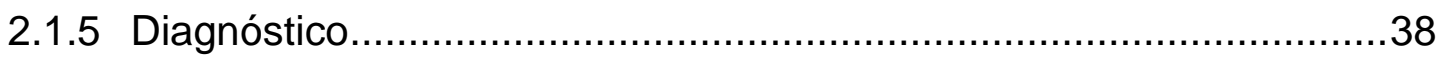

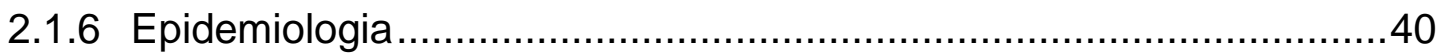

2.1.7 Medidas de Prevenção .................................................................

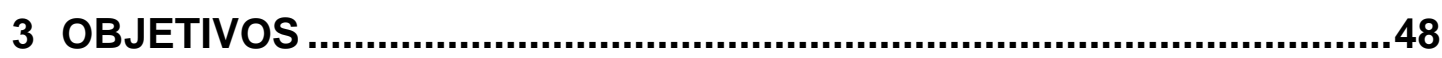

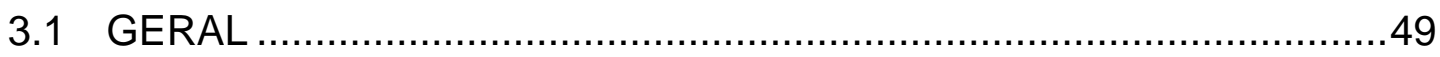

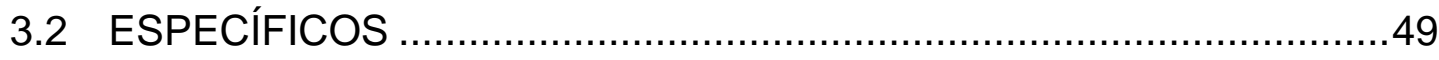

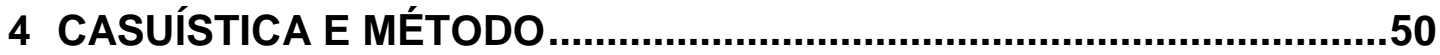

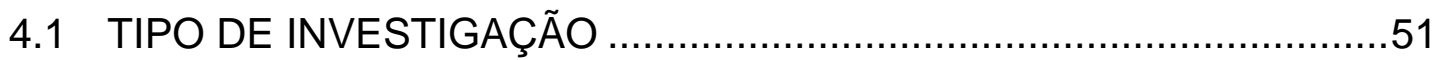

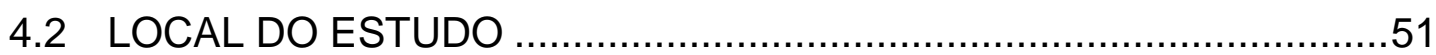

4.3 PRÁTICAS DE PREVENÇÃO E CONTROLE DA ICS-ACVC

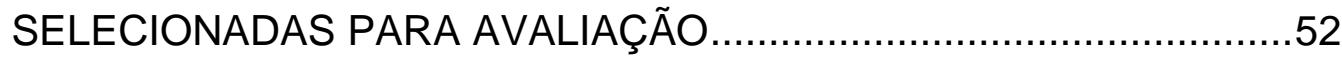

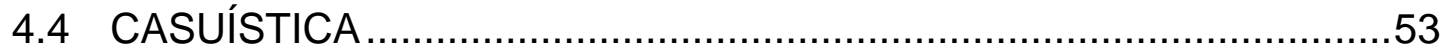

4.4.1 Critérios de inclusão para as avaliações ………..............................53

4.4.2 Critérios de exclusão para as avaliações .........................................54

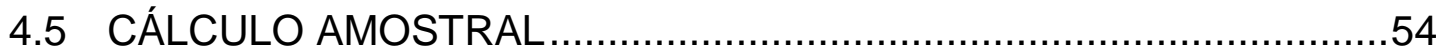

4.5.1 Cálculo amostral referente à avaliação das práticas de inserção e registros de indicação e tempo de permanência do cateter venoso central de curta permanência.

4.5.2 Cálculo amostral referente à avaliação da prática de adesão aos cuidados e manutenção do curativo da inserção do CVC e seus dispositivos 
4.5.3 Cálculo amostral referente à avaliação da prática de adesão à higiene das mãos

4.6 INSTRUMENTOS PARA AVALIAÇÃO DAS PRÁTICAS DE PREVENÇÃO E CONTROLE DE ICS-ACVC

4.7 TESTES DE PRECISÃO DOS INSTRUMENTOS DE AVALIAÇÃO ......61

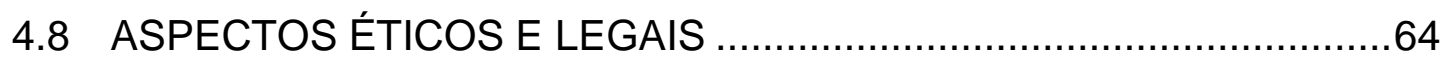

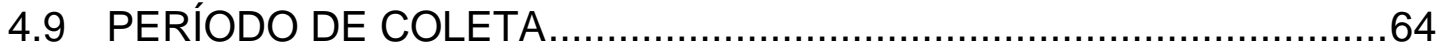

4.10 PROCEDIMENTOS DA COLETA DE DADOS …................................65

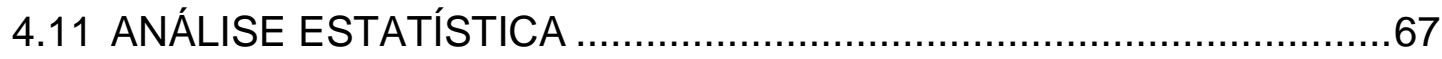

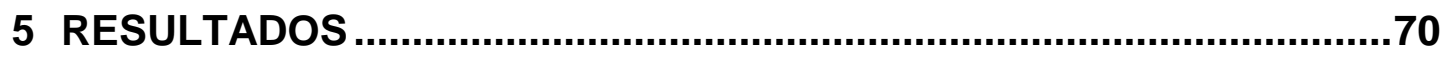

5.1 AVALIAÇÃO DA CONCORDÂNCIA ENTRE OS AVALIADORES INTER E INTRA INSTRUMENTOS ...................................................71

5.2 AVALIAÇÕES DAS PRÁTICAS DE PREVENÇÃO E CONTROLE

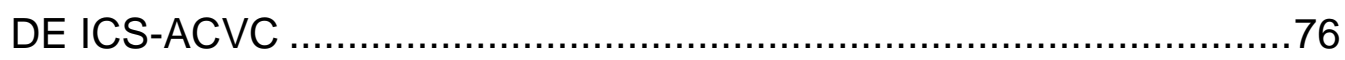

5.2.1 Avaliação da prática de registro de indicação e de tempo de permanência do cateter venoso central de curta permanência (Indicador CSIP)

5.2.2 Avaliação da prática de inserção do cateter venoso central de curta permanência (Indicador CSQI)

5.2.3 Avaliação da prática de adesão aos cuidados e manutenção do curativo do cateter venoso central de curta permanência e seus dispositivos, conforme recomendação da instituição (Indicador CSCM).

5.2.4 Avaliação da prática de higiene das mãos em procedimentos selecionados (Indicador HMSEL)

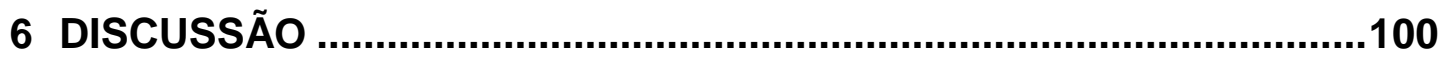

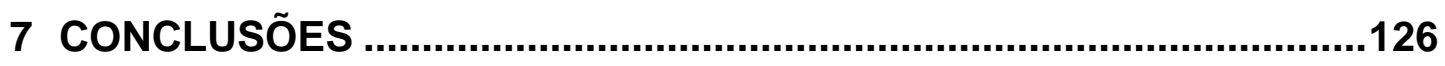

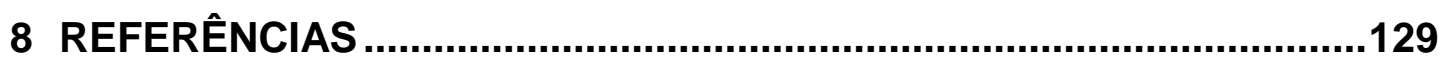

9 APÊNDICES

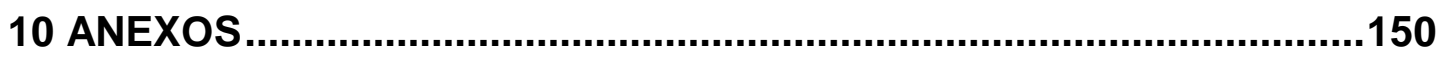


1 INTRODUÇÃO 
Este estudo teve a finalidade de avaliar práticas de prevenção e controle de infecção da corrente sanguínea associada ao cateter venoso central de curta permanência (ICS-ACVC).

A infecção hospitalar $(\mathrm{IH})$, hoje denominada como infecção relacionada à assistência à saúde (IrAS) - por refletir melhor o risco de aquisição dessas infecções -, surgiu no período medieval, época em que foram criadas instituições para alojar pessoas doentes, peregrinos, pobres e inválidos. Essa reunião indiscriminada de pessoas em um mesmo ambiente facilitava a transmissão de doenças contagiosas, pois as práticas de prevenção e controle de infecções, nessa época, ainda não haviam surgido, e esses locais não eram vistos como instituições médicas, já que a medicina era exercida de forma liberal e individualizada ${ }^{(1-3)}$.

As primeiras práticas de controle de infecção só foram surgir com a transformação destas instituições - chamadas com o decorrer do tempo de hospitais - em um local de cura e medicalização, na qual o corpo passou a ser visto como objeto potencial de trabalho ${ }^{(2)}$

A atuação de Florence Nightingale foi um divisor de águas para a ocorrência dessas mudanças, já que o hospital, antes dela, era como uma casa de repouso, onde a morte convivia com a vida, os insetos e roedores disputavam o alimento com os pacientes e os doentes eram colocados em um mesmo ambiente, independente das moléstias, sem nenhuma condição de saneamento, ventilação ou cuidados dirigidos. Após Florence, os hospitais passaram a ver a saúde como o maior bem produzido, a morte como indesejável e a melhoria da qualidade de vida uma busca constante ${ }^{(4)}$.

Mesmo com essas alterações, o ambiente hospitalar ainda continua sendo um local propício para o desenvolvimento de infecções, principalmente devido à sua microbiota residente ${ }^{(5)}$.

$\mathrm{Na}$ década de 60, o reconhecimento da IrAS como problema, resultou no surgimento de Programas de Controle de Infecção Hospitalar (PCIH). Contudo, foi somente entre 1970 e 1980, nos Estados Unidos, que tais programas se sistematizaram como os conhecemos atualmente, por meio da 
organização de Comissões de Controle de Infecção Hospitalar (CCIH). Na França, esse reconhecimento ocorreu apenas em 1988, com a criação dos Comitês de Controle de Infecção ${ }^{(6)}$.

No Brasil, a primeira $\mathrm{CCIH}$, nesse modelo, foi criada em 1963, no Hospital Ernesto Dornelles, no Rio Grande do Sul. Contudo, foi a década de 80 a mais importante para o desenvolvimento do controle da IrAS no Brasil. A morte de Tancredo Neves, que teve sua condição clínica agravada pela infecção, ocasionou maior conscientização dos profissionais de saúde a respeito do tema, acarretando expansão dessas comissões de controle nos hospitais ${ }^{(7-8)}$.

A primeira ação governamental para o controle das IrAS ocorreu apenas em 1983, com a criação da Portaria 196/1983, a qual determinava a criação da $\mathrm{CCIH}$ e sua normatização. Esta Portaria estabelecia os critérios diagnósticos para infecção, orientava vigilância passiva da mesma - análise de prontuários após a alta do paciente - e notificação das infecções por parte dos profissionais da área assistencial. No entanto, a vigilância epidemiológica, ao ser recomendada de forma passiva, gerava alta subnotificação ${ }^{(9-10)}$.

Em 1992, o Ministério da Saúde (MS) expedia uma segunda Portaria, a de $n^{\circ}$ 930/92, substituindo a anterior, onde constavam orientações para todos os hospitais do país manterem um $\mathrm{PClH}$, independente da natureza da entidade mantenedora ${ }^{(11)}$. Mas, foi somente em 1997 que tal programa se tornou obrigatório, com a lei federal $n^{\circ} 9431^{(12)}$.

Finalmente, em 1998 foi editada a Portaria vigente, 2616/98, a qual enfatiza a composição da $\mathrm{CClH}$, suas atividades, as competências de seus membros, a realização de vigilância ativa das IrAS, bem como algumas recomendações e indicadores epidemiológicos para o controle das infecções ${ }^{(13)}$.

No entanto, mesmo com esta portaria e várias outras legislações correlacionadas, muitos hospitais têm dificuldades ou não operacionalizam os $\mathrm{PCIH}$ conforme as recomendações governamentais ${ }^{(14)}$.

Embora nem todos os casos de IrAS sejam evitáveis, há dados na literatura de que o estabelecimento e a aplicação de um programa de controle e prevenção efetiva contribuam para sua redução em até $85 \%$, e a 
realização de vigilância no meio hospitalar tem sido a forma mais utilizada como medida de prevenção ${ }^{(15)}$.

Contudo, essa vigilância não vem sendo considerada suficiente para reconhecer se as práticas recomendadas pelas melhores evidências para a redução das IrAS são realmente executadas ${ }^{(16)}$. Além disso, as informações obtidas sobre as taxas de infecção fornecidas em todo hospital têm de ser comparadas com dados de referência adequada para estimular um maior controle de infecção e efetividade da intervenção ${ }^{(17)}$.

As infecções que ocorrem com maior frequência no ambiente hospitalar, sabidamente, são: infecção do trato urinário (ITU), infecção da ferida cirúrgica (ISC), pneumonia (PN) e infecção da corrente sanguínea (ICS), respectivamente ${ }^{(5)}$. A ICS-ACVC, sabidamente, é uma das mais frequentes dentre todas as ocorrências de infecção no ambiente hospitalar em pacientes críticos ${ }^{(5)}$.

Neste estudo, dissertamos particularmente sobre a ICS, que apresenta uma etiopatogenia complexa e difere de paciente para paciente, assim como de microrganismo para microrganismo. Compreender sua patogênese é essencial para a elaboração de estratégias e sua prevenção ${ }^{(18)}$.

A principal causa de ICS são os dispositivos intravasculares, responsáveis por cerca de $1 / 3$ de todas as infecções primárias na corrente sanguínea ${ }^{(5)}$. Dentre esses, destaca-se o cateter venoso central (CVC) de curta permanência. É importante lembrarmos que em caso de Unidade de Terapia Intensiva (UTI), a taxa de infecção pode ser ainda maior, já que ele é mantido por maior tempo, o paciente tem maiores chances de colonização e a manipulação do CVC ocorre várias vezes ao dia para administração de fluidos, nutrição parenteral total (NPT), drogas e produtos do sangue ${ }^{(19)}$.

Várias medidas de prevenção e controle da ICS-ACVC já são conhecidas, principalmente por meio de diretrizes de recomendações internacionais. A maior questão, no entanto, é reconhecer se são seguidas (19-21). Nesse sentido, programas de educação para os indivíduos envolvidos na realização e promoção de intervenções na área da saúde são, sabidamente, fundamentais, porém não suficientes se não existirem estratégias para avaliar sua adesão. 
A higienização das mãos é a medida mais importante na prevenção e controle das IrAS, além de também ser a mais simples e eficaz a ser realizada. Porém, a falta de adesão dos profissionais de saúde a esta prática é uma realidade constatada. Em estudo conduzido por Pittet et al. (1999) ${ }^{(22)}$, no Hospital Universitário de Genebra, a adesão dos profissionais à prática de higienização das mãos foi considerada moderada, com média de $48 \%$ de aplicação da medida nas oportunidades geradas durante o dia de trabalho. $A$ principal causa de não realização da higienização das mãos foi falta de atenção à necessidade. A evidência mais contundente mostrada neste estudo foi que a menor adesão à higienização das mãos ocorreu durante as atividades de maior risco de transmissão de infecções.

Recentes estudos têm sugerido que a IrAS pode ser evitada através da implementação de evidências baseadas nas "melhores práticas", que nada mais são que uma série de esforços de melhoria envolvendo a execução simultânea de vários procedimentos ("bundles") (23).

Pronovost et al. (2006) demonstraram em um estudo de larga escala com 103 UTIs, em Michigan, que um conjunto de intervenções centrada na higiene das mãos, uso completo das precauções de barreira, limpeza da pele com clorexidina, evitar acesso femoral e remoção de cateter desnecessário, resultou em uma grande redução sustentada da taxa de ICSACVC ${ }^{(24)}$.

Hoje, apesar da melhoria das condições de atendimento, 0 aperfeiçoamento da mão-de-obra, a mudança da visão dos profissionais de saúde, assim como 0 avanço científico-tecnológico propiciando 0 desenvolvimento de procedimentos menos invasivos e técnicas de assepsia, a IrAS ainda figura como uma complicação frequente. Isso preocupa a equipe de saúde, pois além gerar altos custos com tratamento, afastamento familiar e perdas econômicas, outros problemas podem ocorrer, como a resistência bacteriana a diversos antimicrobianos, dificultando ainda mais seu combate. Por isso há a necessidade de alerta da equipe de saúde para a importância da prevenção e controle da ICS-ACVC ${ }^{(25-26)}$.

A aplicação de avaliações das práticas envolvidas no manejo do cateter venoso central é fundamental na prevenção e controle da ICS-ACVC. 
Com essa finalidade, a Secretaria de Estado da Saúde de São Paulo criou um Manual de Avaliação da Qualidade de Práticas de Controle de Infecção Hospitalar, concluído em 2006, que aborda tais práticas através de avaliações de processo ou desempenho ${ }^{(27)}$.

Quanto ao conteúdo desse manual, ele é composto por 59 indicadores de avaliação elaborados e distribuídos nos seguintes grupos: PC - programa de controle de infecção hospitalar; UA - uso de antimicrobianos; CS controle e prevenção da infecção da corrente sanguínea associada a cateter vascular de curta permanência; SC - controle e prevenção de infecção do sítio cirúrgico; IR - controle e prevenção da infecção respiratória; IU - controle e prevenção de infecção do trato urinário associada a cateterismo vesical; IS indicação e aplicação das medidas de isolamento; HM - Higiene das mãos; AR - processamento de artigos odonto-médico-hospitalares; RO - prevenção e controle de riscos ocupacionais biológicos ${ }^{(27)}$.

Esse conjunto de indicadores contempla avaliações de estrutura, processo e resultado, referentes ao controle e prevenção das infecções relacionadas à assistência à saúde. Sua forma de elaboração constitui uma proposta original quanto à sua aplicação e ao estabelecimento de índices de conformidade no que tange a assistência prestada. Cada indicador possui um guia operacional que orienta sua aplicação de maneira sistematizada, e estão fundamentados nas melhores práticas disponíveis, permitindo estabelecer o grau de conformidade das práticas realizadas em relação às esperadas. Além disso, favorece a identificação imediata de aspectos problemáticos das práticas avaliadas, permitindo reconhecer e direcionar, de maneira mais específica, ações de treinamento, assim como subsidiar a melhoria da sua conformidade ${ }^{(27)}$.

Para este estudo, foram utilizados os indicadores de avaliação do referido Manual, especificamente voltados às práticas de prevenção e controle da ICS-ACVC, além do indicador de adesão à higiene das mãos em situações relacionadas aos cuidados com inserção e manutenção o cateter venoso central de curta permanência. Todos esses indicadores correspondem a avaliações de processo ou desempenho ${ }^{(27)}$. 
Apesar do reconhecimento e a importância da adesão às medidas de prevenção e controle de ICS-ACVC estarem bem estabelecidas, a realidade aponta para uma necessidade de investigação, pois as evidências, na prática, mostram níveis insatisfatórios de adesão a estas medidas. Por isso, neste estudo, levantamos a hipótese de que as práticas adequadas de prevenção e controle de ICS-ACVC selecionadas não atingirão níveis de conformidades esperados. Sendo assim, esta investigação, além de avaliar essas práticas, permitirá identificar as situações de conformidade e não conformidade com relação os estudos científicos de melhor evidência e recomendações mais recentes para sua prevenção e controle. 
2 ASPECTOS TEÓRICOS 


\subsection{SOBRE A INFECÇÃO DA CORRENTE SANGUÍNEA}

\subsubsection{A diversidade de cateteres e sua relação com a infecção da corrente sanguínea}

A terminologia utilizada para identificar um cateter segue diversos critérios, pois cada pesquisador utiliza diferentes aspectos para sua designação. Ele pode ser identificado pelo tipo de inserção (periférico, central, arterial ou cateter central inserido perifericamente - PICC); permanência (temporários ou de curta permanência, permanentes ou de longa permanência); sítio de inserção (subclávia, femoral e jugular); comprimento físico (longo ou curto); características especiais do cateter (presença ou ausência de uma pulseira ou cuff, impregnação com heparina, antibióticos ou anti-sépticos, bem como o número de lumens) e material na qual ele é confeccionado (PVC, polietileno, poliuretano, sylastic, teflon, silicone ou siliconizados) ${ }^{(19,28)}$.

O uso da primeira agulha hipodérmica foi descrita em 1656 por Sir Christopher Wreu com a finalidade de infundir vinho e cerveja na corrente sanguínea de um cão. Desde então e principalmente nos últimos 30 anos, a variedade e o número de dispositivos intravasculares que são utilizados para o acesso vascular no sistema de cuidados de saúde, têm aumentado consideravelmente ${ }^{(29)}$.

A punção com agulha é a forma de acesso venoso mais antiga e frequentemente utilizada para a coleta de sangue e infusão de medicamento por curto período. Sua inserção ocorre frequentemente nos membros superiores e tem como principais problemas: flebite, extravasamento de fluido para o tecido e ruptura do dispositivo. A ICS por punção periférica é pouco descrita na literatura, podendo ser resultado da subnotificação ${ }^{(28)}$. 
Os cateteres venosos periféricos são os dispositivos mais utilizados para o acesso venoso. Embora a incidência da infecção local ou da corrente sanguínea associada aos cateteres periféricos também seja pouco relatada, complicações infecciosas graves produzem anualmente considerável morbidade devido à frequência com que tais cateteres são utilizados ${ }^{(19)}$.

Quando utilizamos cateteres periféricos ou agulhas para infusão de fluido, o tipo de solução administrada, localização do vaso, condições físicas do paciente, técnica utilizada para sua inserção, tamanho e tipo de material do cateter, estão diretamente relacionados com complicação ${ }^{(30)}$.

O cateter arterial que pode ser inserido na femoral, axilar, braquial ou artéria tibial posterior, é utilizado para realização de monitorização contínua da pressão arterial e pronto acesso para amostras de sangue, especialmente para medições de gasometria arterial. A taxa de ICS associada ao cateter arterial é mais baixa quando comparado ao CVC de curta permanência (1,7 versus 2,7 por 1000 cateteres/dia) ${ }^{(31)}$.

Os cateteres de linha média são inseridos através da fossa antecubital na basílica proximal ou veia cefálica e medem em torno de 3 a 8 polegadas. Apresentam menores taxas de flebite, no entanto, há casos de choque anafilático relatados com cateteres feitos de hidrogel elastomeric $^{(19)}$.

O cateter venoso central recebe esse nome quando, após sua inserção, termina no coração ou próximo deste, ou está situado em um grande vaso. Sua inserção deve ser realizada percutaneamente ${ }^{(19,29,32)}$.

O PICC, um cateter central inserido perifericamente por punção da veia basílica, cefálica ou braquial, é introduzido até a veia cava superior e está associado com menor incidência de complicação mecânica (trombose ou hemotórax) e de infecção quando comparado aos outros tipos de CVC ${ }^{(19,28)}$.

Outro CVC comumente encontrado em pacientes internados na Unidade de Terapia Intensiva (UTI) é o cateter da artéria pulmonar (Swan Ganz®) que é introduzido pela veia jugular ou subclávia por meio de um introdutor de teflon®. Tem por finalidade a monitorização hemodinâmica. De acordo com referências sobre o assunto há risco significante de colonização 
e ICS-ACVC quando este é mantido por um longo período, e a taxa de ICS relacionada a este cateter é semelhante ao cateter duplo lúmen ${ }^{(19,28,31)}$.

O cateter de hemodiálise também é um CVC, e podem ser inserido por punção ou dissecção e constitui um fator de contribuição para bacteremia em pacientes de diálise. $\mathrm{O}$ uso de cateteres temporários aumenta o risco relativo de desenvolver bacteremia em sete vezes quando são comparados com pacientes com fístula arteriovenosa (FAV) ${ }^{(31)}$.

A cateterização dos vasos umbilicais é frequentemente utilizada em recém-nascidos e permite a coleta de sangue e avaliação hemodinâmica. A incidência de ICS é semelhante entre o cateter umbilical venoso e arterial (19). Estima-se que a incidência de colonização desse tipo de cateter ocorra entre $40-50 \%$ dos cateteres inseridos ${ }^{(31)}$.

O primeiro cateter semi-implantável foi desenvolvido por Broviac, entre 1973 e 1979; Hickman e colaboradores aperfeiçoaram sua idéia e desenvolveram um cateter para pacientes de transplante de medula com maior diâmetro que os demais e com dois cuffs. Estes cateteres são implantados na subclávia, jugular interna ou veias femorais, e possuem duas porções, sendo uma intravascular inserida na subclávia e outra exteriorizada através de um túnel subcutâneo. Nesta última porção existe um cuff de dacron, que bloqueia a migração de bactérias ${ }^{(19,33)}$.

Já os cateteres implantáveis, são inseridos embaixo da pele, (subcutâneo) e possuem uma porta inserida na veia jugular interna ou subclávia. São confeccionados de plástico ou metal inerte, com um diafragma auto-selado de silicone, por onde é realizada infusão. Seu acesso é feito por punção da pele com uma agulha especial. Eles foram primeiramente descritos por Berlim e colaboradores, porém só foram utilizados a partir de 1982, com modificações do original ${ }^{(19,33)}$.

O material na qual os cateteres são confeccionados também está diretamente relacionado ao risco de infecção, estudos in vitro demonstram que cateteres feitos de cloreto de polivinil ou de polietileno são provavelmente menos resistentes à aderência de microrganismos do que os cateteres feitos de Teflon®, silicone ou poliuretano. Portanto, a maioria dos 
cateteres vendidos nos Estados Unidos já não é feita de polietileno ou cloreto de polivinil ${ }^{(19,33)}$.

Desde 1990, estratégias tecnológicas de cateteres impregnados com vários tipos de anti-sépticos (clorexidina e sulfadiazina de prata) e antimicrobianos (minociclina, rifampicina), têm sido desenvolvidas para reduzir o risco da ICS associado ao CVC ${ }^{(34-35)}$.

Apesar de o CVC impregnado existir a vários anos, a maioria das instituições ainda opta pela utilização do CVC convencional, mesmo com evidências que a sua utilização reduz as taxas de ICS-ACVC. As razões vão desde custos (valor elevado do cateter), até questões relacionadas à tomada de decisão sobre qual tecnologia deva ser incorporada. De acordo com O'Grady et al. (2010), o uso de um cateter impregnado é recomendado quando: (1) CVC ficará mais que 5 dias; (2) a instituição possui uma estratégia abrangente para impedir ICS-ACVC, que inclui o uso de clorexidina $2 \%$ e um programa educacional que visa prevenir infecções e (3) a taxa de ICS-ACVC é superior ao fixado pela meta da instituição ${ }^{(31)}$.

Neste estudo dissertaremos sobre os CVC de curta permanência, especificamente o cateter da artéria pulmonar e o cateter com lumens.

\subsubsection{Infecção da Corrente Sanguínea Associada a Cateteres Venosos de Curta Permanência}

Os cateteres intravasculares são indispensáveis na prática da medicina moderna, particularmente na Unidade de Terapia Intensiva (UTI). No entanto, esses cateteres necessitam de acesso vascular, que colocam o paciente em risco para complicação local e sistêmica, incluindo infecção do sítio de inserção, infecção da corrente sanguínea, tromboflebites, endocardites e outras infecções metastáticas, como por exemplo, abscesso pulmonar e osteomielites ${ }^{(19)}$.

O CDC e a Joint Commission on Accreditation of Healthcare Organizations (JCAHO) recomendam que a taxa infecção da corrente 
sanguínea associada ao cateter venoso central (ICS-ACVC) deva ser expressa como o número de ICS associada ao cateter por 1000 cateteres dia. Este parâmetro é mais útil do que a taxa expressa com o número de infecções associadas aos cateteres por 100 CVC dia (ou a porcentagem de cateteres estudados), pois representa mais a ICS e, portanto, ajusta o risco para o número de dias de cateteres em uso ${ }^{(19)}$.

Quanto aos custos, ele é estimado em \$34.508 a \$56.000 dólares americanos, e o gasto anual do cuidado com os pacientes com ICS-ACVC varia de 296 milhões a 2,3 bilhões de dólares americanos ${ }^{(19)}$.

Entretanto, para a redução dos custos e obtenção de melhores resultados, estratégias devem ser implementadas para reduzir a incidência destas infecções. Este esforço deve ser multidisciplinar, envolvendo os profissionais de saúde que realizam a inserção e manutenção dos cateteres intravasculares, gestores dos cuidados de saúde que alocam os recursos, e os pacientes que são capazes de auxiliar no cuidado de seus cateteres $^{(31)}$.

\subsubsection{Patogênese da infecção da corrente sanguínea associada ao cateter venoso central de curta permanência}

A ICS-ACVC é decorrente do acesso de microrganismos às superfícies extraluminal e intraluminal, onde podem aderir e incorporar-se a um biofilme que permite a disseminação da infecção via hematogênica através de: a) migração de microrganismos da pele durante a inserção do dispositivo ou nos dias seguintes por ação dos capilares; b) contaminação direta do cateter ou do hub por contato com dispositivos, fluidos ou mãos contaminadas; c) colonização do dispositivo implantado via hematogênica, de uma fonte remota de infecção (menos comum; d) raramente, infusato contaminado ${ }^{(31-36)}$. A Figura 1 nos ilustra quais as vias de acesso para contaminação de um dispositivo vascular. 


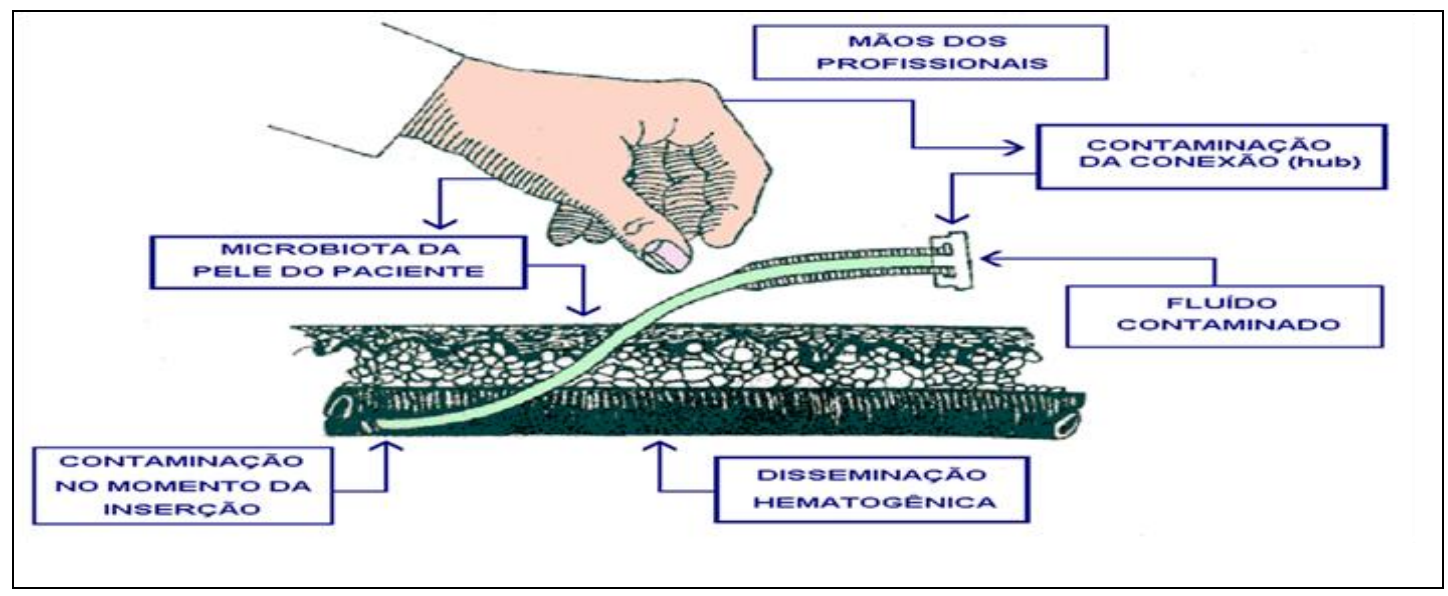

Fonte: Fernandes AT, Ribeiro Filho N. Infecção do acesso vascular. In: Fernandes AT, editor. Infecção e suas interfaces na área da saúde. São Paulo: Atheneu. 2000; V. 1: p. 556-79 (28).

Figura 1 - Vias de acesso para contaminação de um dispositivo vascular

Além destes, existem outros determinantes importantes que devem ser levados em consideração: 1) o material na qual o dispositivo é feito; 2) os fatores intrínsecos à virulência do microrganismo infectante; 3) frequência de manipulação do dispositivo; 4) número de lumens e 5) sítio de inserção ${ }^{(19,28)}$.

A presença de superfícies irregulares que facilitam a aderência microbiana de certas espécies no cateter, um exemplo é o Sthaphilococcus aureus que pode aderir às proteínas (fibronectina) comumente presentes em cateteres. Algumas cepas de estafilococos coagulase-negativa produzem um polissacarídeo extracelular muitas vezes referida como "slime" ou lodo, que na presença de cateteres, potencializa a patogenicidade do microrganismo, permitindo-Ihes suportar aos mecanismos de defesa (atuam como uma barreira aos leucócitos polimorfonucleares) ou, tornando-os menos sensíveis aos agentes antimicrobianos (formação de uma matriz que liga os antimicrobianos antes de seu contato com o organismo da parede celular). Algumas Candida spp., na presença de glicose, podem produzir o "slime", explicando o aumento da proporção de ICS-ACVC causadas por fungos entre os pacientes recebendo nutrição parenteral ${ }^{(19)}$. 
Os microrganismos que comumente causam ICS adquirida no ambiente hospitalar mudou ao longo do tempo. Durante 1986-1989, o estafilococo coagulase-negativo, seguido por Staphylococcus aureus, foram as mais frequentes causas de ICS, representando $27 \%$ e $16 \%$ respectivamente. Dados de 1992 a 1999 indicam que estafilococos coagulase-negativo, seguido por enterococos, eram as causas mais frequentes de ICS adquirida no ambiente hospitalar ${ }^{(19)}$.

Hoje, os patógenos mais comuns da ICS no ambiente hospitalar são: estafilococos coagulase-negativo (31,3\%), S. aureus $(20,2 \%)$, enterococcos spp $(9,4 \%)$ e Candida spp (9,0\%). Os bacilos Gram-negativos ocorrem entre $19-21 \%$ das ICS-ACVC ${ }^{(31)}$.

Para todos os patógenos que causam ICS-ACVC, a resistência a antimicrobianos é um problema, principalmente dentro da UTI. Mais de $50 \%$ dos Staphylococcus aureus, isolados em UTI, são resistentes à meticilina (SARM), contudo a incidência de ICS-ACVC por SARM tem diminuído nos últimos anos, possivelmente como resultado dos esforços de prevenção $(31,37)$.

A resistência da Candida spp. ao fluconazol está cada vez mais elevada, sendo resultado do esquema terapêutico no tratamento da ICSACVC causada por leveduras. $48 \%$ das ICS relacionadas à Candida foram causadas por espécies não-albicans, incluindo $C$. glabrata e $C$. krusei, que são mais prováveis de possuir resistência ao fluconazol e itraconazol que a C. albicans ${ }^{(19,31)}$.

\subsubsection{Fatores de risco para infecção da corrente sanguínea associada ao cateter venoso central de curta permanência}

São vários os fatores de risco associados ao aumento de ICS-ACVC. Os fatores intrínsecos ao paciente são: alteração do estado imunológico, extremos de idade, pré-existência de co-morbidades, gravidade da doença, má nutrição e colonização da pele ${ }^{(38-39)}$. 
Já os fatores extrínsecos podem ser específicos quanto ao tipo de cateter ou comum a todos. Os principais fatores relacionados ao CVC são: local de inserção, presença ou ausência de túnel, número de lumens, uso de sistema de monitorização de pressão, infusão de nutrição parenteral, tempo de permanência do cateter, tipo de cateter, colonização da pele pericateter, dificuldade de inserção do cateter, local de internação e colonização do canhão (hub) ${ }^{(18,23,29,38,39,40)}$.

Além destes fatores de risco, podemos citar outros que são independentes para ICS-ACVC: hospitalização prolongada antes da cateterização, deficiências de cuidado do cateter (excessiva manipulação do cateter), sexo feminino, gravidade e tipo de doença (queimaduras de terceiro grau e pós-operatório de cirurgia cardíaca) ${ }^{(20,41)}$.

A coluna de fluídos necessária para a manutenção da permeabilidade do sistema de monitorização de pressão venosa é a porta de entrada para os microrganismos. A contaminação deste sistema reduziu significativamente após a implantação de transdutores descartáveis, na qual o período máximo de utilização não deve exceder 96 horas ${ }^{(42)}$. A manipulação do CVC é um fator de risco para contaminação deste.

A desinfecção dos conectores antes da manipulação com produto contendo álcool é um importante passo na prevenção da contaminação do CVC e consequente ICS, pois, em primeiro lugar, se a superfície septal não é devidamente desinfetada antes da utilização, o contaminante presente na superfície será forçado pela via intraluminal. Em segundo lugar, as câmaras internas (penetração diferencial septal), uma vez contaminadas são impossíveis de desinfetar ${ }^{(43)}$.

O sítio na qual o cateter é inserido também tem influencia quanto ao risco de infecção. Autoridades recomendam que o CVC deva ser inserido na subclávia ao invés da jugular ou femoral para reduzir o risco de infecção ${ }^{(19)}$. No entanto, de acordo com Marshall et al. (2008), antes da escolha do sítio de inserção do cateter, devemos sempre avaliar os riscos e benefícios em função do potencial de complicações infecciosas e não infecciosas, que devem ser consideradas individualmente, ao determinar qual o local de inserção a ser usado ${ }^{(20)}$. 
Além dos cuidados em relação ao do sítio de inserção do CVC, a padronização dos cuidados com a inserção e manutenção dos cateteres, tem muita importância na prevenção e controle da ICS-ACVC. É importante lembrarmos que a inserção realizada por pessoal inexperiente, eleva o risco de colonização do cateter e consequente ICS-ACVC. Além disso, redução na equipe de enfermagem está diretamente ligada ao aumenta do risco de ICS ${ }^{(19)}$.

O número de lumens do CVC é outro fator de risco para ICS-ACVC; cateteres multi-lúmen são particularmente susceptíveis à colonização bacteriana, pois cada luz é uma fonte potencial de ICS, uma vez que são utilizados para diferentes fins ao mesmo tempo, como monitorização da pressão venosa central (PVC), amostragem arterial, administração de nutrição parenteral total (NPT) e administração contínua e/ou intermitente de medicamentos ${ }^{(44-45)}$. Cabe lembrar que no caso do CVC triplo lúmen este tem maior diâmetro e necessidade de pequena incisão na pele para inserção, elevando ainda mais o risco para ICS ${ }^{(19,41)}$.

A cobertura da inserção - curativo - do CVC deve ser sempre realizada com material estéril, que será substituído em intervalos regulares ou de acordo com a necessidade. Eles podem ser feitos com gaze e cobertos com fita adesiva, filmes transparentes ou semipermeáveis, e sua escolha deve levar em consideração o conforto para o paciente e o fácil manuseio para os profissionais da saúde, ou seja, desde que eles sejam realizados de forma correta e trocados quando necessário, a escolha do curativo passa a ser uma questão pessoal do profissional que realiza tal procedimento, já que tanto o curativo transparente, quanto o curativo convencional (gaze e fita adesiva) apresentam taxas de colonização comparáveis $(5,7 \%$ vs $4,6 \%)$ e indiferente risco de ICS-ACVC ${ }^{(21,31)}$.

$\mathrm{Na}$ atualidade também dispomos de curativos impregnados com clorexidina, que quando comparados ao outros tipos (transparente e convencional) têm sido usados para redução da ICS-ACVC com sucesso ${ }^{(31)}$.

A nutrição parenteral total (NPT) tem característica diferenciada em relação às demais terapias intravenosas, pois sua própria composição 
facilita o crescimento bacteriano, especialmente bactérias Gram negativas e Candidas spp ${ }^{(31-32)}$.

A utilização de sistema aberto ao invés do sistema fechado para infusão de fluidos também predispõem a ICS. Em um estudo realizado no Instituto do Coração do Hospital das Clínicas da Faculdade de Medicina da Universidade de São Paulo (InCor-HCFMUSP), foi verificada a influência do sistema fechado de infusão venosa na incidência ICS em crianças no período pós operatório. Os resultados sugerem que o sistema de infusão venosa fechado é um fator de proteção contra colonização do hub ${ }^{(46)}$.

\subsubsection{Diagnóstico}

O diagnóstico da ICS-ACVC é feito quando outros sítios de infecção foram excluídos. A não realização de um exame aprofundado do paciente pode subestimar ou hiperestimar a sua incidência, afinal ela pode ser secundária a outras fontes ${ }^{(19,31)}$.

A ICS é associada com uma linha central, se ela estava em uso durante o período de 48 horas antes do seu desenvolvimento, e se 0 intervalo de tempo entre início dos sinais de infecção e uso do dispositivo é maior que 48 horas ${ }^{(19)}$.

De acordo com o Centro de Controle de Doenças e Prevenção (CDC), o diagnóstico clínico é feito quando ocorre bacteremia/fungemia em um paciente com cateter intravascular, com pelo menos uma hemocultura positiva obtida a partir de uma veia periférica; manifestações clínicas de infecções, isto é, febre, calafrios e/ou hipotensão; não há fonte aparente para a ICS exceto o cateter. Um dos seguintes itens deve estar presente: uma cultura semi quantitativo positivo (> 15 UFC/segmento cateter) ou quantitativo (> 103 UFC/ segmento cateter), em que o mesmo organismo (espécie e antibiograma) é isolado no segmento do cateter e do sangue periférico ${ }^{(19)}$. 
Para a confirmação laboratorial da ICS devemos reunir pelo menos um dos seguintes critérios, lembrando que os critérios 1 e 2 podem ser utilizados para pacientes de qualquer idade, incluindo os pacientes com idade menor ou igual a 1 ano ${ }^{(36)}$ :

* Critério 1: Paciente tem um reconhecido patógeno cultivado em uma ou mais culturas de sangue, e o organismo cultivado do sangue não está relacionada com uma infecção em outro sítio.

* Critério 2: Paciente tem pelo menos 1 dos seguintes sinais ou sintomas: febre $\left(>38^{\circ} \mathrm{C}\right)$, calafrios, hipotensão e resultados laboratoriais positivos não estão relacionados a uma infecção em outro sítio ou contaminante comum da pele (Corynebacterium spp., Bacillus spp., Propionibacterium spp., estafilococos coagulasenegativa, Aerococcus spp., Micrococcus spp.) é cultivado em 2 ou mais hemoculturas coletadas em ocasiões distintas.

* Critério 3: Pacientes menores ou com idade igual a 1 ano, deve ter pelo menos 1 dos seguintes sinais ou sintomas: febre $\left(>38^{\circ} \mathrm{C}\right.$, retal), hipotermia $\left(<37^{\circ} \mathrm{C}\right.$, retal), apnéia ou bradicardia e estes sinais e sintomas e os resultados laboratoriais positivos não estão relacionados a uma fonte de infecção em outro sítio e contaminante comum da pele é cultivado a partir de 2 ou mais culturas de sangue retiradas em ocasiões distintas.

As amostras de sangue para cultura devem ser sempre coletadas por punção venosa e não através de um acesso vascular ${ }^{(36)}$.

Algo importante a ser falado para o diagnóstico correto da ICSACVC é: 1) a presença de flebite purulenta na inserção do cateter com cultura semi-quantitativa positiva da ponta do cateter, mas com cultura negativa de sangue não é considerada uma ICS; 2) ICS-ACVC é definida como cultura positiva a partir do sangue quando não há outro local de infecção evidente ${ }^{(36)}$. 


\subsubsection{Epidemiologia}

$\mathrm{Na}$ atualidade, o Centro para Controle e Prevenção de Doenças (CDC) estima que 5 a $10 \%$ de todos os pacientes hospitalizados desenvolvem algum tipo de IrAS, o que corresponde a 2 milhões de casos, com quase 100 mil mortes por ano nos EUA ${ }^{(19,23)}$.

A taxa de todas as infecções relacionadas ao CVC (incluindo infecções locais e sistêmicas) é de difícil determinação, já que seus índices são influenciados por fatores relacionados ao paciente, como a severidade da doença e a doença, fatores relacionados ao cateter e fatores institucionais ${ }^{(19,31)}$.

Nos Estados Unidos, estima-se que 15 milhões CVC são inseridos nas UTIs a cada ano, e que, aproximadamente 80.000 são responsáveis pela ICS-ACVC ${ }^{(47)}$. Entre os hospitais participantes do National Healthcare Safety Network (NHSN) durante 2006, a taxa variou de 1,3/1000 cateteres dia em unidade de internação a 5,6 por 1.000 cateteres dia em UTI de queimados, como podemos ver no Quadro $1^{(31)}$.

Quadro 1 - Distribuição da taxa de infecção da corrente sanguínea associada ao cateter venoso central entre hospitais participantes do NHSN, CDC, 2006-2007

\begin{tabular}{|lcc|}
\hline \multicolumn{1}{|c}{ Tipo de UTI } & Número de UTIs & $\begin{array}{c}\text { Taxa por 1000 } \\
\text { cateteres-dia }\end{array}$ \\
\hline Queimados & 22 & 5,6 \\
Coronária & 121 & 2,1 \\
Cirúrgica - Cardiotorácica & 97 & 1,4 \\
Médica & 144 & 2,4 \\
Médico/Cirúrgico - ensino & 104 & 2,0 \\
Médico/Cirúrgico - todas outras & 343 & 1,5 \\
Pediátrica & 71 & 2,9 \\
Neurológica & 15 & 1,2 \\
Neuro-Cirurgia & 39 & 2,5 \\
Cirúrgica & 128 & 2,3 \\
Trauma & 32 & 4,0 \\
\hline
\end{tabular}

Adaptado: O'Grady NP, Alexander M, Burns $L A$, et al. Guidelines for the prevention of intravascular catheter-related infections. Draft. $2010^{(31)}$. 
A mortalidade atribuída para ICS-ACVC é estimada entre 12\% - 25\% para cada infecção, e podem ser menores quando são avaliados os hospitais que não são de ensino, de acordo com o National Healthcare Safety Network (NHSN) ${ }^{(19,31)}$. A taxa de mortalidade específica para a ICS-ACVC, em instituições que não são de ensino, varia entre 2,2 a 1,5 por 1000 cateteres dia $^{(48)}$.

A incidência de ICS entre pacientes da UTI é mais elevada que em pacientes internados na unidade de internação ou ambulatório. Isso ocorre porque o CVC é mantido por período prolongado e é manipulado várias vezes ao dia, para a administração de fluidos, drogas e produtos derivados do sangue, entretanto, esta taxa é variável conforme o tipo de UTI. O International Nosocomial Infection Control Consortium (INICC) entre 2002 e 2007 fez um levantamento de 98 UTIs na América Latina, Ásia, África e Europa quanto às infecções relacionadas aos dispositivos e encontrou taxas de ICS de até 9,2/1000 cateteres dia ${ }^{(49)}$.

Um estudo realizado no Hospital das Clínicas da Universidade de São Paulo, publicado em 2005, referiu que a ICS-ACVC foi a mais importante infecção hospitalar nas UTIs desta instituição, no período em pesquisa, com taxas quatro vezes maiores que o $\mathrm{NHSN}^{(50)}$.

\subsubsection{Medidas de Prevenção}

Várias medidas de prevenção e controle da ICS-ACVC já são conhecidas, principalmente por meio de diretrizes de recomendações internacionais. A maior questão, no entanto, é reconhecer se são seguidas ${ }^{(19-21)}$. Em 2002 o Centro para Controle e Prevenção de Doenças (CDC) dos Estados Unidos da América publicou um guia para prevenção de ICS-ACVC com base em estudos relevantes e, em 2010 foi disponibilizado em seu site um draft sobre novas considerações para prevenção e controle da ICS-ACVC, disponível no site: $\quad$ http://wwwn.cdc.gov/publiccomments/comments/guidelines-for-theprevention-of-intravascular-catheter- of-intravascular-catheter-2038.ashx ${ }^{(31)}$. 
As recomendações são categorizadas conforme a qualidade dos estudos em que foram baseadas na aplicabilidade e impacto econômico. Estas recomendações são destinadas a reduzir as complicações infecciosas associadas ao CVC e foram categorizadas e qualificadas por evidencias ${ }^{(19,31,51)}$.

Essas medidas devem encontrar equilíbrio entre a segurança do paciente e a relação custo-efetividade, como conhecimento, tecnologia, saúde e cuidados. Relatórios abrangendo as duas últimas décadas têm consistentemente demonstrado que o risco para a infecção declina quando há padronização dos cuidados assépticos, e que a inserção e manutenção dos CVC realizada por pessoal sem experiência podem aumentar o risco de colonização e ICS-ACVC ${ }^{(19,52)}$.

A higiene adequada das mãos é o primeiro passo na prevenção de qualquer infecção hospitalar ${ }^{(19,31)}$. De acordo com WHO (2009), há cinco momentos para higienização das mãos: 1) antes de contato com o paciente; 2) antes da realização deprocedimento asséptico; 3) após risco de exposição a fluídos corporais; 4) após contato com o paciente; 5) após contato com áreas próximas ao paciente ${ }^{(53)}$. Em 2009, a Organização Mundial da Saude (OMS), dentro do Primeiro Desafio Global para Segurança do Paciente realizou uma ação global de conscientização sobre a higiene das mãos, com o tema "Salve vidas: higienize as mãos" e utilizou esses cinco momentos em sua campanha ${ }^{(53)}$. É importante lembrarmos que a utilização de luvas, não tira a necessidade de higiene das mãos ${ }^{(20)}$.

De uma forma mais simples, podemos definir o risco de transmissão de microrganismos através das mãos, que podem ser causa de infecção como ${ }^{(54)}$ :

* Alto Risco: procedimento invasivo (inserir cateter venoso e coleta de sangue), realização de curativo, manuseio da membrana mucosa e fluidos corporais, colocação de nutrição parenteral, administração de medicação intravenosa, cuidados com CVC, aspiração endotraqueal, prolongado contato com paciente (exemplo: dar banho, mudança de decúbito) e fisioterapia. 
* Baixo risco: realizar observação, dar medicamento oral, medicamento por sonda nasoentérica (SNE), contato com a pele intacta (estimulação, tocar e segurando as mãos).

Contudo, para compreender o objetivo das diferentes abordagens para a higienização das mãos, um conhecimento da microbiota bacteriana da pele é essencial. Em estudo de 1938, as bactérias recuperadas das mãos foram divididas em categoria transitória e residente ${ }^{(55)}$.

A microbiota residente, normalmente não é implicada em infecções hospitalares, entretanto, podem causar infecções após procedimentos invasivos quando o paciente é gravemente imunocomprometido ou tem um dispositivo implantado ${ }^{(56)}$

A microbiota transitória é formada por microrganismos contaminantes que são adquiridos a partir de doentes infectados ou do ambiente/equipamento contaminado, e estão frequentemente implicados como fonte de infecções hospitalares ${ }^{(56)}$.

A higiene das mãos com um agente anti-séptico surgiu no início do século XIX, quando um farmacêutico francês demonstrou que as soluções contendo cloretos ou soda poderiam erradicar os maus odores associados com cadáveres humanos, e que estas soluções poderiam ser usadas como desinfetantes e anti-sépticos ${ }^{(55)}$.

Semmelweis (1818-1865) descobriu que a principal causa da febre puerperal nas maternidades estava ligada a não higienização das mãos e do instrumental, e passou a utilizar sabão, escovas para unhas e ácido clórico, entre um atendimento e outro, reduzindo as taxas de mortalidade ${ }^{(57)}$.

Os anti-sépticos são projetados para retirar rapidamente a maioria da microbiota transitória pelos seus mecanismos de detergente e por exercer um efeito adicional sustentado sobre a atividade antimicrobiana da microbiota residente da mão ${ }^{(56)}$.

Entretanto, muitos anos após, a higienização das mãos ainda é ignorada por muitos profissionais. O primeiro estudo que avaliou o cumprimento da lavagem das mãos, publicado em 1981, descobriu que os médicos lavavam as mãos $28 \%$ nos hospitais de ensino e $14 \%$ nos hospitais privados ${ }^{(58)}$. 
De acordo com outra referência, os médicos realizam adequada higiene das mãos com menos frequência do que outros profissionais de cuidados saúde, com estimativas variando de um terço a metade do tempo ${ }^{(52)}$.

Em estudo conduzido por Pittet et al. (1999), no Hospital Universitário de Genebra, a adesão dos profissionais à prática de higienização das mãos foi considerada moderada, com média de $48 \%$ de aplicação da medida nas oportunidades geradas durante o dia de trabalho. A principal causa de não realização da higienização das mãos foi falta de atenção à necessidade. $A$ evidência mais contundente mostrada neste estudo foi que a menor adesão à higienização das mãos ocorreu durante as atividades de maior risco de transmissão de infecções ${ }^{(22)}$.

Pesquisa realizada por Galpen et al. (2008), avaliou a higiene das mãos, juntamente com todas as precauções durante a inserção de CVC e preparação adequada da pele com clorexidina e obteve excelentes resultados. A taxa da ICS-ACVC de 5,0 por 1000 cateteres dia foi para 0,9 por 1000 cateteres dia, e esta vantagem foi mantida durante todo o estudo ${ }^{(59)}$.

Os diferentes produtos para a realização da higienização das mãos de acordo com o CDC são: sabão simples (não-antimicrobianos), álcool, clorexidina, iodo e iodoforos, cloroxilenol, hexaclorofeno, compostos de quaternário de amônia e triclosan ${ }^{(55)}$. $\mathrm{Na}$ instituição em que a pesquisa foi realizada, os produtos utilizados para tal procedimento na UTI são: álcool gel e a clorexidina degermante $2 \%$.

O uso de sabão simples não é efetivo na retirada de agentes patogênicos das mãos no ambiente hospitalar. Este sabão pode estar associado com considerável ressecamento e irritação da pele, além do risco de tornarem-se contaminados ${ }^{(55)}$.

O álcool gel é uma medida simples para melhorar a adesão à higienização das mãos, em substituição ao tradicional sabão e água ou antiséptico, não só por requerer menos tempo, agir mais rápido, causar menos irritação das mãos, como também por ser eficiente na prevenção de infecção hospitalar (60-62).

A atividade antimicrobiana dos alcoóis pode ser atribuída à sua capacidade de desnaturar proteínas. Alcoóis têm excelente atividade in vitro 
contra germes gram-positivos e bactérias vegetativas gram-negativas, incluindo patógenos multirresistentes ${ }^{(55)}$.

A higiene das mãos com álcool gel é equivalente a água e sabão, e ele deve ser disponibilizado sempre que o acesso à água for limitado. As mãos devem estar secas antes de seu uso ${ }^{(56)}$.

Quanto à clorexidina, sua atividade antimicrobiana ocorre com a ruptura das membranas citoplasmáticas, resultando em precipitação do conteúdo celular. Sua atividade antimicrobiana é mais lenta do que dos alcoóis. A clorexidina tem boa atividade contra bactérias gram-positivas, menor atividade contra gram-negativas e fungos e mínima atividade contra bacilos tuberculosos ${ }^{(55)}$.

Uma análise econômica mostrou que o uso da clorexidina e seu custo unitário, em relação à diminuição da incidência de ICS-ACVC (com o seu potencial risco de morbidade e mortalidade associadas), conduz a 113 dólares em poupança para cada CVC colocados ${ }^{(63)}$.

A clorexidina também pode ser utilizada para preparo da pela para preparo da pele antes da inserção do acesso intravascular e realização de curativo, e está associada com menor taxa de colonização ou ICS-ACVC, quando comparada ao polvidine iodo e álcool ${ }^{(31)}$.

Entretanto, é importante lembrar que além de incentivar a lavagem das mãos, é necessário haver lavatórios presentes em todo cenário, e estes estarem próximos de onde os cuidados e/ou procedimentos são realizados. As torneiras devem ser de pedal, punho ou operado pelo joelho, se torneiras automáticas não estão disponíveis. Após lavagem, as mãos devem ser cuidadosamente secas com papel toalha de uso único ou secador elétrico ${ }^{(55)}$.

Quanto às demais medidas de prevenção e controle da ICS-ACVC, O'Grady et al. (2010) ${ }^{(31)}$ cita a substituição do cateter em intervalos de tempo como um método para reduzir ICS-ACVC, não tem influenciado significativamente na redução das taxas, no entanto, de acordo com Safdar e Maki (2004) ${ }^{(18)}$, a taxa de infecção é maior quando ele é deixado no local por tempo maior que 1-2 semanas.

A troca do cateter com um fio-guia é válida e está associada ao menor desconforto e risco complicação mecânica, quando comparados a cateteres 
inseridos em um novo sítio ${ }^{(18,31,64)}$. Em caso de bacteremia, a substituição temporária de um cateter por guia não é uma estratégia aceitável ${ }^{(31,64)}$, assim como na suspeita de cateter colonizado, na qual o sítio de inserção deve ser alterado, para que não ocorra rápida colonização do novo cateter ${ }^{(31,65)}$.

É importante lembramos que durante a inserção/troca do CVC, devese sempre utilizar máximas precauções de barreiras estéreis. O uso de luvas estéreis, gorro, máscara, avental estéril e campo estéril ampliado, devem ser obrigatórios para todos os profissionais de saúde envolvidos no processo de inserção do cateter ${ }^{(19-20,31)}$.

A anti-sepsia da pele do paciente deve ser realizada preferivelmente com a clorexidina $2 \%$, mas a tintura de iodo ou álcool $70 \%$ também pode ser utilizada (31). Não é recomendada a aplicação de solventes orgânicos (exemplo: acetona e éter) na pele antes da inserção de cateteres ${ }^{(19)}$.

$\mathrm{Na}$ instituição em que a pesquisa será realizada, as recomendações do manual quanto aos cuidados durante a inserção de um cateter intravascular são: higienização das mãos da pessoa que irá inserir o cateter previamente com clorexidina degermante $2 \%$; uso da paramentação completa; degermação do local de inserção com clorexidina degermante $2 \%$; em seguida anti-sepsia do local com clorexidina alcoólica 0,5\%, que pode ser substituído por álcool $70 \%$ na falta deste; cobrir a área de inserção do cateter com campos estéreis; fixar o cateter na pele para evitar sua movimentação ${ }^{(66)}$.

É importante lembrar que antes da substituição de um CVC, deve-se realizar um julgamento clínico para determinar quando ele deve ser substituído. Levar em consideração que a substituição não deve ser rotineira quando a única indicação de infecção é febre, ou pacientes com bacteremia ou fungemia que a fonte de infecção possa ser outro local ${ }^{(19)}$.

Muitos especialistas acreditam que o treinamento do enfermeiro assistencial para parar qualquer procedimento de inserção de CVC quando a técnica estéril é rompida, é um dos mais importantes componentes do programa de prevenção. Um programa de prevenção multifacetado no Johns Hopkins University, descrito em 2004, praticamente eliminou a ICS-ACVC na UTI, e incluiu: (1) um programa educacional; (2) cuidado diário do CVC; (3) interrupção da inserção do CVC, se técnica asséptica foi quebrada; (4) 
carrinho com materiais para inserção de CVC, a fim de garantir que todos os elementos de inserção fossem mantidos em uma localização comum, e (5) check list da inserção de CVC pelo enfermeiro de cabeceira ${ }^{(52)}$.

Após a inserção do CVC, este deve ser protegido com curativo que pode ser realizado com gaze estéril, curativo transparente ou semipermeável ${ }^{(19,31)}$.

De acordo com o manual da instituição em que a pesquisa se realizará as recomendações de cuidados com cateteres intravasculares são: curativo deve ser realizado com solução fisiológica 0,9\% e em seguida utilizar solução de clorexidina alcoólica $0,5 \%$, a cada troca do curativo. Eles também recomendam a troca do curativo com gaze e fita adesiva a cada 24 horas, ou antes, se curativo sujo ou não estiver íntegro. Quanto ao filme transparente, este deve ser trocado no máximo a cada 7 dias ou antes se curativo sujo ou não estiver íntegro ${ }^{(66)}$.

A monitorização dos sítios de inserção do cateter deve ser diária, sendo visual, no caso de curativo transparente, ou por palpação através do curativo intacto com gaze e fita adesiva. Caso o paciente apresente febre sem fonte óbvia, ou outra manifestação local ou sugestivo de ICS, o curativo deve ser removido para permitir a análise aprofundada do sítio ${ }^{(19)}$.

As soluções parenterais devem ter o equipo utilizado para sua administração trocado a cada 24 horas do início da infusão, em caso de solução que contenha apenas dextrose e aminoácidos, o sistema pode ser trocado a cada 72 horas, ou de acordo com instrução dos fabricantes ${ }^{(19)}$. É importante lembrar que a legislação brasileira determina que soluções parenterais devam ser administradas apenas em sistema fechado ${ }^{(67)}$.

A desinfecção do diafragma dos frascos de múltiplas doses com álcool $70 \%$ deve ser sempre realizada antes de inserir um dispositivo no frasco. Sempre utilizar um dispositivo estéril para acessar um frasco de múltiplas doses e evitar a contaminação do dispositivo antes de penetrar o diafragma, caso a contaminação ocorra, a solução deve ser desprezada ${ }^{(19)}$. 
3 OBJETIVOS 


\subsection{GERAL}

Avaliar a conformidade das práticas de prevenção e controle de infecção da corrente sanguínea associada a cateter venoso central de curta permanência.

\subsection{ESPECÍFICOS}

* Calcular os índices de conformidade das práticas de prevenção e controle de infecção da corrente sanguínea associada a cateter venoso central de curta permanência, por meio de aplicação de indicadores clínicos de avaliação processual;

* Identificar situações de não conformidade das práticas de prevenção e controle de infecção da corrente sanguínea associada a cateter venoso central de curta permanência;

* Associar conformidades e não conformidades com o período de trabalho e categoria profissional. 
4 MÉTOdOS 


\subsection{TIPO DE INVESTIGAÇÃO}

Tratou-se de um estudo transversal, controlado, observacional, envolvendo a avaliação de achados sobre o desempenho de programas, práticas, procedimentos ou normas, buscando acessar a qualidade ou o sucesso desse desempenho. De acordo com Polit et al. (2004), ele se insere na avaliação de análise de processo ${ }^{(68)}$. Já para Novaes (2000), situa-se predominantemente na avaliação para gestão ${ }^{(69)}$.

\subsection{LOCAL DO ESTUDO}

O estudo foi realizado no Instituto do Coração do Hospital das Clínicas da Universidade de São Paulo (InCor-HCFMUSP), localizado na cidade de São Paulo. Esta instituição, com aproximadamente 500 leitos, conjuga a capacidade de assistência e ensino com o desenvolvimento de pesquisa científica e tecnológica. Seu atendimento é dedicado em $80 \%$ a pacientes cujo tratamento é financiado pelo SUS (Sistema Único de Saúde).

A pesquisa foi desenvolvida no Centro Cirúrgico e UTI cirúrgica da instituição.

O Centro Cirúrgico é composto por 14 salas cirúrgicas.

Quanto à UTI cirúrgica, ela possui 71 leitos no total, divididos em duas unidades: uma com 31 leitos (UTI cirúrgica I) e outra com 40 leitos (UTI cirúrgica II). Os pacientes admitidos nestas unidades são, na maioria, provenientes do Centro Cirúrgico (CC) para recuperação do pós-operatório (PO) de cirurgia cardiotorácica.

As características entre as duas UTls se diferem:

* UTI cirúrgica l: com 31 leitos, sendo 20 deles para PO de pacientes submetidos a cirurgias cardiotorácica infantil e/ou congênita e 11 para $\mathrm{PO}$ de pacientes submetidos à cirurgia cardiotorácica no adulto. Esta distribuição de leitos pode variar de acordo com a demanda de cirurgias e características dos pacientes. 
* UTI cirúrgica II: 40 leitos, com todos destinados para PO de pacientes submetidos à cirurgia cardiotorácica adulto. Estes leitos estão subdivididos em quatro módulos: módulo 1 - 7 leitos, módulo II - 12 leitos, módulo III - 13 leitos, módulo IV 8 leitos.

\subsection{PRÁtICAS DE PREVENÇÃo E CONTROLE DA ICS-ACVC SELECIONADAS PARA AVALIAÇÃO}

Foram quatro as práticas selecionadas, conforme seguem:

a) Inserção do Cateter Venoso Central de Curta Permanência

- Componente 1: Inserção percutânea.

- Componente 2: Uso de paramentação completa para inserção de CVC.

- Componente 3: Uso de campo estéril ampliado no momento da instalação do cateter.

- Componente 4: Uso de anti-séptico de veículo alcoólico para preparo da pele do paciente.

- Componente 5: Presença de curativo oclusivo após inserção do cateter.

b) Registros de Indicação e Tempo de Permanência do Cateter Venoso Central de Curta Permanência

- Componente 1: Registro de indicação do cateter venoso central;

- Componente 2: Registro do tempo de permanência do cateter venoso central.

c) Adesão aos Cuidados e Manutenção do Curativo da Inserção do CVC e seus Dispositivos

- Componente 1: Registro de troca do curativo da inserção do CVC;

- Componente 2: Periodicidade da troca do curativo realizada conforme recomendação da instituição; 
- Componente 3: Desinfecção de hubs e conectores com clorexidina alcoólica $0,5 \%$ antes da manipulação;

- Componente 4: Troca de equipos e transdutores conforme recomendação institucional.

d) Adesão à Higiene das Mãos em Situações Ligadas as Linhas Vasculares

- Componente 1: Troca do sistema de infusão.

- Componente 2: Administração de medicamentos.

- Componente 3: Troca e realização de curativo.

- Componente 4: Coleta de sangue.

\subsection{CASUÍSTICA}

Correspondeu às oportunidades de avaliação das práticas selecionadas, realizadas pelos profissionais de saúde em pacientes internados na UTI Cirúrgica-Adulto e que passaram por procedimento de inserção do CVC no CC do referido Hospital.

\subsubsection{Critérios de inclusão para as avaliações}

* Prática de inserção do CVC no CC em maiores de 18 anos;

* Pacientes com CVC inserido no CC da instituição;

* Equipes de enfermagem e médica, que realizaram as práticas assistenciais selecionadas para avaliação, durante os turnos da manhã, tarde e noite. 


\subsubsection{Critérios de exclusão para as avaliações}

* CVC inserido em outro setor do hospital ou outra instituição;

* Pacientes sem CVC;

* Menores de 18 anos;

* Equipes de Enfermagem e Médica, que realizaram práticas assistenciais não selecionadas para avaliação.

\subsection{CÁLCULO AMOSTRAL}

Para estimar o tamanho da amostra da proporção de conformidades, utilizou-se a seguinte fórmula (para o teste uni-caudal) ${ }^{(70)}$.

$$
n=\frac{p_{0} q_{0}\left(z_{1-\alpha}+z_{1-\beta} \sqrt{\frac{p_{1} q_{1}}{p_{0} q_{0}}}\right)^{2}}{\left(p_{1}-p_{0}\right)^{2}}
$$

onde;

$p_{0}$ : proporção de conformidade esperada ou sob a hipótese nula

$q_{0}=1-p_{0}:$ proporção de não-conformidade

$p_{1}$ : proporção de conformidade alternativa

$q_{1}=1-p_{1}$ : proporção de não-conformidade alternativa

$z_{1-\alpha}$ : escore-z para o nível de significância

$z_{1-\beta}:$ escore-z para o poder do teste 
Com base em alguns estudos de avaliação de procedimentos de

enfermagem $^{(71-73)}$ e por meio de observação direta ${ }^{(73-76)}$, a conformidade de $80 \%$ foi definida como ideal para as práticas avaliadas. Cabe ressaltar que estudos de avaliação processual na área de prevenção e controle de IrAS ainda são poucos, assim como as definições de parâmetros de conformidade, que caracterizem a adesão dessas medidas pelos profissionais.

Dois estudos que avaliaram a qualidade dos procedimentos de enfermagem obtiveram resultados acima de 70\%. O primeiro analisou 0 desempenho dos profissionais na punção venosa periférica e constatou uma mediana de acerto de $78 \%$ no desempenho ${ }^{(71)}$. O outro avaliou os procedimentos banho e curativo e obteve índice de positividade igual ou superior a 70\% para cada item do instrumento de avaliação ${ }^{(72)}$.

Já, estudos de avaliação da adesão à higiene das mãos pelos profissionais de saúde são mais frequentes na área de controle e prevenção de IrAS. Neles, as adesões apresentaram variações nos índices de conformidade desde $10,7 \%$ até $95 \%{ }^{(73-77)}$.

\subsubsection{Cálculo amostral referente à avaliação das práticas de inserção e registros de indicação e tempo de permanência do cateter venoso central de curta permanência}

Para a aferição dessas práticas foram utilizadas: proporção aceitável de $80 \%$, proporção de conformidade alternativa de $90 \%$, significância de $5 \%$ e poder de $80 \%$. O tamanho da amostra para aferição foi 83 (n aproximado para o próximo inteiro) avaliações das práticas selecionadas.

Dessa forma, somando-se os componentes de cada prática (cinco referentes à inserção do cateter venoso central de curta permanência e duas ao registro de indicação e tempo de permanência do CVC) totalizou-se 581 avaliações sobre as medidas específicas de prevenção e controle de ICS-ACVC. 
A distribuição das avaliações está presente na Tabela 1.

Tabela 1 - Distribuição da amostra para avaliação das práticas de Inserção e Registros de Indicação e Tempo de Permanência do Cateter Venoso Central de Curta Permanência. São Paulo, 2010

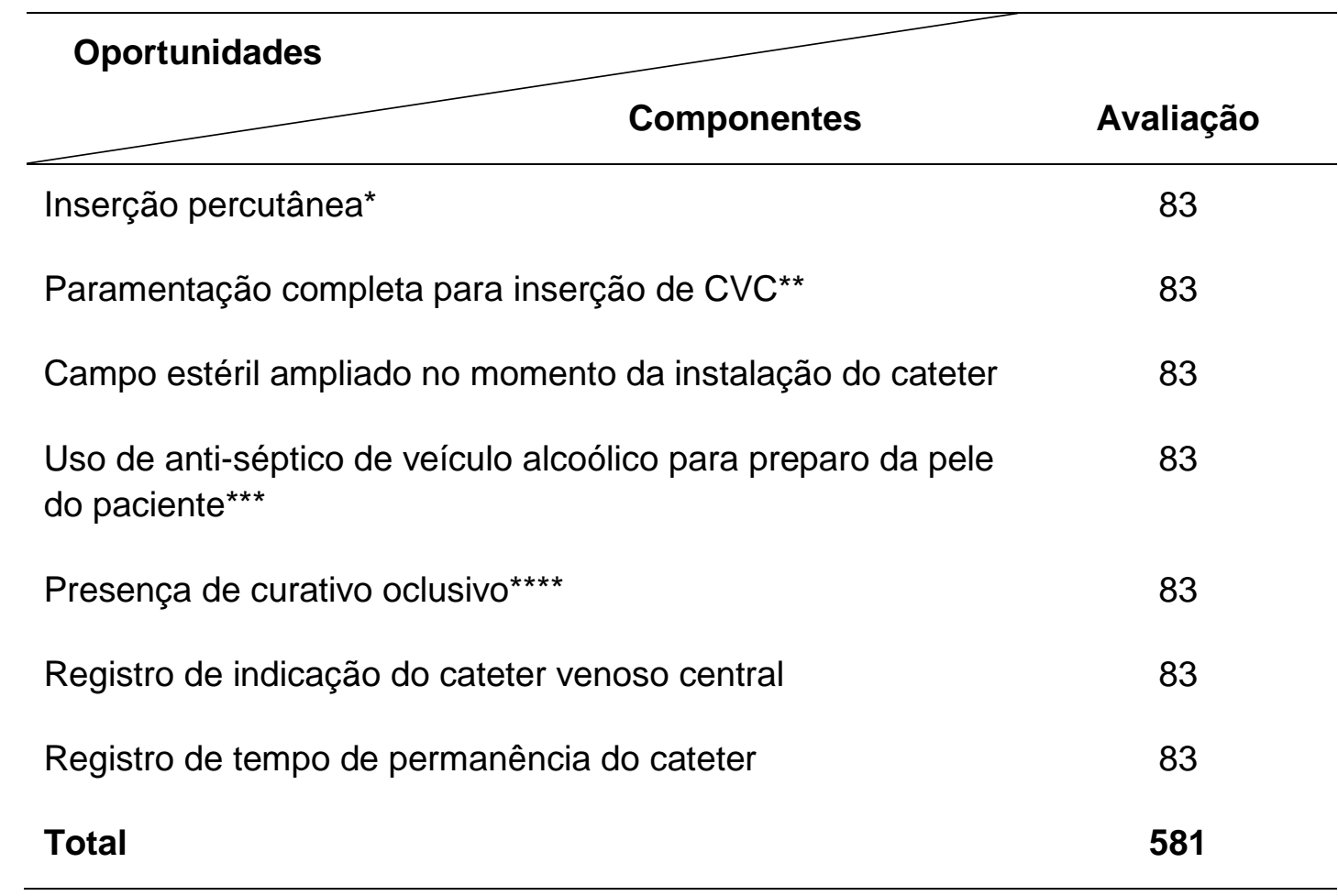

* Inserção realizada apenas por punção

** Uso de máscara, avental estéril, luvas estéreis, gorro, campo estéril

*** Uso de clorexidina alcoólica $0,5 \%$

${ }^{* * * *}$ Realização de curativo oclusivo após a inserção do CVC

\subsubsection{Cálculo amostral referente à avaliação da prática de adesão aos cuidados e manutenção do curativo da inserção do CVC e seus dispositivos}

Para a prática de adesão aos cuidados e manutenção do curativo da inserção do CVC e seus dispositivos utilizou-se: proporção aceitável de $80 \%$, proporção de conformidade alternativa de $84 \%$, significância de $5 \%$ e poder de $95 \%$. O tamanho da amostra para esta aferição foi 993 (n aproximado 
para o próximo inteiro) avaliações, divididas entre os três períodos de trabalho (manhã, tarde e noite). Entretanto, devido ao tipo de cuidados avaliados, apenas a desinfecção de hubs e conectores com clorexidina alcoólica $0,5 \%$ antes da manipulação foi verificado durante os três turnos de trabalho. O cálculo desta amostra foi realizado separadamente das práticas anteriores, pois se considerou o maior número de oportunidades para a avaliação deste indicador.

Desta forma, somando-se os quatro componentes dessa prática, obteve-se 1986 oportunidades, sendo: 993 avaliações para a desinfecção de hubs e conectores com clorexidina alcoólica $0,5 \%$ antes da manipulação e 331 para os demais, que somente foram avaliados no período da manhã, devido às características destes itens e a rotina da UTI Cirúrgica, conforme apresentado na Tabela 2.

Tabela 2 - Distribuição da amostra para avaliação da prática de adesão aos cuidados e manutenção do curativo da inserção do CVC e seus dispositivos. São Paulo, 2010

\begin{tabular}{|c|c|c|c|c|}
\hline \multicolumn{5}{|l|}{ Turno } \\
\hline Componentes & Manhã & Tarde & Noite & Total \\
\hline Registro de troca do curativo & -- & - & 331 & 331 \\
\hline Periodicidade da troca do curativo & - & - & 331 & 331 \\
\hline $\begin{array}{l}\text { Desinfecção de hubs e conectores com } \\
\text { clorexidina alcoólica } 0,5 \% \text { antes da } \\
\text { manipulação }\end{array}$ & 331 & 331 & 331 & 993 \\
\hline $\begin{array}{l}\text { Troca de equipos e transdutores conforme } \\
\text { orientação institucional }\end{array}$ & 331 & - & - & 331 \\
\hline Total & 662 & 331 & 993 & 1986 \\
\hline
\end{tabular}




\subsubsection{Cálculo amostral referente à avaliação da prática de adesão à higiene das mãos}

Quanto à prática de adesão à higiene das mãos durante cuidados e manipulação do CVC, foram utilizadas: proporção aceitável de 80\%, proporção de conformidade alternativa de $84 \%$, significância de $5 \%$ e poder de 95\%. Sendo o tamanho da amostra para aferição de 993 (n aproximado para o próximo inteiro) avaliações que, neste caso, foram divididas entre os três períodos de trabalho (manhã, tarde e noite), com exceção da troca e realização do curativo da inserção do CVC, o qual é rotina apenas do período noturno. Assim como no item 4.5.2 o cálculo desta amostra foi realizado separadamente das práticas anteriores, pois se considerou o maior número de oportunidades para a avaliação deste indicador.

Desta forma, somando-se os quatro componentes dessa prática voltada à higiene das mãos em procedimentos relacionados com linhas venosas, obtivemos 3310 oportunidades, sendo 993 avaliações para cada componente, com exceção da troca e realização do curativo, com 331 avaliações, por ser realizado somente no turno da noite.

A distribuição desta avaliação é apresentada na Tabela 3.

Tabela 3 - Distribuição da amostra para avaliação da prática de adesão à higiene das mãos. São Paulo, 2010

\begin{tabular}{lccccc}
\hline \multicolumn{1}{c}{ Componentes } & Manhã & Tarde & Noite & Total \\
\hline Troca do sistema de infusão & 331 & 331 & 331 & 993 \\
Administração de medicamentos & 331 & 331 & 331 & 993 \\
Coleta de sangue & 331 & 331 & 331 & 993 \\
Troca e realização de curativo* & - & - & 331 & 331 \\
\hline Total & 993 & 993 & $\mathbf{1 3 2 4}$ & $\mathbf{3 3 1 0}$ \\
\hline
\end{tabular}

${ }^{*} \mathrm{~A}$ troca do curativo é rotineiramente realizada no período da noite 


\subsection{INSTRUMENTOS PARA AVALIAÇÃO DAS PRÁTICAS DE PREVENÇÃO E CONTROLE DE ICS-ACVC}

Para a avaliação das conformidades em relação às práticas relacionadas ao manejo do CVC foram utilizados 4 instrumentos. Três desses já elaborados e presentes no Manual de Avaliação da Qualidade de Práticas de Prevenção de Infecção Hospitalar ${ }^{(27)}$. São eles:

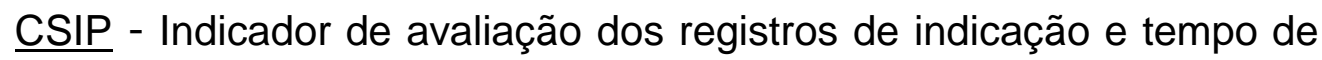
permanência do CVC de curta permanência, que incluem os componentes: registro de indicação e registro do tempo de permanência do cateter venoso central (Anexos A e B).

CSQI - Indicador de avaliação da qualidade de inserção do cateter venoso central de curta permanência, com os componentes: técnica de inserção do CVC por punção; uso de paramentação completa para inserção de CVC (avental de manga longa, gorro, máscara, luvas estéreis); uso de campo estéril ampliado no momento da instalação do cateter; uso de antiséptico de veículo alcoólico para preparo da pele do paciente; presença de curativo oclusivo (Anexos C e D).

HMSEL - Indicador de avaliação da adesão à higiene das mãos em situações ligadas às Linhas Vasculares, contendo os componentes: troca do sistema de infusão; administração de medicamentos; troca e realização de curativo; coleta de sangue (Anexos E e F).

Considerando que o Manual de avaliação da qualidade de práticas de prevenção infecção hospitalar confirma a necessidade de atualização das medidas de prevenção e controle da ICS-ACVC, o presente estudo não se furtou e criou um indicador especificamente para esta pesquisa. Isto porque as medidas de prevenção e controle de ICS-ACVC não estavam totalmente contempladas nos outros indicadores. O indicador criado foi o CSCM que propõem os seguintes itens a serem avaliados:

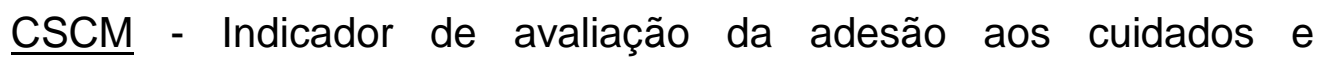
manutenção do curativo do cateter venoso central de curta permanência e seus dispositivos conforme recomendações da instituição durante sua 
utilização, contendo os componentes: registro de troca do curativo da inserção do CVC; periodicidade da troca do curativo realizada conforme recomendação da instituição; desinfecção de hubs e conectores com clorexidina alcoólica $0,5 \%$ antes da manipulação; troca de equipos e transdutores conforme recomendação institucional (Apêndices A e B).

Esclarecemos que, apesar da realização do curativo poder constituir um componente do Indicador CSQI, ele não foi originalmente contemplado no mesmo. Isto porque neste Indicador o curativo é avaliado apenas quanto à sua presença ou ausência após a inserção do CVC, e não é avaliado quanto aos seus cuidados e manutenção diária, sendo mais viável avaliá-lo em outro, ao invés de adicioná-lo às medidas já constantes no indicador CSQI.

Quanto à forma, cada um destes quatro indicadores contém um construto operacional e uma planilha para os registros das avaliações. Estes construtos descrevem e orientam a aplicação da avaliação das práticas a eles correspondentes. Eles estão dispostos, portanto, em operações concretas e indicam o que se avalia e como deve ocorrer a coleta de informações e sua mensuração. Com isso, eles buscam garantir uniformidade na avaliação e legitimidade dos dados. Ao apresentarem, também, a melhor prática disponível, fundamentada cientificamente, permitem calcular índices de conformidade após a avaliação, a fim de definir estratégias para implementar ações de melhoria. Os itens constitutivos dos construtos operacionais de cada indicador são os que seguem.

Título: identifica o nome do indicador, com seu código respectivo

Descrição: enuncia e justifica a prática a ser avaliada e sua importância para o controle de infecção hospitalar (porquê avaliar).

Fundamentação científica e/ou legal: relaciona as bases disponíveis utilizadas para evidência ou sustentação do conteúdo sob avaliação de cada indicador, nas formas de estudos científicos isolados, diretrizes clínicas, normas de órgãos governamentais e de sociedades de especialistas e consenso de especialistas.

Tipo de avaliação: explicita se é estrutura, processo ou resultado. 
Fórmula do indicador: na forma de numerador e denominador, descreve, a maneira mais objetiva possível, sobre o que deve ser medido.

Amostra para cálculo do indicador: orienta sobre a necessidade de proceder a uma amostragem que garanta representatividade da totalidade das ações sob avaliação de um dado período.

Fontes de informações: explicitam locais e formas para coleta das informações necessárias para avaliação de cada indicador, definidas segundo critérios que propiciem maior fidedignidade e/ou acessibilidade possíveis. De acordo com o tipo de indicador, tais fontes podem ser documental (prontuário, manual de procedimentos, atas de reuniões etc.), observação direta, entrevista etc. Algumas fontes documentais necessitam de rastreamento por um dado período a fim de comprovar a realização contínua e regular da atividade sob avaliação, como é o caso de busca de eventos e elaboração de relatórios da vigilância epidemiológica de IRAS.

Critérios de avaliação: descreve como o dado deve ser coletado e qualificado. Os critérios foram padronizados em: A (Atende); NA (Não Atende); AP (Atende Parcialmente); IN (Inaplicável, quando o serviço não realiza ou não possui o item sob avaliação).

Planilha: gráfico construído para a coleta das informações, elaboração do cálculo de conformidade e anotação de observações.

Cálculo do indicador: espaço reservado para cálculo de conformidade do indicador, após todas as aplicações efetuadas.

\subsection{TESTES DE PRECISÃO DOS INSTRUMENTOS DE AVALIAÇÃO}

A precisão, também conhecida como reprodutibilidade, confiabilidade e consistência, é afetada pelo acaso (erro aleatório), portanto, quanto maior o erro, menos precisa é a medida ${ }^{(78)}$. Com base nesses conceitos, os testes utilizados para a busca de precisão neste estudo se referiram a:

- reprodutibilidade inter-observador - diferentes avaliadores realizando as medições; 
- reprodutibilidade intra-instrumento - um único instrumento será utilizado em medições repetidas;

- reprodutibilidade inter-instrumento - instrumentos diferentes serão utilizados para as medições em um conjunto de sujeitos.

Com relação ao instrumento, uma das estratégias indicadas para minimizar possíveis erros aleatórios durante a obtenção dos dados é a padronização dos métodos de medição por meio de instruções por escrito (78). Os instrumentos, consoantes ao Manual de Avaliação da Qualidade de Práticas de Controle de Infecção Hospitalar, já disponibilizam tais instruções, na forma de construtos operacionais para cada indicador, conforme apresentado no item 4.6.

Para realização dos testes de precisão dos instrumentos de avaliação, orientado por Cabral de Menezes (2009), realizou-se treinamento prévio dos avaliadores a fim de testar o domínio das técnicas recomendadas nos construtos operacionais dos indicadores clínicos utilizados no estudo ${ }^{(73)}$.

O treinamento prévio dos avaliadores contribuiu para minimizar a parcialidade da avaliação. Os avaliadores para o piloto foram:

- Avaliador 1: JMJ - enfermeira especialista em cardiologia.

- Avaliador 2: BKN - aluna de graduação em enfermagem.

Os avaliadores foram orientados quanto a:

- identificar somente os cateteres inclusos e as práticas selecionadas;

- registrar nas planilhas de avaliação as informações obtidas à medida que as práticas eram realizadas pelos profissionais de saúde;

- atuar de modo a não interferir na realização da prática;

- efetuar a avaliação de forma discreta.

Para o cálculo do coeficiente de correlação intra-classe, utilizou-se o teste de Kappa (k), indicado para avaliar a intensidade da concordância simultânea entre dois ou mais avaliadores, baseando-se no número de 
respostas concordantes, utilizando um mesmo instrumento - reprodutibilidade intra-instrumento- ou entre instrumentos diferentes utilizados para as medições em um conjunto de sujeitos - reprodutibilidade inter-instrumento ${ }^{(79)}$.

O coeficiente de Kappa é aplicado em variáveis nominais e seus parâmetros variam de 0 a 1, sendo "0" o valor mínimo e o "1" o valor máximo para o grau de concordância entre os observadores. Os parâmetros sugeridos para as categorias e graus de concordância são: < 0,00 ausente; 0,01 a 0,20 fraca; 0,21 a 0,40 discreta; 0,41 a 0,60 moderada; 0,61 a 0,80 substancial; 0,81 a 0,99 quase perfeita e 1,00 concordância perfeita ${ }^{(80)}$.

A seguir, a fórmula para o cálculo do tamanho da amostra para testar o coeficiente de concordância Kappa entre dois observadores ${ }^{(81)}$ :

$$
n=A^{2}\left\{\frac{\left[\pi(1-\pi)\left(\kappa_{1}-\kappa_{0}\right)\right]^{2}}{\pi^{2}+\pi(1-\pi) \kappa_{0}}+\frac{2\left[\pi(1-\pi)\left(\kappa_{1}-\kappa_{0}\right)\right]^{2}}{\pi(1-\pi)\left(1-\kappa_{0}\right)}+\frac{\left[\pi(1-\pi)\left(\kappa_{1}-\kappa_{0}\right)\right]^{2}}{\left.(1-\pi)^{2}+\pi(1-\pi) \kappa_{0}\right)}\right\}^{-1}
$$

onde:

$A=\left(z_{1-\alpha / 2}+z_{1-\beta}\right):$ para o nível de significância $\alpha$ e poder 1 - $\beta$

$\pi$ : proporção esperada para o evento de interesse

$\mathrm{K}_{0}$ : concordância esperada

$\mathrm{K}_{1}$ : concordância alternativa

Arbitrando um nível de significância de 5\%, 80\% de poder, proporção esperada para a conformidade de $80 \%$, proporção de concordância esperada de $70 \%$ e uma proporção de concordância alternativa de $70 \%$, 0 tamanho da amostra necessário para cada componente observado dos quatro indicadores foi de 108 observações para cada avaliador.

Após a validação dos instrumentos e capacitação do observador, os resultados deste estudo foram coletados por um único avaliador (Avaliador 1). 


\subsection{ASPECTOS ÉTICOS E LEGAIS}

Essa pesquisa foi aprovada pela Comissão de Ética para Análise de Projetos de Pesquisa do Hospital das Clínicas da Faculdade de Medicina da Universidade de São Paulo (CAPPesq/HCFMUSP), sob protocolo $n^{\circ} 196 \mathrm{em}$ 26 de agosto de 2010 (Anexo I). Após a aprovação, cópias foram encaminhadas às chefias de enfermagem e médica para ciência e colaboração com a pesquisa.

Todos os profissionais (equipes médica e de enfermagem) que, em algum momento poderiam ser avaliados, foram previamente informados por meio de Termo de Consentimento Livre Esclarecido (TCLE) e tiveram total liberdade na decisão de participar ou serem retirados da pesquisa a qualquer momento, se assim quisessem como já citados anteriormente (Anexo G), a fim de evitar que os profissionais envolvidos não se sentissem coagidos, tendo livre escolha na decisão de participar ou não e/ou retirar-se da pesquisa a qualquer momento se assim desejasse.

Quanto à avaliação da prática da inserção do CVC, também foi solicitada a assinatura do TCLE pelo paciente (Anexo $\mathrm{H}$ ).

Todos os profissionais foram informados que a avaliação seria realizada de acordo com o leito/sala cirúrgica e não com o profissional.

\subsection{PERÍODO DE COLETA}

A coleta iniciou-se após a aprovação do projeto pela Comissão de Ética para Análise de Projetos de Pesquisa do Hospital das Clínicas da Faculdade de Medicina da Universidade de São Paulo (CAPPesq/HCFMUSP), e compreendeu os meses de agosto a novembro de 2010, com variação de frequência entre os turnos, à medida em que se atingia o total da amostra estabelecida para cada prática selecionada. As avaliações ocorreram de segunda a sexta-feira, nos turnos da manhã (9:00-12:00), tarde (15:00-18:00) e noite (19:30-22:30). Os finais de semana e feriados 
foram excluídos, pela possibilidade de redução na escala dos profissionais de saúde, contribuindo para desvio das práticas.

\subsection{PROCEDIMENTOS DA COLETA DE DADOS}

Os dados foram coletados conforme as orientações dos construtos operacionais dos indicadores, disponibilizados no referido Manual, que incluem, predominantemente, observação direta, além de análise de registros de prontuários ${ }^{(27)}$.

A avaliação dos indicadores realizou-se da seguinte maneira:

* Indicadores HMSEL e CSQI: avaliação obtida puramente por meio de observação direta (OD);

* Indicador CSIP: verificação dos registros nos prontuários dos pacientes;

* Indicador CSCM: observação direta e verificação dos registros nos prontuários dos pacientes.

A seleção dos leitos e salas cirúrgicas, de grande parte das práticas avaliadas, foi feita através de um programa gerador de sequências, disponível no site http://www.random.org/sequences ${ }^{(82)}$.

Para avaliação dos indicadores HMSEL e CSCM, com base nas características da UTI cirúrgica, infra-estrutura e número elevado de leitos (71 ao todo), realizou-se seleção criteriosa dos leitos avaliados, com utilização do Random (2009) ${ }^{(82)}$. O módulo IV da UTI cirúrgica II, que possui seus oito leitos dentro de quartos, não foi incluso na pesquisa, devido à dificuldade na avaliação dos indicadores.

Os critérios para seleção foram:

1. Sorteio entre UTI cirúrgica I (número 1) e UTI cirúrgica II (número 2);

2. Se UTI cirúrgica I selecionada, por ter apenas 11 leitos para o PO de cirurgia em adultos, todos eram inseridos automaticamente, depois de satisfeitos os critérios de inclusão. Se UTI cirúrgica II selecionada, houve sorteio entre os módulos; 
3. Após seleção dos módulos, no caso do módulo I selecionado, todos os leitos foram observados, satisfeitos os critérios de inclusão e exclusão. No caso de Módulo II e III, os leitos eram numerados e o programa Random (2009) ordenava os leitos, sendo os 8 primeiros leitos os selecionados para avaliação.

Para avaliação do indicador CSQI, o Random (2009) também foi utilizado para seleção da sala cirúrgica, conforme os critérios de inclusão e exclusão ${ }^{(82)}$. Devido ao procedimento cirúrgico cardiotorácico ser longo, e a coleta deste indicador ser realizada apenas por um avaliador, após os testes de aferição, somente uma sala foi avaliada por dia. Pelas características do Random (2009), que apenas realizou a aleatoriedade das salas, optou-se pela escolha da primeira sala da sequência ${ }^{(82)}$.

A avaliação do indicador CSIP foi realizada com o seguimento na UTI cirúrgica, dos mesmos pacientes observados na CC durante o procedimento de inserção do CVC.

A conformidade das práticas de prevenção e controle da ICS-ACVC foi considerada individualmente para cada Indicador (CSQI e CSIP), sendo necessário que todos os componentes avaliados (de um mesmo indicador) fossem conformes em uma única avaliação.

Para avaliação do indicador HMSEL, a conformidade foi considerada quando o profissional higienizou as mãos antes e após a realização das práticas previamente selecionadas (troca do sistema de infusão; administração de medicamentos; troca e realização de curativo; coleta de sangue), seja utilizando água e sabão anti-séptico ou aplicando álcool gel. E a não conformidade foi conferida quando o profissional não higienizou as mãos antes e/ou após a realização das situações selecionadas e ou situações inadequadas, conforme consideradas por Cabral de Menezes (2009) ${ }^{(73)}$ :

- Realização de outro procedimento assistencial no paciente logo após término da prática selecionada, sem higienizar as mãos;

- Retirar-se do quarto do paciente ou do local próximo ao leito para outras áreas sem realizar a higiene das mãos;

- Troca de luvas sem higienizar as mãos; 
- Sobrepor luvas de procedimento ou estéreis sobre as mãos já enluvadas e utilizadas no mesmo paciente em outro procedimento.

Antes, porém, da aplicação da avaliação da higiene das mãos, foi seguida uma sugestão de Cabral de Menezes (2009), na qual foi realizada uma avaliação adicional da estrutura existente para sua adequada realização, considerando-se a funcionalidade de lavatórios, dispensadores de sabão, papel toalha e dispensadores de álcool gel ${ }^{(73)}$.

\subsection{ANÁLISE ESTATÍSTICA}

As avaliações foram lançadas em banco específico para este estudo, no programa Windows/Excel da Microsoft ${ }^{\circledR}$ 2003, e analisadas quantitativamente, em números absolutos e percentuais. Os resultados obtidos foram apresentados em Tabelas e Gráficos. Para o cálculo dos índices de conformidades das práticas incluídas nos indicadores aplicados foram utilizadas as fórmulas recomendadas nos seus construtos operacionais, de dois modos: conformidade geral de cada indicador e conformidade de cada componente avaliado, conforme detalhada abaixo:

\section{Conformidade Geral}

CSIP: Indicador de avaliação da prática de registros de indicação e tempo de permanência do cateter vascular central de curta permanência.

№ cateteres vasculares centrais de curta permanência instalados em pacientes em que há registros de justificativa para sua indicação e o registro diário do seu tempo de permanência 
CSQI: Indicador de avaliação da prática de inserção e manutenção do cateter vascular central de curta permanência.

$\begin{gathered}\text { № total de cateteres vasculares centrais de curta permanência com } \\ \text { procedimentos corretos de inserção e manutenção }\end{gathered}$
\[ \begin{array}{c}\text { № total de cateteres vasculares centrais de curta permanência } \\ \text { avaliados }\end{array} \]

HMSEL: Indicador de avaliação da prática de adesão à higiene das mãos em situações selecionadas (antes e após a realização de curativo do cateter venoso central, infusão medicamentosa e coleta de sangue em CVC).

$$
\begin{aligned}
& \text { № total de oportunidades que o profissional de saúde teve } \\
& \text { para higienizar as mãos e efetivamente o fez } x 100 \\
& \text { № total de oportunidades de higiene das mãos observadas }
\end{aligned}
$$

CSCM: Indicador de avaliação da prática de adesão aos cuidados e manutenção do curativo do cateter venoso central de curta permanência e seus dispositivos conforme recomendações da instituição durante sua utilização.

$N^{\circ}$ de oportunidades que os profissional teve para realizar a anotação de realização do curativo, periodicidade da troca do curativo, desinfecção dos hubs e conectores com álcool $70 \%$ antes da manipulação e troca de equipos e transdutores realizada conforme recomendação da instituição $x 100$ № total de oportunidades avaliadas sob as condições descritas no numerador 


\section{Conformidade por Componente dos Indicadores}

Para o cálculo de conformidade relacionada a cada componente dos indicadores foi aplicada a mesma fórmula para obtenção da conformidade geral, descrita acima.

Os índices de conformidade obtidos para cada prática avaliada foram relacionados com as seguintes variáveis:

* Categoria profissional;

* Turno de trabalho avaliado.

Para comparar as proporções de conformidade entre os grupos e os períodos avaliados foi utilizado o teste do Qui-Quadrado. Quando o teste do Qui-Quadrado não pôde ser aplicado devido à ocorrência de frequências esperadas menores do que cinco, o teste da Razão da Verossimilhança foi utilizado e em caso de Tabela $2 \times 2$ o teste exato de Fisher.

Foi estabelecido o nível de significância de 5,0\% $(p<0,05)$ para essa análise. O programa utilizado para os cálculos foi o Statistical Package for the Social Sciences (SPSS), versão 16.0. 
5 RESULtAdOS 
Os resultados obtidos neste estudo são descritos abaixo, seguindo os seguintes tópicos:

a) Avaliação da Concordância entre avaliadores inter e intra instrumentos

b) Avaliações das Práticas de Prevenção e Controle de ICS-ACVC:

* Registro de indicação e de tempo de permanência do cateter venoso central de curta permanência (Indicador CSIP).

* Inserção do cateter venoso central de curta permanência (Indicador CSQI).

* Adesão aos cuidados e manutenção do curativo do cateter venoso central de curta permanência e seus dispositivos, conforme recomendação da instituição (Indicador CSCM).

* Adesão à prática de higiene das mãos em procedimentos selecionados (Indicador HMSEL).

\subsection{AVALIAÇÃO DA CONCORDÂNCIA ENTRE OS AVALIADORES INTER E INTRA INSTRUMENTOS}

Foram avaliados os componentes dos indicadores CSIP (216 observações), CSQI (540 observações), HMSEL (324 observações) e CSCM (432 observações), totalizando 1512 observações para a aferição de concordância. As avaliações foram contabilizadas em dupla, que atuou simultaneamente e registrou as informações em planilhas independentes.

Na Tabela 4 estão apresentados os resultados da concordância entre os avaliadores para o Indicador CSIP. 
Tabela 4 - Aferição da concordância obtida entre a dupla de avaliadores para os componentes do indicador CSIP. São Paulo, 2010

\begin{tabular}{lccc}
\hline \multicolumn{1}{c}{ Variáveis } & $\begin{array}{c}\text { Total } \\
\mathbf{n = 2 1 6}\end{array}$ & Kappa & $\mathbf{p}$ \\
\hline Observadores 1 e $\mathbf{2}$ & & & \\
Registro de indicação do CVC & 108 & 1,00 & 0,000 \\
Registro do tempo de permanência do CVC & 108 & 0,91 & 0,000 \\
\hline $\mathrm{p}<0,05$ & & &
\end{tabular}

A tabela acima nos mostra que houve concordância entre os observadores em relação aos registros de indicação e permanência do CVC, sendo $p<0,05$, em que o Kappa foi perfeito $(1,00)$ e quase perfeito $(0,91)$.

A Tabela 5 apresenta a conformidade das avaliações relacionadas ao Indicador CSQI.

Tabela 5 - Aferição da concordância obtida entre a dupla de avaliadores para os componentes do indicador CSQI. São Paulo, 2010

\section{Total}

\begin{tabular}{|c|c|c|c|}
\hline Variáveis & $n=540$ & Kappa & $\mathbf{p}$ \\
\hline \multicolumn{4}{|l|}{ Observadores 1 e 2} \\
\hline Inserção Percutânea & 108 & 1,00 & 0,000 \\
\hline $\begin{array}{l}\text { Uso de paramentação completa para } \\
\text { inserção do CVC }\end{array}$ & 108 & 1,00 & 0,000 \\
\hline $\begin{array}{l}\text { Uso de campo estéril ampliado no momento } \\
\text { da instalação do cateter }\end{array}$ & 108 & 1,00 & 0,000 \\
\hline $\begin{array}{l}\text { Uso de anti-séptico de veículo alcoólico para } \\
\text { preparo da pele }\end{array}$ & 108 & 1,00 & 0,000 \\
\hline Presença de curativo oclusivo & 108 & 1,00 & 0,000 \\
\hline
\end{tabular}

$p<0,05$ 
No Indicador CSQI, a concordância entre as observações dos avaliadores foi perfeita em todos os componentes, com $p<0,05$. As Tabelas 6 e 7 comparam as observações dos avaliadores em relação aos componentes do indicador HMSEL .

Tabela 6 - Aferição de concordância obtida entre a dupla de avaliadores para o indicador HMSEL. São Paulo, 2010

\section{Cuidado com Cateter venoso Central}

\begin{tabular}{ccccc}
\hline Avaliadores & Total & $\mathbf{n}$ & $\mathbf{k}$ & $\mathbf{p}$ \\
\hline Avaliadores 1 e 2 & $\mathbf{1 0 8}$ & 108 & 0,93 & 0,000 \\
\hline
\end{tabular}

k=Kappa 
Tabela 7 - Aferição de concordância obtida entre a dupla de avaliadores para os componentes do indicador HMSEL. São Paulo, 2010.

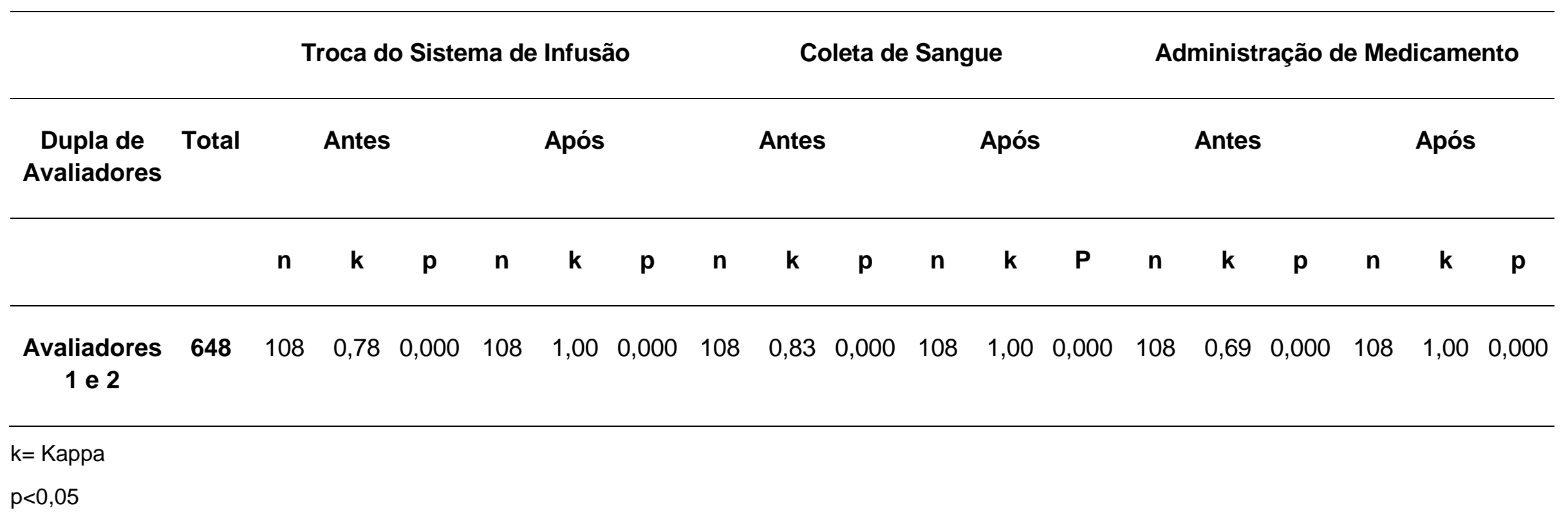


$\mathrm{Na}$ Tabela 6 , os avaliadores foram concordantes quanto às observações realizadas, de forma geral, onde $p<0,05$, e Kappa com concordância quase perfeita $(0,93)$.

Quanto à Tabela 7 , na qual os componentes foram analisados individualmente dentro do indicador HMSEL, a concordância foi perfeita para a higiene das mãos após a realização de todos os procedimentos (troca do sistema de infusão, administração de medicamento e coleta de sangue), com $k=1,00$. Ao analisarmos a higiene das mãos antes da realização dos procedimentos avaliados, a concordância foi substancial antes da troca do sistema de infusão $(\mathrm{k}=0,78)$ e antes da administração de medicamento $(k=0,69)$ e quase perfeita antes da coleta de sangue $(k=0,83)$. Apesar de ter havido um Kappa com resultado substancial ( $k=0,69$ e 0,78), houve concordância entre os resultados das observações dos avaliadores. Todos os resultados foram estatisticamente significantes com $p<0,05$.

A Tabela 8 apresenta os resultados da concordância entre as informações obtidas pelos avaliadores, para os componentes do indicador CSCM.

Tabela 8 - Aferição da concordância obtida entre a dupla de avaliadores para os componentes do indicador CSCM. São Paulo, 2010

\section{Total}

Variáveis $\quad n=432 \quad$ Kappa $p$

\section{Observadores 1 e 2}

Desinfecção de hubs e conectores antes da manipulação com clorexidina alcoólica 0,5\%

Troca de equipos e transdutores conforme norma da instituição

Registro de troca do curativo

$108 \quad 0,88 \quad 0,000$

Periodicidade da troca do curativo 108 $1,00 \quad 0,000$

$p<0,05$

$108 \quad 1,00 \quad 0,000$

$\mathrm{Na}$ Tabela 8 podemos observar que em todos os componentes houve concordância estatisticamente significante entre os avaliadores $p<0,05$, onde o índice Kappa variou de concordância perfeita $(1,00)$ a quase perfeita $(0,88)$. 


\subsection{AVALIAÇÕES DAS PRÁTICAS DE PREVENÇÃO E CONTROLE DE ICS-ACVC}

Foram realizadas 5877 avaliações, sendo $166(2,8 \%)$ relacionadas ao registro de indicação e tempo de permanência do CVC (CSIP), 415 (7,1\%) à prática de inserção do CVC (CSQI), 1986 (33,8\%) à adesão aos cuidados e manutenção do curativo do CVC e seus dispositivos (CSCM) e 3310 (56,3\%) à higiene das mãos em procedimentos selecionados (HMSEL).

Para o cálculo de conformidade geral, de acordo com as fórmulas dos indicadores de avaliação, era necessário que TODOS os componentes de cada um deles estivessem em conformidade no MESMO paciente. Se a prática de um deles não estivesse corretamente realizada o indicador era pontuado como não conforme.

As práticas avaliadas, as conformidades, não conformidades, associações entre categorias profissionais, turnos de trabalho e motivos de não conformidade são apresentadas a seguir.

\subsubsection{Avaliação da prática de registro de indicação e de tempo de permanência do cateter venoso central de curta permanência (Indicador CSIP)}

Este indicador (CSIP) foi avaliado na UTI cirúrgica. Os CVCs inicialmente avaliados no CC foram os mesmos considerados para esta avaliação. $\mathrm{O}$ registro de indicação do CVC foi verificado no prontuário do paciente após sua chegada na UTI. Quanto ao registro do tempo de permanência do CVC, este foi avaliado diariamente na folha de anotação de enfermagem até a sua retirada, alta ou óbito do paciente da UTI.

Assim como no indicador anterior (CSQI), bastou apenas um dos componentes não estar corretamente realizado em algum dia da avaliação para 
que não se obtivesse a conformidade geral deste indicador. Ou seja, todos os componentes necessitavam estar em conformidade simultaneamente.

$\mathrm{Na}$ Tabela 9, abaixo, está apresentada a conformidade geral para este indicador.

Tabela 9 - Conformidade geral da prática de registro de indicação e tempo de permanência do cateter venoso central de curta permanência (Indicador CSIP). São Paulo, 2010

\begin{tabular}{cccc}
\hline Prática & Total & \multicolumn{2}{c}{ Conformidade } \\
\cline { 3 - 4 } & $\mathbf{n}$ & $\mathbf{n}$ & $\%$ \\
\hline Conformidade Geral & 83 & 76 & 91,6 \\
Total & 83 & 76 & $\mathbf{9 1 , 6}$ \\
\hline
\end{tabular}

Pela Tabela 9, a conformidade geral para este indicador foi de 91,6\%, ou seja, superior ao considerado como ideal (80\%). Tais resultados apontam uma alta adesão dos profissionais quanto ao registro de indicação e tempo de permanência do CVC.

A conformidade e não conformidade específica para cada medida avaliada, quanto ao registro de indicação e tempo de permanência do CVC, são apresentadas na Tabela 10.

Tabela 10 - Conformidade e não conformidade dos componentes da prática de registro de indicação e de tempo de permanência do cateter venoso central de curta permanência (Indicador CSPI). São Paulo, 2010

\begin{tabular}{lcccccc}
\hline Componentes & Total & & \multicolumn{2}{c}{ Conforme } & \multicolumn{2}{c}{ Não conforme } \\
\cline { 3 - 7 } & $\mathbf{n}$ & $\mathbf{n}$ & $\%$ & $\mathbf{n}$ & $\%$ \\
\hline Registro de indicação & 83 & 80 & 96,4 & 3 & 3,6 \\
Registro do tempo de permanência & 83 & 79 & 95,2 & 4 & 4,8 \\
Total & $\mathbf{1 6 6}$ & $\mathbf{1 5 9}$ & $\mathbf{9 5 , 8}$ & $\mathbf{7}$ & $\mathbf{4 , 2}$ \\
\hline
\end{tabular}


$\mathrm{Na}$ Tabela 10, notamos que a conformidade de cada componente foi, isoladamente, superior à conformidade geral desse indicador (91,6\% Tabela 9). Ou seja, 96,4\% para registro de indicação e 95,2\% para registro do tempo de permanência do CVC.

Ressalte-se que a avaliação de tais registros não foi submetida à análise de correlação estatística por serem realizados somente por uma categoria profissional e independente do turno de trabalho. $\mathrm{O}$ registro de indicação do CVC era realizado por médicos e o registro do tempo de permanência por enfermeiros.

O Gráfico 1 ilustra a distribuição dos resultados referentes a este Indicador.

Gráfico 1 - Conformidade dos componentes da prática de registro de indicação e tempo de permanência do cateter venoso central de curta permanência (Indicador CSPI). São Paulo, 2010

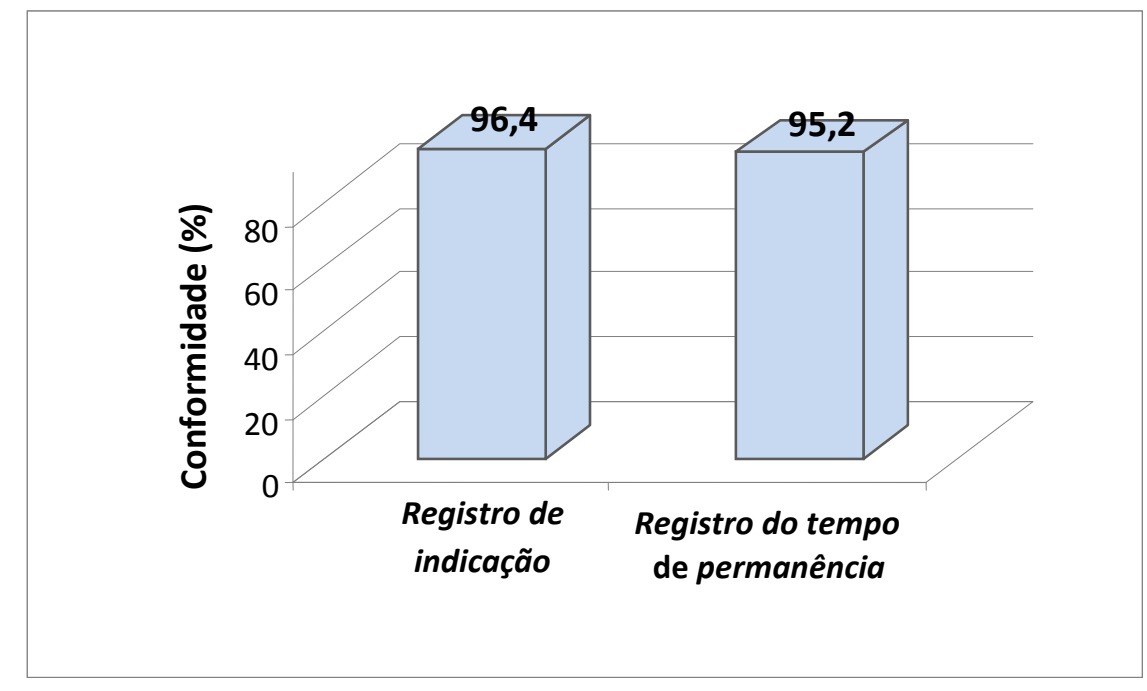

\subsubsection{Avaliação da prática de inserção do cateter venoso central de curta permanência (Indicador CSQI)}

O indicador CSQI foi avaliado no centro cirúrgico durante a inserção do CVC, antes da cirurgia cardíaca. Conforme já citado, a conformidade de 
cada prática somente é obtida quando todos os procedimentos que a compõe estão corretos.

Para esse indicador a conformidade foi nula (0,0\%). Isso se deveu à ausência de realização de curativo oclusivo em todas as práticas avaliadas de inserção do cateter venoso central.

A Tabela 11 corresponde às conformidades e não conformidades específicas para cada componente do indicador do CSQI.

Tabela 11 - Conformidade e não conformidade dos componentes da prática de inserção do cateter venoso central de curta permanência (Indicador CSQI). São Paulo, 2010

\begin{tabular}{lcccccc}
\hline Componentes & Total & \multicolumn{3}{c}{ Conforme } & Não conforme \\
\cline { 3 - 7 } & $\mathbf{n}$ & $\mathbf{n}$ & $\%$ & $\mathbf{n}$ & $\%$ \\
\hline Inserção Percutânea & 83 & 83 & 100,0 & 0 & 0,0 \\
$\begin{array}{l}\text { Uso de paramentação completa para } \\
\text { inserção do CVC }\end{array}$ & 83 & 83 & 100,0 & 0 & 0,0 \\
$\begin{array}{l}\text { Uso de campo estéril ampliado no } \\
\text { momento da instalação do cateter }\end{array}$ & 83 & 83 & 100,0 & 0 & 0,0 \\
$\begin{array}{l}\text { Uso de anti-séptico de veículo } \\
\text { alcoólico para preparo da pele }\end{array}$ & 83 & 83 & 100,0 & 0 & 0,0 \\
$\begin{array}{l}\text { Presença de curativo oclusivo** } \\
\text { Total }\end{array}$ & 83 & 0 & 0,0 & 83 & 100,0 \\
\hline
\end{tabular}

** Presença de curativo oclusivo após a inserção do CVC

$\mathrm{Na}$ tabela acima podemos observar que os quatro primeiros componentes atingiram $100 \%$ de conformidade e a presença do curativo oclusivo não foi observada em nenhuma avaliação realizada.

A ausência do curativo oclusivo na inserção do CVC, portanto, foi a única medida que interferiu negativamente na obtenção da conformidade geral (0,0\%). O Gráfico 2, abaixo, permite visualizar a distribuição desses resultados. 
Gráfico 2 - Conformidade de cada componente da prática de inserção do cateter venoso central de curta permanência (Indicador CSQI). São Paulo, 2010

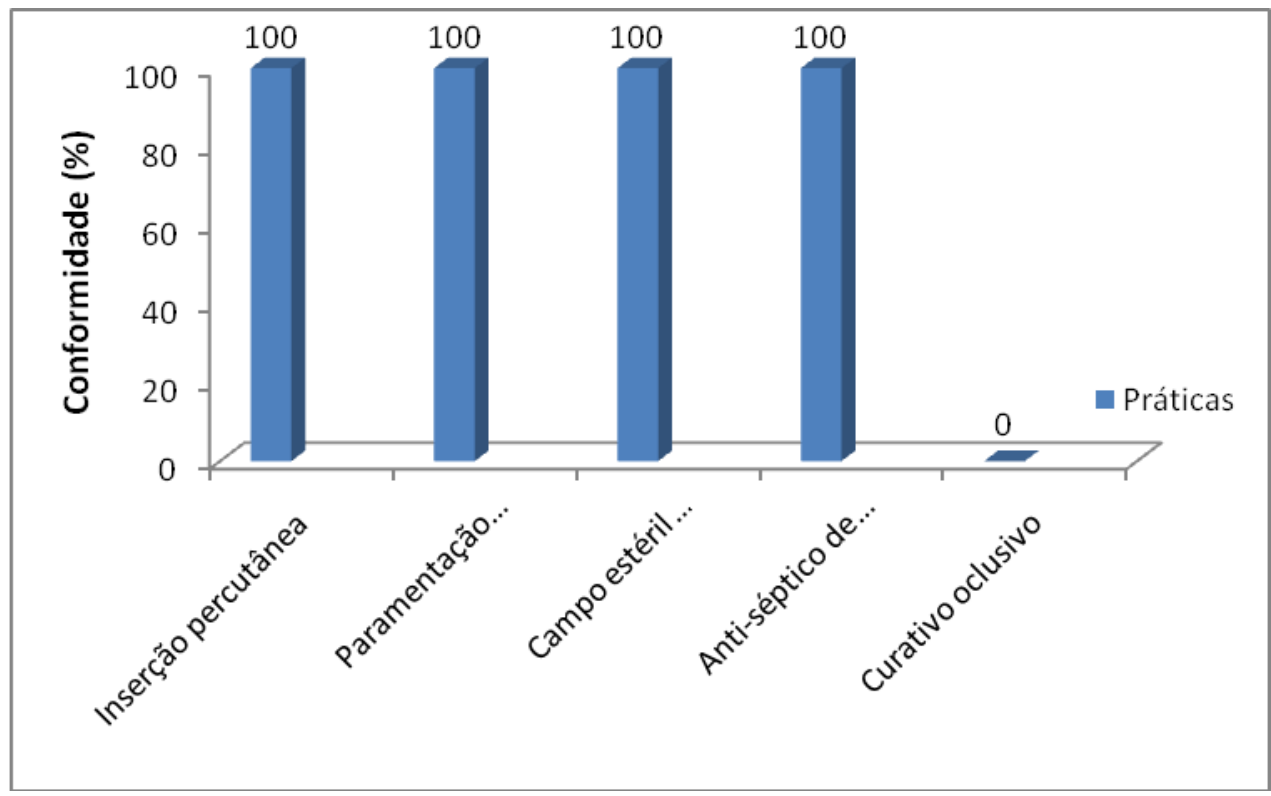

Finalmente, por esta prática ter sido realizada por apenas uma categoria profissional (médicos), e ser avaliada independente do período, não foi possível realizar correlações estatísticas.

5.2.3 Avaliação da prática de adesão aos cuidados e manutenção do curativo do cateter venoso central de curta permanência e seus dispositivos, conforme recomendação da instituição (Indicador CSCM)

$\mathrm{Na}$ instituição na qual a pesquisa foi realizada e, de acordo com a literatura, a desinfecção das hubs e conectores com clorexidina alcoólica 0,5\% deve ser feita antes de toda manipulação ${ }^{(31)}$. O período de troca dos equipos varia de acordo com seu uso e indicação do fabricante, não ultrapassando 72 horas. E os transdutores devem ser trocados a cada 96 horas ${ }^{(66)}$.

Quanto aos curativos (de acordo com as recomendações institucionais), quando este for realizado com gaze estéril e fita adesiva, deve ser trocado a cada 24 horas e no caso de filme transparente, a cada 7 
dias. Lembrando que em presença de sujidade ou curativo não íntegro, este deve ser trocado ${ }^{(66)}$.

Para o cálculo de conformidade geral, como já citado anteriormente e, de acordo com as fórmulas dos indicadores de avaliação, foi necessário que TODOS os componentes de cada um deles estivessem em conformidade no MESMO paciente. Se a prática de um deles não estivesse corretamente realizada, ela era pontuada como não conforme.

A Tabela 12, a seguir, permite observar as conformidades, de acordo com os turnos de trabalho.

Tabela 12 - Conformidade geral da prática de adesão aos cuidados e manutenção do curativo do cateter venoso central de curta permanência e seus dispositivos (Indicador CSCM), de acordo com o turno de trabalho. São Paulo, 2010

\begin{tabular}{|c|c|c|c|c|c|c|c|c|c|}
\hline & & \multicolumn{6}{|c|}{ Turnos } & \multirow{2}{*}{\multicolumn{2}{|c|}{ Total }} \\
\hline & & \multicolumn{2}{|c|}{ Manhã } & \multicolumn{2}{|c|}{ Tarde } & \multicolumn{2}{|c|}{ Noite } & & \\
\hline & & $\mathbf{n}$ & $\%$ & $\mathbf{n}$ & $\%$ & $\mathbf{n}$ & $\%$ & $\mathbf{n}$ & $\%$ \\
\hline \multirow[t]{2}{*}{ Conformidade } & SIM & 409 & 61,8 & 88 & 26,6 & 526 & 53,0 & 1023 & 51,5 \\
\hline & NÃO & 253 & 38,2 & 243 & 73,4 & 467 & 47,0 & 963 & 48,5 \\
\hline \multicolumn{2}{|c|}{ Total } & 662 & 100,0 & 331 & 100,0 & 993 & 100,0 & 1986 & 100,0 \\
\hline
\end{tabular}

De acordo com a Tabela 12, podemos observar que a conformidade geral $(51,5 \%)$ obtida está abaixo da conformidade ideal considerada para este estudo (80\%). O mesmo ocorreu em cada período de trabalho, sendo que o da manhã apresentou a maior conformidade $(61,8 \%)$ e o da tarde, a menor $(26,6 \%)$.

Importante lembrar que o número de avaliações foi diferente para cada turno de trabalho devido à rotina da unidade e aos momentos em que os procedimentos são realizados. A maior frequência de observações ocorreu no turno da noite (993), seguindo-se o da manhã (662) e, por último, o da tarde (331). Pelas conformidades obtidas por turno, constata-se que as diferenças de quantidade de avaliações não interferiram nos resultados. 
A Tabela 13 apresenta as conformidades e não conformidades para cada componente da prática de adesão aos cuidados e manutenção do curativo do cateter venoso central de curta permanência e seus dispositivos, de acordo com os turnos de trabalho.

Tabela 13 - Conformidade e não conformidade dos componentes da prática de cuidados e manutenção do curativo do cateter venoso central de curta permanência e seus dispositivos, segundo o turno de trabalho. São Paulo, 2010

\begin{tabular}{|c|c|c|c|c|c|c|}
\hline \multirow[t]{2}{*}{ Turno/Componentes } & \multicolumn{2}{|c|}{ Conforme } & \multicolumn{2}{|c|}{$\begin{array}{c}\text { Não } \\
\text { Conforme }\end{array}$} & \multicolumn{2}{|c|}{ Total } \\
\hline & $\mathbf{n}$ & $\%$ & $\mathbf{n}$ & $\%$ & $n$ & $\%$ \\
\hline \multicolumn{7}{|l|}{ Manhã } \\
\hline 1. Registro de Troca do Curativo & -- & -- & -- & -- & -- & -- \\
\hline $\begin{array}{l}\text { 2. Periodicidade da troca do curativo } \\
\text { conforme recomendação }\end{array}$ & -- & -- & -- & -- & -- & -- \\
\hline $\begin{array}{l}\text { 3. Desinfecção de hubs e conectores } \\
\text { com clorexidina alcoólica } 0,5 \%\end{array}$ & 128 & 38,7 & 203 & 61,3 & 331 & 100,0 \\
\hline $\begin{array}{l}\text { 4. Troca de equipos e transdutores } \\
\text { conforme recomendação }\end{array}$ & 331 & $\begin{array}{c}100 \\
0\end{array}$ & 0 & 0,0 & 331 & 100,0 \\
\hline Subtotal & 459 & 69,3 & 203 & 30,7 & 662 & 100,0 \\
\hline \multicolumn{7}{|l|}{ Tarde } \\
\hline 1. Registro de Troca do Curativo & -- & -- & -- & -- & -- & -- \\
\hline $\begin{array}{l}\text { 2. Periodicidade da troca do curativo } \\
\text { conforme recomendação }\end{array}$ & -- & -- & -- & -- & -- & -- \\
\hline $\begin{array}{l}\text { 3. Desinfecção de hubs e conectores } \\
\text { com clorexidina alcoólica } 0,5 \%\end{array}$ & 103 & 31,1 & 228 & 68,9 & 331 & 100,0 \\
\hline $\begin{array}{l}\text { 4. Troca de equipos e transdutores } \\
\text { conforme recomendação }\end{array}$ & -- & -- & -- & -- & -- & -- \\
\hline Subtotal & 103 & 31,1 & 228 & 68,9 & 331 & 100,0 \\
\hline \multicolumn{7}{|l|}{ Noite } \\
\hline 1. Registro de Troca do Curativo & 252 & 76,1 & 79 & 23,9 & 331 & 100,0 \\
\hline $\begin{array}{l}\text { 2. Periodicidade da troca do curativo } \\
\text { conforme recomendação }\end{array}$ & 330 & 99,7 & 1 & 0,3 & 331 & 100,0 \\
\hline $\begin{array}{l}\text { 3. Desinfecção de hubs e conectores } \\
\text { com clorexidina alcoólica } 0,5 \%\end{array}$ & 41 & 12,4 & 290 & 87,6 & 331 & 100,0 \\
\hline $\begin{array}{l}\text { 4. Troca de equipos e transdutores } \\
\text { conforme recomendação }\end{array}$ & -- & -- & -- & -- & -- & -- \\
\hline Subtotal & 623 & 62,7 & 370 & 37,3 & 993 & 100,0 \\
\hline Total & 1185 & 59,7 & 801 & 40,3 & 1986 & 100,0 \\
\hline
\end{tabular}

*A troca de equipos e transdutores é realizada rotineiramente no período da manhã 
$\mathrm{Na}$ Tabela 13, ao analisarmos este indicador por componentes, notamos que somente a troca de equipos e transdutores, realizada apenas no período da manhã, obteve conformidade total $(100,0 \%)$. Quanto à periodicidade da troca do curativo, realizada somente no noturno, a conformidade foi quase total $(99,7 \%)$. E o registro de troca de curativo, realizado somente no noturno, obteve conformidade próxima da ideal $(76,1 \%)$.

A conformidade geral para essa prática foi abaixo de $80 \%$, e deveu-se principalmente ao componente desinfecção de hubs e conectores com clorexidina alcoólica $0,5 \%$, único procedimento realizado em todos os turnos, com conformidades sempre abaixo de $40,0 \%$, principalmente no noturno $(12,4 \%)$.

As causas de não conformidade quanto à adesão aos cuidados e manutenção do curativo do cateter venoso central de curta permanência e seus dispositivos, de acordo com o turno de trabalho, são apresentadas na Tabela 14. 
Tabela 14 - Causas de não conformidade dos componentes da prática de cuidados e manutenção do curativo do cateter venoso central de curta permanência e seus dispositivos, de acordo com o turno de trabalho. São Paulo, 2010

Componentes/ Não conformidade

\begin{tabular}{cccc}
\multicolumn{4}{c}{ Turnos de Trabalho } \\
Manhã & Tarde & Noite & Total \\
\hline $\mathbf{n}(\%)$ & $\mathbf{n}(\%)$ & $\mathbf{n}(\%)$ & $\mathbf{n ( \% )}$
\end{tabular}

1. Desinfecção dos hubs, torneirinhas e conectores com clorexidina alcoólica $0,5 \%$ antes de toda manipulação

Não realização de desinfecção antes da manipulação do cateter

$\begin{array}{cccc}103 & 152 & 197 & 425 \\ (50,7) & (66,7) & (68,0) & (62,7)\end{array}$

Realização de desinfecção com álcool 70\%

$\begin{array}{cccc}100 & 76 & 93 & \mathbf{2 6 9} \\ (49,3) & (33,3) & (32,0) & (\mathbf{3 7 , 3 )} \\ 203 & 228 & 290 & \mathbf{7 2 1} \\ (100,0) & (100,0) & (100,0) & (\mathbf{1 0 0 , 0 )}\end{array}$

\section{Registro de Troca do Curativo}

Ausência de descrição da realização do

\begin{tabular}{|c|c|c|c|}
\hline -- & -- & $\begin{array}{c}79 \\
(100,0)\end{array}$ & $\begin{array}{c}79 \\
(100,0)\end{array}$ \\
\hline -- & -- & $\begin{array}{c}79 \\
(100,0)\end{array}$ & $\begin{array}{c}79 \\
(100,0)\end{array}$ \\
\hline
\end{tabular}

3. Periodicidade da troca do curativo conforme recomendação

Curativo com filme transparente há mais de 7 dias

$\begin{array}{cccc}-- & - & 1 & \mathbf{1} \\ & & (100,0) & (\mathbf{1 0 0 , 0 )} \\ -- & -- & 1 & \mathbf{1} \\ & & (100,0) & (100,0) \\ 203 & 228 & 370 & 801 \\ (100,0) & (100,0) & (100,0) & (100,0)\end{array}$

Subtotal

Total 
Pela Tabela 14, as causas que levaram aos resultados de não conformidade para o componente desinfecção dos hubs e conectores com clorexidina alcoólica $0,5 \%$ antes da manipulação do CVC foram: 1) não realização de desinfecção antes da manipulação do cateter e 2) realização de desinfecção com álcool 70\%. Isso revela um descumprimento da rotina da instituição, em ambos os casos, e em relação a todos os turnos.

A causa para não conformidade do componente de registro de troca do curativo, em sua totalidade, foi a própria ausência de descrição da realização do curativo da inserção do CVC.

E a causa de não conformidade relacionada ao componente periodicidade da troca do curativo, conforme recomendação da instituição, foi a presença de curativo com filme transparente por mais de 7 dias. Este resultado revela uma adesão da equipe em relação à prática da troca de curativos, pois apresentou somente uma não conformidade.

O cálculo de correlação estatística para o indicador CSCM foi possível apenas para o componente de adesão à desinfecção de hubs e conectores com clorexidina alcoólica $0,5 \%$ antes da manipulação, pois somente ele foi coletado nos três turnos de trabalho, variando também a categoria profissional que a realizava. Os resultados seguem na Tabela 15. 
Tabela 15 - Conformidade e não conformidade do componente adesão à desinfecção de hubs e conectores com clorexidina alcoólica 0,5\% antes da manipulação, segundo a categoria profissional e turno de trabalho. São Paulo, 2010

\begin{tabular}{|c|c|c|c|c|c|c|c|c|}
\hline \multirow[t]{3}{*}{ Turno } & & \multicolumn{4}{|c|}{ Categoria Profissional } & & & \multirow{3}{*}{$\mathbf{p}$} \\
\hline & & \multicolumn{2}{|c|}{ Enfermeiro } & \multicolumn{2}{|c|}{$\begin{array}{l}\text { Auxiliar/Técnico } \\
\text { de Enfermagem }\end{array}$} & \multicolumn{2}{|c|}{ Total } & \\
\hline & & $\mathbf{n}$ & $\%$ & $\mathbf{n}$ & $\%$ & $\mathbf{n}$ & $\%$ & \\
\hline \multicolumn{9}{|c|}{ Manhã } \\
\hline & SIM & 50 & 44,6 & 78 & 35,6 & 128 & 38,7 & $0,122^{c}$ \\
\hline & NÂO & 62 & 55,4 & 141 & 64,4 & 203 & 61,3 & $0,122^{c}$ \\
\hline & Total & 112 & 100,0 & 219 & 100,0 & 331 & 100,0 & \\
\hline \multicolumn{9}{|c|}{ Tarde } \\
\hline & SIM & 52 & 41,6 & 51 & 24,8 & 103 & 31,1 & $0,001^{a}$ \\
\hline & NÂO & 73 & 58,4 & 155 & 75,2 & 228 & 68,9 & $0,001^{a}$ \\
\hline & Total & 125 & 100,0 & 206 & 100,0 & 331 & 100,0 & \\
\hline \multicolumn{9}{|c|}{ Noite } \\
\hline & SIM & 17 & 14,6 & 24 & 11,1 & 41 & 12,4 & $0,384^{a}$ \\
\hline & NÂO & 99 & 85,4 & 191 & 88,9 & 290 & 87,6 & $0,384^{a}$ \\
\hline & Total & 116 & 100,0 & 215 & 100,0 & 331 & 100,0 & \\
\hline
\end{tabular}

${ }^{a}$ Teste do Qui-quadrado

${ }^{\mathrm{c}}$ Teste Exato de Fisher

Conforme podemos observar na Tabela 15, em todos os turnos de trabalho e entre as duas categorias profissionais observadas, a conformidade ideal (80\%) não foi atingida.

Destacamos que os turnos da manhã $(44,6 \%)$ e da noite $(14,6 \%)$ apresentaram baixa frequência de conformidade e, quando comparados 
entre as duas categorias profissionais, não houve diferença estatisticamente significante $(p>0,05)$.

Quanto ao turno da tarde, as duas categorias profissionais obtiveram baixa concordância (enfermeiros - 41,6\%, auxiliar/técnico de enfermagem $24,8 \%)$, e a diferença entre elas foi estatisticamente significante $(p<0,05)$.

A Tabela 16, a seguir, mostra a conformidade e não conformidade geral e por turno de trabalho para a desinfecção de hubs e conectores com clorexidina alcoólica 0,5\% antes da manipulação.

Tabela 16 - Conformidade e não conformidade do componente desinfecção de hubs e conectores com clorexidina alcoólica 0,5\% antes da manipulação, de acordo com os turnos de trabalho. São Paulo, 2010

\begin{tabular}{|c|c|c|c|c|c|c|c|c|c|c|}
\hline & & \multicolumn{6}{|c|}{ Turnos } & & & \multirow{3}{*}{$\mathbf{p}$} \\
\hline & & \multicolumn{2}{|c|}{ Manhã } & \multicolumn{2}{|c|}{ Tarde } & \multicolumn{2}{|c|}{ Noite } & \multicolumn{2}{|c|}{ Total } & \\
\hline & & $\mathbf{n}$ & $\%$ & $\mathbf{n}$ & $\%$ & $\mathbf{n}$ & $\%$ & $\mathbf{n}$ & $\%$ & \\
\hline \multirow[t]{2}{*}{ Conformidade } & SIM & 128 & 38,7 & 103 & 31,1 & 41 & 12,4 & 272 & 27,4 & 0,000 \\
\hline & NÃO & 203 & 61,3 & 228 & 68,9 & 290 & 87,6 & 721 & 72,6 & 0,000 \\
\hline Total & & 331 & 100,0 & 331 & 100,0 & 331 & 100,0 & 993 & 100,0 & \\
\hline
\end{tabular}

De acordo com a Tabela 16, a conformidade geral para esta prática manteve-se bem distante da ideal, com apenas $27,4 \%$. Ao analisarmos cada turno de trabalho, o da manhã apresentou o maior índice de conformidade $(38,7 \%)$ e o da noite, o pior (12,4\%).

Quando comparamos os três turnos entre si em relação à conformidade desta prática, encontramos diferença estatisticamente significante $(p<0,05)$. 


\subsubsection{Avaliação da prática de higiene das mãos em procedimentos selecionados (Indicador HMSEL)}

Foram realizadas 3310 observações referentes às oportunidades de realização da higiene das mãos pelos profissionais durante os três turnos de trabalho, sendo 331 para a troca e realização do curativo, avaliada apenas no período noturno, pois este é o período em que é realizado este procedimento, e 993 para os demais procedimentos previamente selecionados: troca de sistema de infusão, administração de medicamentos e coleta de sangue.

A conformidade foi considerada somente quando 0 profissional realizava a higiene das mãos ANTES e APÓS cada procedimento selecionado, seja com água e sabão degermante ou com álcool gel. Com isso, a não conformidade foi pontuada quando a higiene das mãos era realizada somente antes, somente após ou em nenhum momento.

A Tabela 17 apresenta a conformidade geral e por componentes obtidas para a prática de higiene das mãos.

Tabela 17 - Conformidade geral e por componentes da prática de higiene das mãos em situações selecionadas. São Paulo, 2010

\begin{tabular}{lccc}
\hline \multirow{2}{*}{ Componentes } & \multicolumn{2}{c}{ Conformidade } & $\mathbf{n}$ \\
\cline { 2 - 3 } & $\mathbf{n}$ & $\%$ & \\
\hline Troca do sistema de infusão & 88 & 8,9 & 993 \\
Administração de medicamentos & 95 & 9,6 & 993 \\
Coleta de Sangue & 101 & 10,2 & 993 \\
Troca e realização de curativo & 70 & 21,1 & 331 \\
Geral & $\mathbf{3 5 4}$ & $\mathbf{1 0 , 7}$ & $\mathbf{3 3 1 0}$ \\
\hline
\end{tabular}


A conformidade geral da higiene das mãos para procedimentos selecionados foi $10,7 \%$, distante da conformidade esperada, de $80 \%$. Para cada componente avaliado isoladamente também encontramos baixa porcentagem de conformidade. A troca e realização de curativo foi 0 procedimento com maior porcentagem de conformidade $(21,1 \%)$, enquanto 0 componente de menor conformidade foi o procedimento de troca do sistema de infusão (8,9\%).

Na Tabela 18 está apresentada a conformidade da higiene das mãos para os procedimentos selecionados de acordo com o turno de trabalho.

Tabela 18 - Conformidade geral da prática de higiene das mãos de acordo com os turnos de trabalho. São Paulo, 2010

\begin{tabular}{|c|c|c|c|c|c|c|c|c|c|c|}
\hline & & \multicolumn{6}{|c|}{ Turnos } & & & \multirow{3}{*}{$\mathbf{p}$} \\
\hline & & \multicolumn{2}{|c|}{ Manhã } & \multicolumn{2}{|c|}{ Tarde } & \multicolumn{2}{|c|}{ Noite } & \multicolumn{2}{|c|}{ Total } & \\
\hline & & $\mathbf{n}$ & $\%$ & n & $\%$ & $\mathbf{n}$ & $\%$ & $\mathbf{n}$ & $\%$ & \\
\hline \multirow[t]{2}{*}{ Conformidade } & SIM & 127 & 12,8 & 116 & 11,7 & 111 & 8,4 & 354 & 10,7 & 0,000 \\
\hline & NÃO & 866 & 87,2 & 877 & 88,3 & 1213 & 91,6 & 2956 & 89,3 & 0,000 \\
\hline Total & & 993 & 100,0 & 993 & 100,0 & 1324 & 100,0 & 3310 & 100,0 & \\
\hline
\end{tabular}

De acordo com a Tabela 19, em todos os turnos observados a conformidade foi baixa e esteve distante da considerada ideal (80,0\%). Quanto aos turnos de trabalho, o maior índice de conformidade foi encontrado no período da manhã $(12,8 \%)$ e o menor no da noite $(8,4 \%)$. Ao compararmos os três turnos de trabalho, houve diferença estatisticamente significativa em relação à prática de higiene das mãos, com $p<0,05$.

$\mathrm{Na}$ Tabela 19 está distribuída a quantidade de oportunidades de higiene das mãos para cada categoria profissional, de acordo com 0 procedimento observado e o turno de trabalho. 
Tabela 19 - Oportunidades da prática de higiene das mãos segundo a categoria profissional, o tipo de procedimento observado e o turno de trabalho. São Paulo, 2010

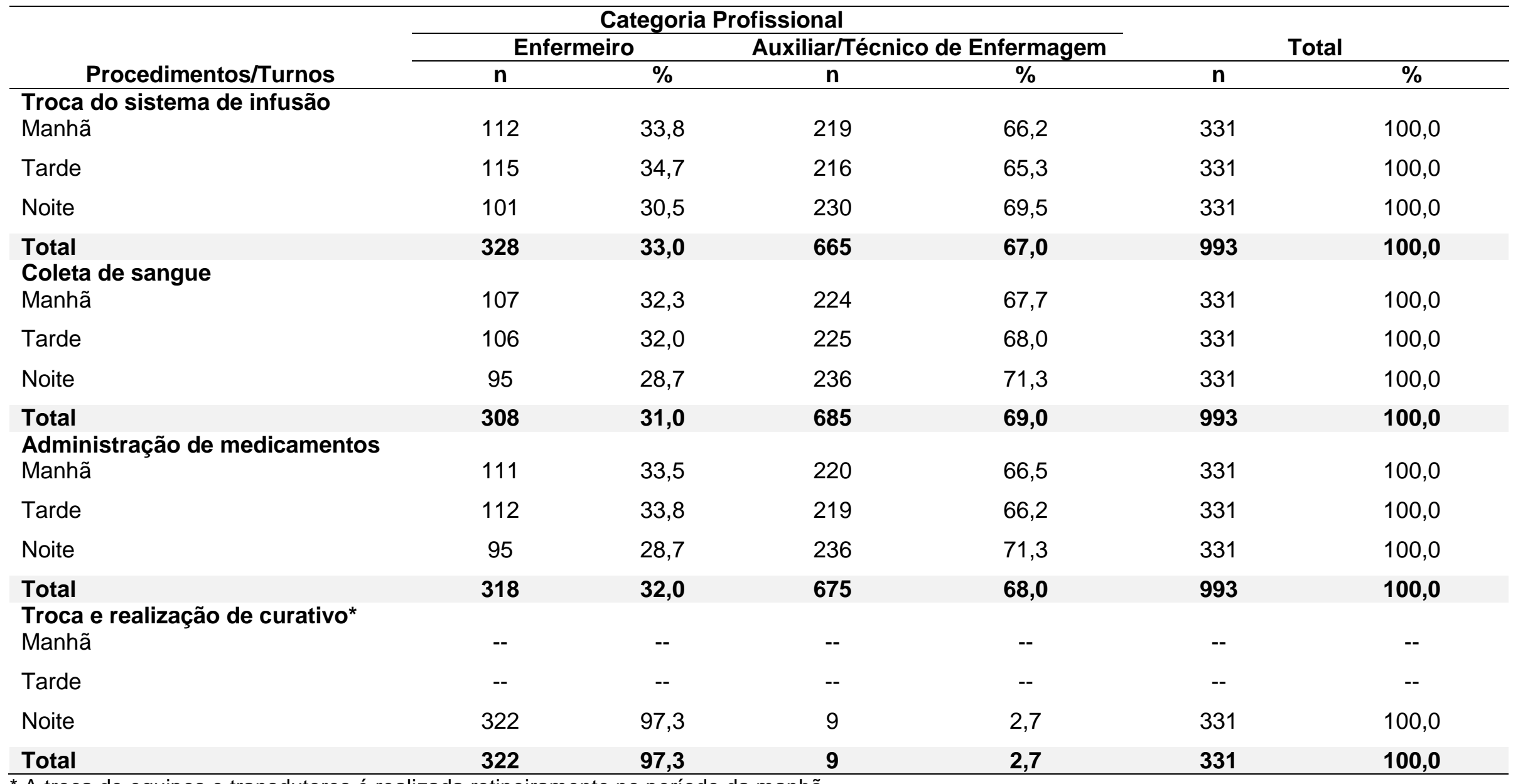


A Tabela 19 evidencia que a categoria profissional de auxiliares/técnicos de enfermagem foi a mais observada em todos os turnos de trabalho e na realização da maioria dos procedimentos: troca do sistema de infusão - 67,0\%, coleta de sangue - 69,0\% e administração de medicamento - 68,0\%). Na troca e realização do curativo, ao contrário, $97,3 \%$ foi realizada pelos enfermeiros, e somente no período noturno.

A maior frequência observada junto a auxiliares/técnicos de enfermagem se deve, obviamente, por esta categoria ser quantitativamente maior no local. E a quase totalidade da troca e realização do curativo por enfermeiros ocorreu devido à rotina da unidade, pois enquanto os auxiliares/técnicos de enfermagem fazem outros procedimentos como o banho, preparo de drogas e outras medicações, verificação dos sinais vitais etc., os enfermeiros realizam a troca do curativo.

Os resultados de conformidade e não conformidade da higiene das mãos de acordo com a categoria profissional e tipo de procedimento observado estão apresentados na Tabela 20. 
Tabela 20 - Conformidade e não conformidade em relação à prática de higiene das mãos de acordo com a categoria profissional e procedimentos selecionados. São Paulo, 2010

\begin{tabular}{|c|c|c|c|c|c|c|}
\hline \multirow[t]{3}{*}{ Procedimentos } & \multicolumn{3}{|c|}{ Categoria Profissional } & \multirow{2}{*}{\multicolumn{2}{|c|}{ Total }} & \multirow[b]{2}{*}{ p } \\
\hline & Enfermeiro & $\begin{array}{l}\text { Auxi } \\
\text { de } E\end{array}$ & $\begin{array}{l}\text { cnico } \\
\text { agem }\end{array}$ & & & \\
\hline & $\%$ & $n$ & $\%$ & $\mathbf{n}$ & $\%$ & \\
\hline
\end{tabular}

Troca do Sistema

de Infusão

\begin{tabular}{rrrrrrrr} 
SIM & 59 & 18,0 & 29 & 4,4 & 88 & $\mathbf{8 , 9}$ & $0,000^{\mathrm{a}}$ \\
NÂO & 269 & 82,0 & 636 & 95,6 & 905 & $\mathbf{9 1 , 1}$ & $0,000^{\mathrm{a}}$ \\
Total & $\mathbf{3 2 8}$ & $\mathbf{1 0 0 , 0}$ & $\mathbf{6 6 5}$ & $\mathbf{1 0 0 , 0}$ & $\mathbf{9 9 3}$ & $\mathbf{1 0 0 , 0}$ & \\
\hline
\end{tabular}

Coleta de Sangue

\begin{tabular}{rrrrrrrr} 
SIM & 66 & 21,4 & 35 & 5,1 & $\mathbf{1 0 1}$ & $\mathbf{1 0 , 2}$ & $0,000^{\mathrm{a}}$ \\
NÂO & 242 & 78,6 & 650 & 94,9 & $\mathbf{8 9 2}$ & $\mathbf{8 9 , 8}$ & $0,000^{\mathrm{a}}$ \\
Total & $\mathbf{3 0 8}$ & $\mathbf{1 0 0 , 0}$ & $\mathbf{6 8 5}$ & $\mathbf{1 0 0 , 0}$ & $\mathbf{9 9 3}$ & $\mathbf{1 0 0 , 0}$ & \\
\hline
\end{tabular}

Administração de

Medicamentos

\begin{tabular}{rrrrrrrrr} 
SIM & 65 & 20,4 & 30 & 4,4 & 95 & 9,6 & $0,000^{\mathrm{a}}$ \\
NÂO & 253 & 79,6 & 645 & 95,6 & $\mathbf{8 9 8}$ & $\mathbf{9 0 , 4}$ & $0,000^{\mathrm{a}}$ \\
Total & $\mathbf{3 1 8}$ & $\mathbf{1 0 0 , 0}$ & $\mathbf{6 7 5}$ & $\mathbf{1 0 0 , 0}$ & $\mathbf{9 9 3}$ & $\mathbf{1 0 0 , 0}$ & \\
\hline
\end{tabular}

Troca e realização

de curativo*

\begin{tabular}{lrrrrrrr} 
SIM & 70 & 21,7 & 0 & 0,0 & $\mathbf{7 0}$ & $\mathbf{2 1 , 1}$ & $0,213^{\mathrm{c}}$ \\
NÂO & 252 & 78,3 & 9 & 100,0 & $\mathbf{2 6 1}$ & $\mathbf{7 8 , 9}$ & $0,213^{\mathrm{c}}$ \\
Total & $\mathbf{3 2 2}$ & $\mathbf{1 0 0 , 0}$ & $\mathbf{9}$ & $\mathbf{1 0 0 , 0}$ & $\mathbf{3 3 1}$ & $\mathbf{1 0 0 , 0}$ & \\
\hline
\end{tabular}

\footnotetext{
${ }^{*}$ A troca do curativo é realizada rotineiramente no período da noite

${ }^{\text {a }}$ Teste do Qui-quadrado

${ }^{\mathrm{c}}$ Teste Exato de Fisher
} 
De acordo com a Tabela 20, constata-se, novamente, que as não conformidades na adesão à higiene das mãos foram altas entre os enfermeiros (variação de $78,3 \%$ a $82,0 \%$ ), mas principalmente entre os auxiliares/técnicos de enfermagem (variação de 94,9\% a 100,0\%), em todos os turnos de trabalho.

Quando comparados os índices de conformidade entre os enfermeiros e auxiliares/técnicos de enfermagem, na maioria das oportunidades que tiveram para realizar a higienização das mãos, houve diferença estatisticamente significante entre as equipes.

$\mathrm{Na}$ conformidade em relação ao procedimento de troca e realização de curativo não houve diferença estatisticamente significante quando comparada esta prática entre as categorias profissionais $(p=0,213)$.

A Tabela 21, a seguir, apresenta os valores de conformidade e não conformidade em relação à higiene das mãos, segundo os procedimentos selecionados, categoria profissional e turnos de trabalho. 
Tabela 21 - Conformidade e não conformidade na adesão à prática de higiene das mãos conforme procedimentos selecionados, categoria profissional e o turno de trabalho. São Paulo, 2010

\begin{tabular}{|c|c|c|c|c|c|c|c|c|c|c|c|c|c|c|c|c|c|c|c|c|c|c|c|c|c|c|c|c|}
\hline \multicolumn{29}{|c|}{ Conformidade } \\
\hline & \multicolumn{7}{|c|}{ Troca do sistema de infusão } & \multicolumn{7}{|c|}{ Coleta de sangue } & \multicolumn{7}{|c|}{ Administração de medicamento } & \multicolumn{7}{|c|}{ Troca e realização de curativo } \\
\hline & \multicolumn{2}{|c|}{ 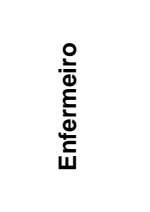 } & \multicolumn{2}{|c|}{ 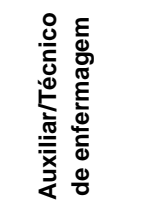 } & \multicolumn{2}{|c|}{$\begin{array}{l}\bar{\Xi} \\
\text { 。ँ }\end{array}$} & \multicolumn{3}{|c|}{ 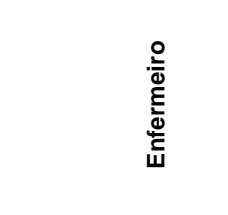 } & \multicolumn{2}{|c|}{ 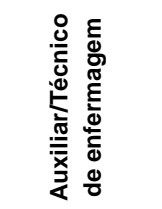 } & \multicolumn{2}{|c|}{$\begin{array}{l}\overline{\widetilde{J}} \\
\text { 。 }\end{array}$} & \multirow[b]{2}{*}{ p } & \multicolumn{2}{|c|}{ 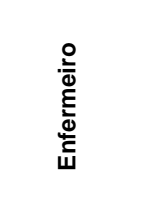 } & \multicolumn{2}{|c|}{ 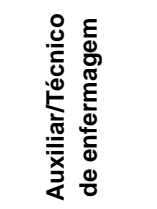 } & \multicolumn{3}{|c|}{$\begin{array}{l}\bar{\varpi} \\
\text { 。 }\end{array}$} & \multicolumn{2}{|c|}{ 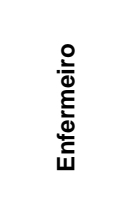 } & \multicolumn{2}{|c|}{ 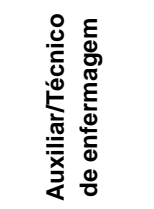 } & \multicolumn{2}{|c|}{ 홍 } & \\
\hline & $\mathbf{n}$ & $\%$ & $\mathbf{n}$ & $\%$ & $\mathbf{n}$ & $\%$ & p & $\mathbf{n}$ & $\%$ & $\mathbf{n}$ & $\%$ & $\mathrm{n}$ & $\%$ & & $\mathbf{n}$ & $\%$ & $\mathbf{n}$ & $\%$ & $\mathbf{n}$ & $\%$ & $\mathbf{p}$ & $\mathbf{n}$ & $\%$ & $\mathbf{n}$ & $\%$ & $\mathbf{n}$ & $\%$ & $\mathbf{p}$ \\
\hline \multicolumn{29}{|l|}{ Manhã } \\
\hline SIM & 22 & 19,6 & 16 & 7,3 & 38 & 11,5 & $0,001^{a}$ & 29 & 27,1 & 19 & 8,5 & 48 & 14,5 & $0,000^{\mathrm{a}}$ & 25 & 22,5 & 16 & 7,5 & 41 & 12,4 & $0,000^{\mathrm{a}}$ & -- & -- & -- & -- & -- & -- & -- \\
\hline NÃO & 90 & 80,4 & 203 & 92,7 & 293 & 88,5 & $0,001^{\mathrm{a}}$ & 78 & 72,9 & 205 & 91,5 & 283 & 85,5 & $0,000^{\mathrm{a}}$ & 86 & 77,5 & 204 & 92,5 & 290 & 87,6 & $0,000^{\mathrm{a}}$ & -- & -- & -- & -- & -- & -- & -- \\
\hline Subtotal & 112 & 100,0 & 219 & 100,0 & 331 & 100,0 & & 107 & 100,0 & 224 & 100,0 & 331 & 100,0 & & 111 & 100,0 & 220 & 100,0 & 331 & 100,0 & & -- & -- & -- & -- & -- & -- & -- \\
\hline \multicolumn{29}{|l|}{ Tarde } \\
\hline SIM & 32 & 27,8 & 5 & 2,3 & 37 & 11,2 & $0,000^{\mathrm{a}}$ & 30 & 28,3 & 9 & 4,0 & 39 & 11,8 & $0,000^{a}$ & 35 & 31,3 & 5 & 2,3 & 40 & 12,1 & $0,000^{\mathrm{a}}$ & -- & -- & -- & -- & -- & -- & -- \\
\hline NÃO & 83 & 72,2 & 211 & 97,7 & 294 & 88,8 & $0,000^{\mathrm{a}}$ & 76 & 71,7 & 216 & 916,0 & 292 & 88,2 & $0,000^{\mathrm{a}}$ & 77 & 68,7 & 214 & 97,7 & 291 & 87,9 & $0,000^{\mathrm{a}}$ & -- & -- & -- & -- & -- & -- & -- \\
\hline Subtotal & 115 & 100,0 & 216 & 100.0 & 331 & 100,0 & & 106 & 100,0 & 225 & 100,0 & 331 & 100,0 & & 112 & 100,0 & 219 & 100,0 & 331 & 100,0 & & -- & - & -- & -- & -- & -- & -- \\
\hline \multicolumn{29}{|l|}{ Noite * } \\
\hline SIM & 5 & 5,0 & 8 & 3,5 & 13 & 3,9 & $0,534^{b}$ & 7 & 7,4 & 7 & 3,0 & 14 & 4,2 & $0,086^{b}$ & 5 & 5,3 & 9 & 3,8 & 14 & 4,2 & $0,561^{\mathrm{b}}$ & 70 & 21,7 & 0 & 0,0 & 70 & 21,1 & $0,213^{c}$ \\
\hline NÃO & 96 & 95,0 & 222 & 96,5 & 318 & 96,1 & $0,534^{b}$ & 88 & 92,6 & 229 & 97,0 & 317 & 95,8 & $0,086^{b}$ & 90 & 94,7 & 227 & 96,2 & 317 & 95,8 & $0,561^{b}$ & 252 & 78,3 & 9 & 100,0 & 261 & 78,9 & $0,213^{\circ}$ \\
\hline Subtotal & 101 & 100,0 & 230 & 100,0 & 331 & 100,0 & & 95 & 100,0 & 236 & 100,0 & 331 & 100,0 & & 95 & 100,0 & 236 & 100,0 & 331 & 100,0 & & 322 & 100,0 & 9 & 100,0 & 331 & 100,0 & \\
\hline
\end{tabular}

${ }^{*}$ A troca do curativo é realizada rotineiramente no período da noite

a Teste do Qui-quadrado

${ }^{\mathrm{b}}$ Razão de Verossimilhança (Likelihood Ratio)

${ }^{c}$ Teste Exato de Fisher 
$\mathrm{Na}$ Tabela 21, quando observamos os turnos de trabalho em relação à higiene das mãos quanto aos procedimentos de troca de sistema de infusão, coleta de sangue e administração de medicamento, os períodos da manhã e tarde apresentaram diferença estatisticamente significante quando comparada a conformidade entre as categorias profissionais, $p<0,05$. A diferença ocorreu devido à maior conformidade pelos enfermeiros. Mesmo assim, as duas categorias de profissionais, nesses dois turnos, apresentaram baixa conformidade. Em relação aos mesmos procedimentos citados, o período noturno não apresentou diferença estatística entre as categorias profissionais.

Troca e realização de curativo são feitas no período noturno, devido à rotina da unidade. O resultado da avaliação desse procedimento neste período apontou baixa conformidade para ambas as categorias profissionais. Não houve diferença estatística em relação a esta prática quando comparadas as equipes, porém os auxiliares/técnicos de enfermagem foram não conformes na sua totalidade.

A Tabela 22 apresenta os índices de conformidade e não conformidade da higiene das mãos segundo os procedimentos selecionados e turnos de trabalho. 
Tabela 22 - Conformidade e não conformidade da prática de higiene das mãos de acordo com os procedimentos selecionados e turno de trabalho. São Paulo, 2010

\begin{tabular}{|c|c|c|c|c|c|c|c|c|c|c|}
\hline \multirow{3}{*}{\multicolumn{2}{|c|}{ Procedimentos }} & \multicolumn{6}{|c|}{ Turno de trabalho } & & & \multirow{3}{*}{$\mathbf{p}$} \\
\hline & & \multicolumn{2}{|c|}{ Manhã } & \multicolumn{2}{|c|}{ Tarde } & \multicolumn{2}{|c|}{ Noite } & \multicolumn{2}{|c|}{ Total } & \\
\hline & & $\mathbf{n}$ & $\%$ & $\mathbf{n}$ & $\%$ & $\mathbf{n}$ & $\%$ & $\mathbf{n}$ & $\%$ & \\
\hline \multicolumn{11}{|c|}{$\begin{array}{l}\text { Troca do sistema } \\
\text { de infusão }\end{array}$} \\
\hline & SIM & 38 & 11,5 & 37 & 11,2 & 13 & 3,9 & 88 & 8,9 & $0,001^{a}$ \\
\hline \multicolumn{11}{|c|}{ Conformidade } \\
\hline & NÂO & 293 & 88,5 & 294 & 88,8 & 318 & 96,1 & 905 & 91,1 & $0,001^{a}$ \\
\hline & Total & 331 & 100,0 & 331 & 100,0 & 331 & 100,0 & 993 & 100,0 & \\
\hline \multicolumn{11}{|c|}{ Coleta de sangue } \\
\hline \multirow{4}{*}{ Conformidade } & SIM & 48 & 14,5 & 39 & 11,8 & 14 & 4,2 & 101 & 10,2 & $0,000^{a}$ \\
\hline & & & & & & & & & & \\
\hline & NÂO & 283 & 84,5 & 292 & 88,2 & 317 & 95,3 & 892 & 89,8 & $0,000^{\mathrm{a}}$ \\
\hline & Total & 331 & 100,0 & 331 & 100,0 & 331 & 100,0 & 993 & 100,0 & \\
\hline \multicolumn{11}{|c|}{$\begin{array}{l}\text { Administração de } \\
\text { medicamentos }\end{array}$} \\
\hline \multirow{4}{*}{ Conformidade } & SIM & 41 & 12,4 & 40 & 12,1 & 14 & 4,2 & 95 & 9,6 & $0,000^{a}$ \\
\hline & & & & & & & & & & \\
\hline & NÂO & 290 & 87,6 & 291 & 87,9 & 317 & 95,8 & 898 & 90,4 & $0,000^{a}$ \\
\hline & Total & 331 & 100,0 & 331 & 100,0 & 331 & 100,0 & 993 & 100,0 & \\
\hline \multicolumn{11}{|c|}{$\begin{array}{l}\text { Troca e realização } \\
\text { de curativo* }\end{array}$} \\
\hline \multirow{4}{*}{ Conformidade } & SIM & -- & -- & -- & -- & 70 & 21,1 & 70 & 21,1 & $* *$ \\
\hline & & & & & & & & & & \\
\hline & NÂO & -- & -- & -- & -- & 261 & 78,9 & 261 & 78,9 & $* *$ \\
\hline & Total & -- & -- & -- & -- & 331 & 100,0 & 331 & 100,0 & \\
\hline
\end{tabular}

${ }^{*}$ A troca do curativo é realizada rotineiramente no período da noite

** Sem possibilidade de análise comparativa, pois este procedimento é realizado somente no período noturno.

${ }^{\text {a }}$ Teste do Qui-quadrado

${ }^{\mathrm{c}}$ Teste Exato de Fisher 
Os resultados obtidos na Tabela 22 permitem concluir que houve diferença estatisticamente significante quando comparados os turnos em relação à conformidade de higienização das mãos em todas as avaliações dos procedimentos selecionados. Todos os períodos apresentaram baixa conformidade. O período noturno se destaca pela baixa adesão em todos os itens avaliados.

A Tabela 23 sumariza os resultados das causas de não conformidade e caracteriza se a higiene das mãos não ocorreu em nenhum momento, apenas ANTES ou somente APÓS o procedimento, de acordo com os procedimentos selecionados e as categorias profissionais. 
Tabela 23 - Causas de não conformidades da prática de higiene das mãos, de acordo com os procedimentos selecionados e a categoria profissional. São Paulo, 2010

\begin{tabular}{|c|c|c|c|c|c|c|c|}
\hline \multirow{3}{*}{ Procedimento } & \multicolumn{4}{|c|}{ Categoria Profissional } & & & \multirow{3}{*}{$\mathbf{p}$} \\
\hline & \multicolumn{2}{|c|}{ Enfermeiros } & \multicolumn{2}{|c|}{$\begin{array}{l}\text { Auxiliar/Técnico } \\
\text { de Enfermagem }\end{array}$} & \multicolumn{2}{|c|}{ Total } & \\
\hline & $\mathbf{n}$ & $\%$ & $\mathbf{n}$ & $\%$ & $\mathbf{n}$ & $\%$ & \\
\hline \multicolumn{8}{|l|}{$\begin{array}{l}\text { Troca do Sistema } \\
\text { de Infusão }\end{array}$} \\
\hline Não Higienizou & 136 & 50,6 & 454 & 71,4 & 590 & 65,2 & $0,001^{a}$ \\
\hline Somente ANTES & 76 & 28,2 & 78 & 12,2 & 154 & 17,0 & $0,000^{\mathrm{a}}$ \\
\hline Somente DEPOIS & 57 & 21,2 & 104 & 16,4 & 161 & 17,8 & $0,019^{a}$ \\
\hline Total & 269 & 100,0 & 636 & 100,0 & 905 & 100,0 & \\
\hline \multicolumn{8}{|l|}{ Coleta de sangue } \\
\hline Não Higienizou & 109 & 45,0 & 449 & 69,1 & 558 & 62,6 & $0,000^{\mathrm{a}}$ \\
\hline Somente ANTES & 72 & 29,8 & 70 & 10,8 & 142 & 15,9 & $0,000^{a}$ \\
\hline Somente DEPOIS & 61 & 25,2 & 131 & 20,1 & 192 & 21,5 & $0,001^{a}$ \\
\hline Total & 242 & 100,0 & 650 & 100,0 & 892 & 100,0 & \\
\hline \multicolumn{8}{|l|}{$\begin{array}{l}\text { Administração de } \\
\text { medicamentos }\end{array}$} \\
\hline Não Higienizou & 132 & 52,2 & 457 & 70,9 & 589 & 65,6 & $0,000^{\mathrm{a}}$ \\
\hline Somente ANTES & 69 & 27,2 & 78 & 12,1 & 147 & 16,4 & $0,000^{a}$ \\
\hline Somente DEPOIS & 52 & 20,6 & 110 & 17,0 & 162 & 18,0 & $0,005^{a}$ \\
\hline Total & 253 & 100,0 & 645 & 100,0 & 898 & 100,0 & \\
\hline \multicolumn{8}{|l|}{$\begin{array}{l}\text { Troca e realização } \\
\text { de curativo** }\end{array}$} \\
\hline Não Higienizou & 91 & 36,1 & 6 & 66,7 & 97 & 37,2 & $0,213^{\mathrm{c}}$ \\
\hline Somente ANTES & 104 & 41,3 & 1 & 11,1 & 105 & 40,2 & $0,015^{\mathrm{a}}$ \\
\hline Somente DEPOIS & 57 & 22,6 & 2 & 22,2 & 59 & 22,6 & $0,491^{\mathrm{c}}$ \\
\hline Total & 252 & 100,0 & 9 & 100,0 & 261 & 100,0 & \\
\hline
\end{tabular}

${ }^{*}$ A troca do curativo é realizada rotineiramente no período da noite

a Teste do Qui-quadrado

${ }^{\mathrm{c}}$ Teste Exato de Fisher 
A causa mais freqüente de não conformidade na adesão à higiene das mãos foi sua não realização em nenhum momento, em quase todos os procedimentos avaliados: troca do sistema de infusão $(65,2 \%)$, coleta de sangue (62,6\%), administração de medicamentos (65,6\%). E a segunda causa de não conformidade foi a realização de higiene das mãos apenas DEPOIS: troca e realização do curativo $(22,6 \%)$, coleta de sangue $(21,5 \%)$, administração de medicamentos (18,0\%), troca do sistema de infusão $(17,8 \%)$. Em outras palavras, quando ocorria a adesão à higiene das mãos, ela era realizada mais frequentemente antes do procedimento do que depois.

A não higienização das mãos em nenhum momento foi a principal causa de não conformidade observada entre os auxiliares/técnicos de enfermagem, em todos os procedimentos, com variação de 66,7\% a 71,4\%. Com exceção da troca e realização de curativo, essa mesma causa foi observada entre os enfermeiros (variação de 36,1\% a 52,2\%)

Ao relacionarmos as categorias profissionais e as não conformidades, não houve diferença quando: não ocorreu higiene das mãos em nenhum momento e somente APÓS ( $p>0,05)$. Já, para a não conformidade higiene das mãos somente ANTES, ocorreu diferença estatisticamente significante entre as categorias $(p<0,05)$. 
6 DISCUSSÃO 
A problemática da IrAS é uma preocupação antiga, que inicialmente tinha seu foco voltado sobre o impacto na morbidade e mortalidade. No entanto, com o avanço científico-técnológico e evolução da assistência, outras consequências passaram a ser consideradas, como a sua associação à qualidade no atendimento prestado, custos decorrentes com a infecção, perdas econômicas e o afastamento familiar, que despertam preocupação das políticas públicas. Tal questão levou à implementação de programas voltados à prevenção e controle das IrAS a partir da década de $60{ }^{(6)}$.

Atualmente, há uma série de evidências científicas, diretrizes clínicas e regulamentações governamentais que fundamentam as ações para sua prevenção e controle que, mesmo não sendo suficientes para sua erradicação, podem contribuir para reconhecer como e quando ela ocorre e, com isso gerar ações na prática assistencial ${ }^{(27)}$.

No Brasil, a criação dos Programas de Controle de IrAS constituiu a condição inicial para o desenvolvimento e estabelecimento de diretrizes que possam subsidiar a qualificação das práticas assistenciais, e a alternativa para o estabelecimento de ações de prevenção e controle das infecções. Entretanto, suas ações estão focadas em estrutura e resultados, sem associação da análise dos processos utilizados na assistência, sendo um método de avaliação restrito e que necessita de uma abordagem mais abrangente ${ }^{(27)}$.

Com a finalidade de melhorar a atuação desses programas de controle, novos sistemas de atuação que buscam a melhoria das ações de prevenção e controle da IrAS, têm surgido. Um deles é a aplicação de avaliações processuais, as quais têm recebido cada vez mais destaque e incentivo pelas entidades governamentais e não governamentais e por especialistas na área de controle e prevenção de IrAS ${ }^{(73)}$.

Neste estudo, utilizou-se a aplicação de avaliações processuais, referentes às práticas de prevenção e controle de infecção da corrente sanguínea associada ao cateter venoso central de curta permanência. Essas avaliações foram realizadas na UTI Cirúrgica Adulto e Centro Cirúrgico do Instituto do Coração - InCor/HCFMUSP, ocorreram nos três turno de trabalho (manhã, tarde e noite) e foram referentes à: Avaliação do Registro 
de Indicação e Tempo de Permanência do Cateter Venoso Central (Indicador CSIP); Avaliação da Qualidade da Inserção do Cateter Vascular Central (indicador CSQI); Adesão aos Cuidados e Manutenção com do Curativo do Cateter Venoso Central de Curta Permanência e seus Dispositivos Conforme Recomendações da Instituição Durante sua Utilização (Indicador CSCM) e Adesão às Práticas de Higiene das Mãos em Situações Selecionadas (Indicador HMSEL).

Os indicadores CSQI, CSIP e HMSEL, foram construídos e validados quanto ao seu conteúdo e apresentados no Manual de Avaliação da Qualidade de Práticas de Controle de Infecção Hospitalar, disponibilizado pela Divisão de Infecção Hospitalar do Centro de Vigilância Epidemiológica da Secretaria de Estado da Saúde de São Paulo ${ }^{(27)}$. O indicador CSCM foi elaborado exclusivamente para este estudo e construído semelhantemente ao dos construtos operacionais dos anteriores.

O manual acima citado, em sua apresentação, considera que o sistema de avaliação e qualificação da prevenção e controle de IrAS precisa ser constantemente atualizado, incorporando novas práticas e abordagens que dêem conta da evolução da assistência clínica e de novas evidências científicas. A elaboração destes indicadores na forma de construtos operacionais e sob fundamentação teórico-científica nos permite orientar tanto a aplicação da avaliação, quanto obter índices de conformidade com relação às melhores recomendações disponíveis ${ }^{(27)}$.

Para este estudo, a fim de evitar desvios durante a avaliação dos indicadores e seguindo a recomendação da Organização Mundial da Saúde (OMS), realizou-se previamente a capacitação dos avaliadores para a avaliação da concordância entre os avaliadores, pelo teste estatístico de Kappa ${ }^{(53)}$. Os resultados de Kappa variaram de substancial a perfeito, e houve concordância estatisticamente significante entre os avaliadores em todos os componentes avaliados $(p<0,05)$, demonstrando que eles estavam aptos para prosseguir a coleta efetiva dos dados, que ocorreu por um desses avaliadores, autor deste estudo.

Após a capacitação do avaliador a coleta efetiva dos dados, seguindo as aplicações orientadas pelos indicadores neste estudo, ocorreu 
predominantemente por meio da observação direta (OD), e quando apropriado e recomendado foi realizada a verificação dos dados em prontuário.

No caso do indicador CSCM, a OD exigiu averiguação da troca dos equipos e transdutores, por meio da data colocada nos mesmos. A troca do curativo do CVC e o indicador CSIP foram avaliados por meio de verificação de registros em prontuário. Quanto à prática de desinfecção de hubs e conectores com clorexidina alcoólica $0,5 \%$ antes da manipulação, a troca do curativo do CVC conforme recomendação institucional, prática de inserção do CVC (Indicador CSQI) e higiene das mãos em situações selecionadas (Indicador HMSEL), a OD implicou em acompanhar os momentos de sua realização.

A OD apresenta vantagens e desvantagens. A vantagem seria o fato de ela ser a melhor maneira de avaliar como a tarefa está sendo executada, além de obter variedade de informações sobre o comportamento do indivíduo e os eventos que ocorrem ao seu redor, o que permite a análise das condições da realidade imediata que favorecem ou desfavorecem sua conformidade. Nela podemos distinguir as categorias profissionais e os procedimentos envolvidos, além de reconhecer as necessidades de cada indivíduo, assim como a realização de treinamento para melhor adesão às práticas ${ }^{(73)}$.

Em relação às desvantagens da $\mathrm{OD}$, a principal seria a influência dos avaliadores no comportamento dos profissionais observados, conhecido como efeito Hawthorne, isto é, uma mudança provisória do comportamento ou desempenho, podendo resultar em taxas falsamente elevadas de adequação dos dados avaliados ${ }^{(83)}$. Outra desvantagem é a necessidade de treinamento de avaliadores e utilização de testes de aferição de concordância para capacitar instrumentos e avaliadores, com ocupação de tempo e custos ${ }^{(79)}$.

Mesmo assim, de acordo com a OMS, a OD é considerada como "padrão ouro" para monitorar o cumprimento de práticas assistenciais e tem sido utilizada, principalmente, para a avaliação das práticas de higiene das mãos ${ }^{(53)}$. 
Para Polit et al. (2004), a fim de se minimizar o efeito Hawthorne, recomenda-se que a coleta dos dados seja realizada de forma discreta e sigilosa, de modo que o sujeito não saiba que está sendo observado ${ }^{(80)}$. Contudo, em nosso estudo todas as categorias profissionais envolvidas (médicos, enfermeiros e auxiliares/técnicos de enfermagem), assim como os pacientes que tiveram a prática de inserção do CVC avaliada no CC, foram informados sobre a pesquisa, através de TCLE (Anexo $\mathrm{G}$ e H), para que eles não se sentissem pressionados, tivessem livre escolha na decisão de participar ou não e/ou retirar-se da pesquisa a qualquer momento se assim desejasse, de acordo com solicitação da Comissão de Ética para Análise de Projetos de Pesquisa do Hospital das Clínicas da Faculdade de Medicina da Universidade de São Paulo (CAPPesq/HCFMUSP).

Entretanto, no estudo realizado por Eckmanns et al. (2006), foi determinada a influência do efeito Hawthorne sobre a indicação da higiene das mãos entre os cuidadores de saúde ${ }^{(84)}$. Médico, enfermeiros e outros profissionais da saúde foram monitorados em dois períodos: 1) no primeiro período as equipes não tinham conhecimento de estarem sendo observadas; 2) no segundo período de observação todos foram conscientizados com antecedência sobre o monitoramento. A taxa geral de adesão à higiene das mãos foi de $29 \%$ no primeiro período e $45 \%$ no segundo período. O resultado deste estudo demonstra que o efeito Hawthorne tem influência marcante na adesão da higienização das mãos, pois aumentou em 55\% a conformidade $^{(84)}$.

Em estudo realizado por Cabral de Menezes (2009), no qual a prática de higiene das mãos durante as práticas de prevenção e controle da pneumonia associada à ventilação mecânica foi avaliada, todos os profissionais envolvidos foram informados de que seriam objeto de OD, mas não exatamente sobre quais práticas estariam sob avaliação. A conformidade geral da prática de higiene das mãos em situações selecionadas foi de $10,7 \%$, resultado igual ao obtido neste estudo.

Tais resultados nos levam a uma questão sobre o nosso estudo, se as taxas de adesão avaliadas poderiam ser ainda menores se os profissionais não tivessem sido conscientizados quanto à nossa avaliação. 
É importante lembrar, também, que mesmo com a concordância dos profissionais sobre as práticas selecionadas, a conjunção dos dados foi realizada de maneira agregada e o compromisso de anonimato por parte do pesquisador foi mantido, oferecendo acato à ética. Porém, concordando com Cabral de Menezes (2009), a não possibilidade de intervenção, no momento em que as práticas são realizadas incorretamente constituem uma questão intrigante e, infelizmente, ainda pouco discutida nas implicações éticas ${ }^{(73)}$.

Quanto à utilização da OD em nosso estudo, a evidência da relevância deste método de obtenção de informações foi demonstrada nos resultados a seguir. Contudo, além de avaliarmos as conformidades e não conformidades das práticas por meio da OD foi possível reconhecer, com maior clareza, questões sobre recursos humanos e de materiais, infraestrutura, processo de trabalho e necessidade de treinamento sobre as práticas de prevenção e controle de infecção principalmente para a equipe de enfermagem.

O Indicador CSQI, avaliado puramente pela OD, é composto por cinco medidas referentes às práticas de inserção do CVC de curta permanência (inserção percutânea, paramentação completa, uso de campo estéril, uso de anti-séptico de veículo alcoólico, curativo oclusivo), sendo 83 avaliações para cada componente, totalizando 415 avaliações.

Utilizando-se a fórmula de cálculo da conformidade para esse indicador, que considera a somatória das cinco medidas corretas ao mesmo tempo e em um mesmo paciente, a conformidade foi nula. Contudo, ao avaliarmos cada medida, isoladamente, constatou-se que a "presença do curativo" foi o único componente responsável pela não obtenção da conformidade geral esperada, pois a conformidade para esta prática foi nula $(0,0 \%)$. Quanto às demais medidas, todas obtiveram conformidade de $100 \%$, o que nos permite constatar que apenas a presença do curativo não está bem estabelecida na prática de inserção do CVC na instituição investigada.

No entanto, o CC, local em que este indicador foi avaliado, a prática de inserção do CVC é realizada com técnica totalmente asséptica, em um ambiente limpo e a inserção do cateter fica protegida por campos estéreis durante todo o procedimento cirúrgico. Além disso, a presença de um 
curativo convencional (gaze estéril e fita adesiva) poderia invadir o campo cirúrgico ou tornar-se úmido ao longo da cirurgia, aumentando ainda mais as chances de colonização da inserção do CVC. Uma solução para este problema seria a utilização de curativos impermeáveis - que podem ser utilizados nesse momento -, melhorando a qualidade da inserção do CVC e contribuindo na prevenção e controle de ICS-ACVC.

A anti-sepsia da pele com anti-séptico de veículo alcoólico é outro aspecto de extrema importância na prevenção e controle da ICS. Em nosso estudo a conformidade para este componente foi de $100 \%$ e a clorexidina alcoólica $0,5 \%$ foi o produto utilizado.

Contudo, a realidade não é mesma em outros hospitais. Estudo realizado por Lobo et al. (2005), no qual foi aplicado pré-teste para avaliar o conhecimento da equipe multiprofissional de uma UTI Médica, identificou que $40 \%$ dos médicos residentes não souberam a resposta correta sobre 0 preparo da pele antes da inserção do CVC ${ }^{(50)}$.

Estudo que comparou a eficácia da prevenção da colonização do CVC com uso de PVPI 10\%, clorexidina aquosa $2 \%$ e clorexidina alcoólica $0,5 \%$ para anti-sepsia da pele antes da inserção do CVC e durante os cuidados encontrou superioridade da clorexidina alcoólica $0,5 \%$ quanto à redução do risco de colonização, em todos os casos ${ }^{(85)}$. Em outro estudo, no qual foram comparados o PVPI 10\%, álcool 70\% e gluconato de clorexidina, a clorexidina também foi superior e reduziu o risco de bacteremia relacionada ao cateter, em comparação aos outros anti-sépticos ${ }^{(86)}$. Esses resultados demonstram que a clorexidina deve ser o anti-séptico de escolha para anti-sepsia da pele antes da inserção do CVC e sua manutenção.

No estudo realizado por Magerl et al. (2009) foi introduzido um protocolo para inserção e manutenção do CVC como parte de um programa educacional. A montagem de um carrinho contendo todos os itens necessários para a inserção do CVC reduziu as taxas de ICS de 11,2/1000 cateteres dia para 6,5/1000 cateteres dia, após a intervenção ${ }^{(87)}$.

Em nosso estudo, apenas dois tipos de cateteres de curta permanência foram avaliados quanto à inserção no CC: cateter duplo lúmen e cateter da artéria pulmonar. 
De acordo com Dezfulian et al. (2003), o número de lumens está diretamente relacionado com o risco de desenvolvimento da ICS. A avaliação de 15 estudos, em sua metanálise, encontrou que vários lumens estavam associados com um risco ligeiramente superior de infecções, quando comparados com cateteres de único lúmen. Nesse estudo a relação de risco para cada lúmen adicional foi de 4,4 vezes. Estes dados dão indícios de que cateteres com múltiplos lumens devem ser utilizados restritivamente ou removidos logo que possível, a fim de reduzir as chances de contaminação, infecção local e ICS ${ }^{(44)}$.

O sítio de inserção do CVC também deve ser levado em consideração antes do início do procedimento. Em nossa pesquisa - das 83 práticas de inserção do CVC avaliadas - 71 cateteres (85,5\%) foram inseridos na veia jugular (VJ), 12 (14,5\%) na subclávia (SC) e nenhum cateter foi inserido na veia femoral (VF). Em estudo realizado por Templeton et al. (2008), na qual foram avaliados 1396 cateteres em 1162 pacientes, as taxas de ICS-ACVC estavam diretamente relacionadas com o sítio de inserção do cateter (SC-2,0/1000 cateteres dia; VJ 2,9/1000 cateteres dia e VF 12,7/1000 cateteres dia) ${ }^{(88)}$. No estudo realizado por Nagashima et al. (2006), a SC também esteve associada ao menor risco de colonização quando comparado à VJ, e o acesso femoral com maior risco de colonização e ICS-ACVC em comparação com a VJ e SC ${ }^{(89)}$. Além disso, o acesso femoral também esteve associado com maior risco de trombose ${ }^{(89)}$.

A veia subclávia deve ser preferível, pois a veia jugular apresenta maior proximidade com as secreções orofaríngeas, além da dificuldade de imobilizar o cateter. Cateteres inseridos na veia femoral devem ser evitados, pois estão associados a um maior risco de trombose venosa profunda do que a jugular interna ou subclávia, além de, no caso de adultos, a femoral apresentar colonização pesada, sendo um importante fator de risco para ICS-ACVC. No caso de cateter para hemodiálise a veia subclávia deve ser evitada, pois tem maior chance de estenose ${ }^{(18,19,31)}$.

Em outro estudo, a realização de um programa educacional, no qual foi introduzida a preferência pela SC para inserção do CVC, juntamente com outras medidas (uso de máximas precauções de barreira estéril na inserção, 
tipo de curativo utilizado na inserção do CVC, evitar uso de dânulas e colocação de imagem das etapas de manutenção do CVC em cada leito), foi efetivo na redução da taxa de ICS-ACVC ${ }^{(90)}$.

Contudo, é importante lembrar que antes da escolha do local para inserção do CVC o risco de colonização e/ou ICS-ACVC, os fatores individuais do paciente, a densidade da flora cutânea local e os problemas mecânicos que podem ocorrer com maior frequência durante a punção da SC precisam ser avaliados.

A escolha pela veia jugular para inserção dos CVC, na maior parte dos casos $(85,5 \%)$, pode ter ocorrido porque nossa investigação foi realizada em um hospital escola. Estudo multicêntrico, realizado por Kritchevisky et al. (2008), encontrou que hospitais escola estão associados com maior densidade de incidência de ICS e que mais de uma tentativa de inserção do CVC (fato comum em hospitais de ensino) contribui para a ocorrência da infecção com risco relativo de $1,6^{(91)}$. Isso ocorre, porque a cateterização por profissionais inexperientes está associada com aumento do risco de infecções e problemas mecânicos. A utilização de ultra-som para guia seria uma solução para redução destes problemas ${ }^{(31,91,92)}$.

Para o Indicador CSIP, composto de duas medidas, referentes à avaliação dos registros de indicação e tempo de permanência do CVC, foram realizadas 166 avaliações, sendo 83 para cada componente, todas verificadas através de checagem em prontuário.

O cálculo da conformidade foi realizado somando-se as duas medidas ao mesmo tempo e em um mesmo paciente. Com isso, obtivemos uma conformidade geral de $91,6 \%$, bem acima da conformidade esperada ( $80 \%)$, o que demonstra um excelente resultado em relação a esta prática. No entanto, este foi o único indicador que apresentou conformidade acima da considerada ideal.

Quando avaliamos isoladamente cada componente desta prática, encontramos conformidades ainda melhores, sendo 96,4\% para indicação do CVC e 95,2\% para o registro de seu tempo de permanência.

A prática do registro de indicação do cateter apresentou excelente conformidade $(95,2 \%)$ porque no InCor/HCFMUSP, devido às características 
das cirurgias avaliadas (alta complexidade), a inserção do CVC passa a ser um ato necessário, pois os pacientes necessitam de monitorização hemodinâmica durante e após o procedimento cirúrgico, coleta de amostras de sangue para gasometria, infusão de grandes volumes e administração de drogas vasoativas e de hemoderivados.

A presença de registro do tempo de permanência do CVC é de extrema importância na prevenção e controle de ICS-ACVC e não apresentou conformidade em apenas $4,8 \%$ dos casos. Ao sabermos o tempo de permanência do cateter é possível avaliar a necessidade de troca ou não.

De acordo com a literatura, a substituição rotineira do CVC em intervalos regulares de tempo como método para reduzir a ICS-ACVC não tem influenciado significativamente na redução das taxas; contudo, se ele é deixado por tempo maior que 1-2 semanas, a taxa de infecção associada ao CVC é maior ${ }^{(18,31)}$. Por esse motivo, é de extrema importância a presença de registro do tempo de permanência do CVC, evitando, assim, sua permanência por tempo prolongado indevidamente.

A remoção de cateter desnecessário, juntamente com outras quatros medidas relacionadas à prática de inserção do CVC (lavagem das mãos, uso de barreiras de precaução, limpeza da pele com clorexidina e evitar o acesso femoral), todas baseadas em evidências, contribuiu na redução das taxas de ICS-ACVC de 7,7/1000 cateteres dia (pré-intervenção) para 2,3/1000 cateteres dia (pós-intervenção) ${ }^{(93)}$.

O Indicador CSCM refere-se à adesão aos cuidados e manutenção do curativo do CVC e seus dispositivos, composto por quatro componentes: desinfecção de hubs e conectores com clorexidina alcoólica 0,5\% antes da manipulação, registro da troca do curativo do CVC, troca do curativo do CVC conforme recomendação institucional e troca de equipos e transdutores de acordo com recomendação institucional. Ele foi criado exclusivamente neste estudo, pois não constava como medida em nenhum dos indicadores de avaliação das medidas específicas de prevenção e controle de ICS-ACVC previamente construídas.

A conformidade geral para este Indicador foi de 51,5\%, portanto, abaixo da conformidade considerada ideal (80\%). Ao avaliarmos a 
conformidade de acordo com cada turno de trabalho, encontramos que a conformidade ideal também não foi atingida. O turno da manhã apresentou a melhor conformidade $(61,8 \%)$ e o da tarde a pior (26,6\%). Todavia, quando avaliamos cada componente deste indicador encontramos componentes que atingiram $100 \%$ da conformidade ou ficaram bem próximos disso.

A prática de troca dos equipos e transdutores foi um dos componentes com conformidade em 100\% dos casos. Ele é de extrema importância na prevenção de ICS-ACVC, pois a coluna de fluidos necessária para a manutenção da permeabilidade do sistema de monitorização da pressão venosa central (PVC) e os equipos utilizados para infusão de medicamentos, NPT, hemoderivados e volumes são a porta de entrada para os microrganismos. A contaminação destes sistemas é reduzida significativamente quando os transdutores são trocados a cada 96 horas no máximo e os equipos com periodicidade de 24 a 76 horas de acordo com sua utilização ${ }^{(42,66)}$.

A periodicidade da troca do curativo conforme recomendação também alcançou excelente conformidade, com concordância em 99,7\% dos casos avaliados, ou seja, apenas 1 curativo não foi trocado em período recomendado (permanência de filme transparente por mais de 7 dias).

De acordo com recomendação da instituição, o curativo da inserção do CVC pode ser realizado tanto de modo convencional (gaze estéril e fita adesiva), quanto com filme transparente ou semipermeável. A escolha do curativo a ser utilizado deve levar em consideração o conforto do paciente e seu fácil manuseio ${ }^{(21,31)}$. A periodicidade da troca do curativo, de acordo com as recomendações institucionais, varia com o tipo do curativo, ou seja, quando este for realizado com gaze estéril e fita adesiva, deve ser trocado a cada 24 horas, e, no caso de utilização de filme transparente, a cada 7 dias. Além disso, em caso de curativo não íntegro ou com sujidade, ele deve ser trocado imediatamente ${ }^{(66)}$.

A utilização de curativo transparente, desde que fixado corretamente, permite a inspeção visual contínua da inserção do CVC e trocas menos frequentes do que o curativo convencional com gaze ${ }^{(19)}$. 
No entanto, além do filme transparente impermeável comumente presente em nossa rotina, existe no mercado o curativo impregnado com clorexidina que, em pesquisa realizada por Timsit et al. (2009), reduziu as taxas de ICS em UTI mesmo quando elas já eram baixas ${ }^{(94)}$. Nesta pesquisa, a taxa de ICS antes da utilização do curativo impregnado com clorexidina era de 1,4/1000 cateteres dia e, após a introdução de curativo impregnado, ela foi reduzida para 0,6/1000 cateteres dia, o que é um excelente resultado ${ }^{(94)}$. Contudo, ele ainda não faz parte da rotina da Instituição na qual a pesquisa foi realizada.

Quanto à prática de registro da troca do curativo do CVC, em 76,1\% das avaliações houve anotações corretamente, resultado bem próximo do considerado ideal (80\%). No entanto, esse resultado nos remete a outro componente que foi citado anteriormente: "troca dos curativos conforme recomendação institucional', que apresentou conformidade em 99,7\% das avaliações, ou seja, o profissional realiza o procedimento, mas nem sempre anota sua realização. Isto demonstra um descumprimento da Sistematização da Assistência de Enfermagem (SAE), em que a anotação de enfermagem é uma de suas fases.

$\mathrm{Na}$ tentativa de melhorar esta prática o enfermeiro deve estar atento de que a qualidade dos serviços de enfermagem inclui não só as condições de sua formação, o processo de restauração da saúde do cliente ou, quando isto não é possível, a melhoria das condições de vida, as orientações quanto ao auto cuidado, a simplificação e a segurança nos procedimentos de enfermagem, mas também o resultado do produto hospitalar, medido por meio da qualidade da documentação e do registro de todas as ações de enfermagem. A qualidade do registro das ações assistenciais reflete a qualidade da assistência e a produtividade do trabalho. E, com base nesses registros, pode-se permanentemente construir melhores práticas assistenciais, além de implementar ações que melhorem os resultados operacionais ${ }^{(95)}$.

A anotação é uma dentre as formas mais importantes de comunicação da enfermagem, levando em conta que tem como finalidades: estabelecer uma efetiva comunicação entre a equipe de enfermagem e os 
demais profissionais envolvidos no cuidado ao ser humano; servir de base para a elaboração do plano assistencial ao paciente; constituir fonte de subsídios para a avaliação da assistência prestada; servir para acompanhar a evolução do paciente; constituir documento legal, tanto para o paciente quanto para a equipe de enfermagem referente à assistência prestada; contribuir para a auditoria de enfermagem e colaborar para o ensino e pesquisa em enfermagem ${ }^{(95)}$.

A solução para a melhoria da SAE é a realização de novo treinamento teórico e prático para esclarecer as dúvidas sobre o processo de enfermagem, o modelo teórico que sustenta as fases da $\mathrm{SAE}$, a relação que existe entre estas, assim como o registro escrito do cuidado prestado. A busca da qualidade da assistência de enfermagem, apresentando-a com coerência, completa e sequencial, direciona uma ação benéfica no tratamento do paciente ${ }^{(96)}$.

No entanto, devemos considerar que método de trabalho, falta de recursos materiais para o cuidado, resistência na utilização e não valorização da SAE são empecilhos para sua eficaz e eficiente aplicação ${ }^{(97)}$.

Outra prática avaliada no Indicador CSCM foi a desinfecção dos hubs e conectores com clorexidina alcoólica $0,5 \%$ antes da manipulação, com conformidade geral de 27,4\%. Este foi o único componente avaliado nos três turnos de trabalho e a conformidade ideal também não foi atingida em nenhum turno. Os resultados de conformidade de acordo com os turnos de trabalho foram: manhã- $38,7 \%$, tarde $31,1 \%$ e noite $12,4 \%$.

Em relação às oportunidades de observação entre as categorias profissionais avaliadas para esta prática, os auxiliares/técnicos de enfermagem tiveram maior número de oportunidades para observação em todos os períodos de trabalho, entretanto, a categoria profissional que obteve maior concordância durante a realização dessa prática foi a dos enfermeiros, em todos os turnos de trabalho (manhã - 44,6\%; Tarde $41,6 \%$; noite - 14,6\%). A diferença entre esses profissionais foi estatisticamente significante apenas no período da tarde $(p<0,05)$.

A realização de desinfecção do hub e conectores com clorexidina alcoólica $0,5 \%$ antes da manipulação do CVC é relevante na prevenção de 
ICS ${ }^{(20,38)}$. A clorexidina alcoólica deve ser o produto de escolha para a desinfecção dos hubs e conectores antes de seu acesso, pois, com base em vários estudos, ela demonstrou ser mais eficiente quando comparada aos outros anti-sépticos de veículo alcoólico ${ }^{(20,31,98,99)}$.

Antes do início da presente investigação, esta prática era realizada na instituição com álcool $70 \%$, porém de acordo com vários estudos que comprovam a eficiência da clorexidina alcoólica perante os outros antisépticos de veículo alcoólico, o álcool $70 \%$ foi substituído pela clorexidina alcoólica $0,5 \%$, conforme orientação da UCIH da instituição ${ }^{(20,31)}$. Contudo, a realização de desinfecção com álcool $70 \%$ ainda foi uma das causas de não conformidade para este componente, com $27,1 \%$ de ocorrências.

O tempo de duração da desinfecção do hub não está relacionado com a redução das taxas de ICS ou colonização do CVC, como mostram Simmons et al. (2011), ao avaliar 3 grupos de hubs contaminados pela mesma solução bacteriana e realizar desinfecção com álcool $70 \%$ por diferentes períodos de tempo (3 segundos, 10 segundos e 15 segundos) (100). Os resultados revelaram que entre os diferentes níveis de duração da desinfecção não foram encontradas diferenças significativas na carga bacteriana, que foi reduzida nos três grupos, ou seja, independente do tempo de duração da desinfecção do hub, o importante é que ela seja realizada ${ }^{(100)}$.

A inclusão da avaliação da higiene das mãos (HM) foi motivada pelo seu reconhecimento como uma das principais medidas de prevenção da transmissão de microrganismos de origem hospitalar ${ }^{(74)}$.

Contudo, antes da avaliação da prática de HM das mãos para os procedimentos selecionados, realizou-se levantamento quanto à disponibilidade de lavatórios, presença de toalha de papel, presença de sabão degermante e álcool gel para a higiene das mãos dos profissionais na instituição. Ao todo, foram contabilizados 13 lavatórios exclusivos para a higiene das mãos dos profissionais. Todos os lavatórios possuíam dispensadores de sabão líquido degermante e papel toalha. Dos doze leitos que podem ser utilizados para isolamento, nenhum possuía lavatórios exclusivos para higiene das mãos dos profissionais dentro dos quartos, pois 
estavam localizados fora do quarto ou ante-sala, no entanto, cada leito possuía um dispensador de álcool gel, para que a higienização das mãos seja realizada.

Quanto à prática de higiene das mãos, o Indicador HMSEL foi selecionado para este estudo (Anexo E e F), referente aos seguintes procedimentos, implicados com a prevenção e controle de ICS-ACVC, no qual se recomenda a HM: troca do sistema de infusão, coleta de sangue, administração de medicamentos e realização do curativo.

Foram realizadas 3310 observações referentes a oportunidades de HM pelos profissionais de saúde, durante os três turnos de trabalho, sendo 993 observações para cada procedimento selecionado, com exceção da troca do curativo, realizada apenas no período da noite, com 331 avaliações para este componente. A conformidade foi considerada somente quando o profissional realizava a HM antes e após cada procedimento. Portanto, a não conformidade foi conferida quando a HM era realizada somente antes, ou somente após, ou, então, quando o profissional, ao terminar o procedimento sob avaliação, realizava outro procedimento assistencial no paciente sem higienizar as mãos, se retirava do leito do paciente para outra área, trocava luvas ou sobrepunha luvas de procedimento ou estéreis sobre as mãos já enluvadas.

A conformidade geral de adesão à $\operatorname{HM~(10,7\% )~foi~muito~inferior~}$ àquela esperada (80\%) e, ressalta-se, inferior também às demais práticas avaliadas. A troca e realização do curativo foi o componente que obteve maior conformidade $(21,1 \%)$, seguida por coleta do sangue $(10,2 \%)$ e administração de medicamentos (9,6\%). A medida que apresentou a menor conformidade foi na troca do sistema de infusão (8,9\%).

O impacto da HM na ocorrência de IrAS tem sido muito estudado e a avaliação dos surtos de infecção tem evidenciado a importância da transmissão cruzada de microrganismos ${ }^{(73)}$. Embora as evidências sejam fortes a respeito do papel da $\mathrm{HM}$ na redução da transmissão de microrganismos e na redução da incidência de IrAS, os profissionais ainda mantêm uma atitude passiva diante deste problema de saúde pública ${ }^{(101)}$. A higiene das mãos constitui um ponto fundamental na prevenção da contaminação do CVC e, consequentemente, a ICS ${ }^{(102) .}$ 
A questão da HM é universal. Pela revisão da literatura realizada para este estudo constata-se grande variabilidade na sua adesão, com índices ainda mais baixos que os encontrados em nossa investigação, conforme destacaremos a seguir.

Golan et al. (2006), avaliando 1619 oportunidades de HM de forma correta (antes e após) em duas UTIs, encontraram resultados inferiores ao nosso $(5 \%){ }^{(103)}$.

Em estudo conduzido por Cabral de Menezes (2009), no qual foram realizadas 684 observações em UTI adulto, referentes à HM relacionada com a prevenção e controle de pneumonia associada à ventilação mecânica (PAVM), os resultados obtidos foram iguais aos do nosso estudo $(10,7 \%)$.

Karabey et al. (2002) investigaram a adesão à HM em uma UTI por meio de OD quanto à duração, método, técnica e uso de luvas, nos seguintes momentos: antes e após o contato direto com o paciente ou com feridas; ao se retirarem da unidade; antes dos procedimentos invasivos, medicação, manuseio do cateter; após contato com as secreções e excretas, membrana mucosa e equipamentos contaminados. A taxa de adesão foi de apenas $12,9 \%{ }^{(104)}$.

Ricart et al. (2003) realizaram uma investigação sobre a HM entre enfermeiros e encontrou alto índice de adesão (90,1\%), porém a coleta dos dados foi feita com questionário, por meio de auto-relato, e a resposta se referiu a HM entre os pacientes, isto é, não significando, necessariamente, antes e após o procedimento ${ }^{(105)}$.

Outro estudo que encontrou alto índice de adesão à HM foi realizado por Sharir et al. (2001), e vem sendo reconhecido como aquele que contraria os baixos índices encontrados na maioria dos estudos ${ }^{(76)}$. A duração e alguns passos da técnica de HM (uso de sabão, papel toalha e presença de jóias) foram avaliados antes e após 1035 procedimentos em unidades de internação e quatro UTIs. Os profissionais avaliados desconheciam os objetivos da pesquisa. A conformidade geral de adesão à HM foi de 76\%, entretanto não ficou claro se esse índice geral de adesão considerou a HM antes e após os procedimentos. Essa elevada taxa de adesão foi atribuída a um programa educacional implantado há mais de vinte anos, que inclui o 
treinamento dos profissionais e enfatiza a $\mathrm{HM}$ através de manuais e monitores responsáveis.

Dentre os procedimentos selecionados no presente estudo para adesão à HM todos se referem à manipulação do CVC em situações selecionadas. Entretanto, apesar do foco da avaliação ter sido somente a HM antes e após o procedimento, constatou-se durante a observação que o uso de luvas limpas foi frequente na realização das práticas selecionadas.

O uso de luvas vem sendo considerado um obstáculo para adesão às recomendações de $\mathrm{HM}$, dando a impressão de que a luva elimina tal necessidade, o que não é verdade ${ }^{(74)}$. É importante lembramos que, conforme cita o recente guia de HM divulgado pela OMS, a utilização de luvas não substitui a HM (categoria IB) ${ }^{(53)}$.

Karabey et al. (2002), em seu estudo por OD em uma UTI, encontrou que a baixa adesão obtida na adesão à HM (12,9\%) pode ser justificada pelo uso excessivo de luvas, número insuficiente de profissionais em relação aos pacientes, problemas de estrutura (ausência de lavatórios e álcool gel indisponível) ${ }^{(104)}$.

Os fatores para baixa adesão, sugeridos por Karabey et al. (2002), também podem ser aplicados ao presente estudo, exceto aos recursos de infra-estrutura para a HM, como já citado anteriormente ${ }^{(104)}$. Mesmo com a localização das pias não serem adequadas, a HM das mãos poderia ter sido realizado com álcool-gel, que estava disponível em cada leito da UTI.

O uso de luvas, principalmente de procedimentos, pelos profissionais da saúde remonta à década de 80 do Século $X X$, com o amplo reconhecimento da presença de patógenos em substâncias orgânicas e o risco de sua transmissão não somente aos pacientes, como também aos profissionais. Desde então, inúmeras questões têm sido geradas, entre elas, um efeito oposto à sua finalidade, por seu uso inadequado. Outra consequência de seu uso excessivo tem sido o aumento exponencial de reações alérgicas ao talco e a proteínas do látex ${ }^{(73,106)}$. Percebe-se certo predomínio de concepção de "auto-proteção", o qual é plenamente questionável, quando mãos sem luvas frequentemente tocam os mesmos locais tocados por mãos com luvas; além disso, luvas não impedem acidentes percutâneos ${ }^{(73)}$. 
No entanto, a recomendação praticamente universal de se higienizar as mãos após retirar as luvas não apresenta, ainda, evidências científicas claras sobre diferença de incidência de infecção ocupacional. Sua principal justificativa se pauta no risco de rasgo da luva e contato direto com substâncias orgânicas ${ }^{(73,106)}$.

Cabral de Menezes (2009) evidencia que já se faz necessária a discussão com maior profundidade da questão do uso de luvas e a HM de forma mais contextualizada, nas condições reais da prática assistencial ${ }^{(73)}$.

Em relação às diferenças de conformidade observadas na $\mathrm{HM}$ entre os turnos de trabalho no presente estudo (M- 12,8\%; T- 11,7\%; N- 8,4\%), houve coincidência com um estudo encontrado, mas não com outro. Cabral de Menezes (2009) apresentou conformidade de adesão mais baixa no período noturno e mais alta na manhã (M-16,7\%; T- 12,3\%; N-3,1\%) ${ }^{(73)}$. Já Sharir et al. (2001) encontrou o inverso, sendo o turno da noite o período de maior adesão e o da manhã o de menor (M- 72,9\%; T- 78,2\%; N- 80,0\%) ${ }^{(76)}$.

Essa disparidade de resultados pode estar diretamente relacionada ao tipo de hospital (ensino ou privado), número insuficiente de trabalhadores, máxima lotação, característica dos pacientes e até mesmo inexperiência dos profissionais. Além disso, tanto países desenvolvidos, quanto em desenvolvimento encontraram taxas de adesão à $\mathrm{HM}$ que variaram de muito baixos a muito altos (5\% a $89 \%$ ). De acordo com OD, os profissionais da saúde higienizam suas mãos, em média, de 5 a 42 vezes por turno e de 2 a 15 vezes por hora ${ }^{(53)}$.

Podemos dizer que nossos resultados podem ter se igualado aos encontrados por Cabral de Menezes (2009), pois algumas características do local em que a coleta dos dados foi realizada são semelhantes, isto é, ambos são hospitais públicos e de ensino e os dados foram coletados em UTI adulto ${ }^{(73)}$.

Segundo Souza e Santana (2009), a avaliação da adesão à HM deve incluir também a avaliação do tempo que o profissional da saúde leva para higienizar as mãos ${ }^{(101)}$. A higienização das mãos, feita de forma inadequada (por exemplo, tempo insuficiente ou pouco produto), de acordo com WHO (2009), leva a uma pobre descontaminação das mãos ${ }^{(53)}$. 
O tempo de higienização, quando realizado com álcool-gel, deve ter duração total do processo de 20 a 30 segundos, já, quando realizada com água e sabão anti-séptico leva em torno de 40 a 60 segundos, para que seja realizada de forma correta ${ }^{(53)}$.

Em nosso estudo, esta prática não foi avaliada, visto que somente verificamos a realização da HM e não a forma de sua realização.

$\mathrm{Na}$ ausência de sangue ou fluídos corporais nas mãos a utilização do álcool gel para HM é uma boa opção, devido à sua praticidade, rápida ação em reduzir a contagem microbiana da pele, além de irritar menos a pele. Outras vantagens do álcool gel incluem: (1) efeito imediato e residual; (2) não há necessidade de lavatório para o seu uso; (3) pode ser convenientemente disponibilizado perto de cada paciente/cliente; (4) é mais prático quando não há tempo suficiente para lavar as mãos ${ }^{(56)}$. Estudo realizado por Pittet et al (2000), sobre o impacto da higiene das mãos com álcool gel, demonstrou que houve melhora de $48 \%$ para $66 \%$, e foi associado com uma queda significativa da taxa de IrAS de $16,9 \%$ para $9,9 \%{ }^{(74)}$.

Contudo, em nossas observações, verificamos que o álcool gel é pouco utilizado pelos profissionais, o que, de qualquer forma, não é justificado, uma vez que seu dispensador estava localizado junto ao leito do paciente.

Com relação às categorias profissionais envolvidas no presente estudo, apesar de ter ocorrido variações por turno e procedimento, o maior índice de conformidade geral à $\mathrm{HM}$ foi obtido entre os enfermeiros $(7,9 \%)$ em relação aos auxiliares/técnicos de enfermagem (2,8\%). Cabe ressaltar que entre as duas categorias avaliadas a conformidade foi muito abaixo da esperada (80,0\%).

Assim como nosso estudo, Golan et al. (2006) encontraram sequência de conformidade superior entre enfermeiros (39\%), seguidos por médicos $(38 \%)$ e fisioterapeutas $(22 \%){ }^{(103)}$. Já, Cabral de Menezes (2009) encontrou superioridade entre fisioterapeutas $(25,8 \%)$, seguidos pelos enfermeiros $(15,6 \%)$ e, por último, auxiliares e técnicos de enfermagem $(4,4 \%){ }^{(73)}$.

Cabe lembrar que não houve uniformidade das oportunidades observadas em relação às categorias profissionais, já que os auxiliares/técnicos de enfermagem excederam, e muito, os enfermeiros (Enfermeiros - 38,5\% de oportunidades; auxiliares/técnicos de enfermagem - $61,5 \%$ de oportunidades). 
Com relação à prática de $\mathrm{HM}$, de acordo com cada procedimento selecionado e as categorias profissionais avaliadas, encontramos que os enfermeiros mantiveram conformidade superior aos auxiliares/técnicos de enfermagem em todas as práticas avaliadas, mesmo com menor frequência de avaliações. A medida com maior conformidade entre os enfermeiros foi a troca e realização de curativo $(21,7 \%)$, seguida por coleta de sangue $(21,4 \%)$, administração de medicamentos $(20,4 \%)$ e, por último, a troca do sistema de infusão (18,0\%).

A prática de troca e realização do curativo foi realizada quase que exclusivamente pelos enfermeiros (322 oportunidades). Isso ocorreu devido à rotina da unidade, como já citado no capítulo anterior, isto é, enquanto os enfermeiros realizam a troca do curativo do CVC (após o banho), os auxiliares/técnicos de enfermagem fazem o banho no leito ou encaminham 0 paciente para o banho de aspersão, preparam as drogas vasoativas e outras medicações e verificam os sinais vitais, etc.

Uma característica intrigante quanto à conformidade geral das práticas selecionadas foi que os maiores índices de conformidade ocorreram quando os profissionais iriam ter contato com sangue ou secreção (troca e realização de curativo - $21,1 \%$, seguida por coleta de sangue - 10,2\%).

Quanto às causas de não conformidade, de forma geral, a principal foi a não HM em nenhum momento na maioria das práticas avaliadas (troca do sistema de infusão - 65,2\%, coleta de sangue - 62,6\%, administração de medicamentos - 65,6\%), seguida pela higienização das mãos somente DEPOIS, também na maioria das práticas avaliadas (troca do sistema de infusão - 18,8\%, coleta de sangue - 21,5\%, administração de medicamentos - 18,0\%). Ao comparamos as causas de não conformidade entre as categorias avaliadas (enfermeiros e auxiliares/técnicos de enfermagem) encontramos diferença estatisticamente significante $(p<0,05)$ nos seguintes procedimentos: troca do sistema de infusão, coleta de sangue, administração de medicamentos, com $p<0,05$.

A exceção entre as causas de não conformidade ocorreu na prática de troca e realização do curativo, em que a HM somente ANTES (40,2\%) foi 
a principal causa de não conformidade, com diferença estatisticamente significante entre as categorias avaliadas $(p<0,05)$.

Ao contrário do nosso estudo, outro que avaliou o cumprimento da HM entre médicos e enfermeiros para pacientes em isolamento de contato de uma UTI cirúrgica e UTI médica, encontrou que esses profissionais estavam mais preocupados em higienizar as mãos DEPOIS (UTI Médica 63,3\%; UTI Cirúrgica 66,4\%), que ANTES (UTI Médica 27,3\%; UTI Cirúrgica 32,7\%) ${ }^{(107) .}$

Outro estudo que utilizou a OD e questionários para sua análise obteve adesão para HM menor de 50\%, com diferença entre as categorias profissionais $(p<0,05)$. Além disso, de acordo com questionário preenchido pelos profissionais, as principais causas de não conformidade para HM foram: realização de outra prioridade do paciente $(51,2 \%)$, esquecimento $(35,7 \%)$ e irritação da pele $(15,5 \%)^{(108)}$.

Nesse momento, cabe a mesma questão feita por Cabral de Menezes (2009) (73): "se houvesse distribuição de oportunidades semelhantes entre as categorias, as taxas de conformidade entre as categorias teriam sido diferentes?" De acordo com resultados citados anteriormente, a resposta seria NÃO, pois em nosso estudo, mesmo tendo superioridade das observações, os auxiliares/técnicos de enfermagem apresentaram as menores taxas de conformidade, em relação aos enfermeiros.

Outro paradoxo encontrado nos nossos resultados foi a adesão à HM na troca do sistema de infusão, com conformidade de apenas 8,9\%. Esta foi a prática com menor conformidade, no entanto, ao avaliarmos o componente da troca do sistema de infusão conforme recomendação da instituição, presente no Indicador CSCM, verificamos que os profissionais se preocupam em realizar a troca dos sistemas (100\% de conformidade), mas não higienizam as mãos adequadamente para realizar esta prática.

Uma questão constatada durante as observações foi que, algumas vezes, os mesmos profissioanis ora realizavam procedimento de forma correta, ora não. Isso nos permite considerar que tais ações estariam mais relacionadas com 0 contexto dos momentos de atuação (condições individuais do paciente, excesso de trabalho, recursos materiais, etc) do que com desconhecimento sobre como realizar corretamente o procedimento. 
Com isso, podemos dizer que a análise do contexto de atuação, portanto, mostra-se fator relevante também para a melhoria de conformidade de práticas assistenciais.

Enfim, não há dúvidas de que as IrAS elevam os custos da assistência à saúde, contudo, a promoção de programas educacionais também, pois exigem a capacitação de pessoal, treinamentos e material didátido. Mesmo assim, esses últimos estão longe dos gastos destinados ao tratamento de infecções, além de serem descritos como um elemento essencial para o sucesso das estratégias de controle de infecções nosocomial, incluindo o controle da ICS-ACVC.

Pesquisa qualitativa realizada por Erasmus et al. (2009) ${ }^{(109)}$, na qual foram avaliadas as potenciais causas condicionantes de conformidade para HM entre os profissionais de saúde no ambiente hospitalar, encontrou os seguintes resultados: a) enfermeiros e estudantes de medicina realizam HM para prevenção da infecção cruzada entre pacientes e entre si; b) médicos, para auto-proteção. Esses profissionais ainda relatam que a HM é mais frequente após as tarefas que eles percebem serem sujas.

Em estudo que estimou o custo da campanha de promoção de HM em hospitais da Universidade de Genebra, após ampla divulgação e distribuição de produtos alcoólicos para assepsia em todos os hospitais, os gastos foram estimados em 57.000 dólares anuais, com média de 1.42 dólares por paciente ${ }^{(110)}$.

Em revisão integrativa realizada pela pesquisadora do presente estudo, a utilização de programas educacionais mostrou ser efetiva na redução das taxas de ICS-ACVC em UTI adulto. Foram identificados 13 estudos que utilizaram as seguintes intervenções: higiene das mãos, uso adequado de barreira máxima de proteção, preferência pelo acesso na região subclávia, curativo impregnado com clorexidina, uso de cateter impregnado, remoção de cateter desnecessário e anti-sepsia da pele com clorexidina. Em todos esses estudos, a junção de todas as medidas citadas foi efetiva na redução das taxas de ICS-ACVC ${ }^{(111)}$.

No Quadro 2, a seguir, são apresentados esses estudos inclusos na revisão integrativa, sobre as práticas realizadas para redução das taxas de 
ICS-ACVC, as taxas de redução após as intervenções, profissionais inseridos nas pesquisas, tipo de UTI e países em que os estudos foram realizados.

Quadro 2 - Revisão integrativa de estudos sobre intervenção educacional e redução das taxas de infecção da corrente sanguínea associada ao cateter venoso central em Unidade de Terapia Intensiva adulto. São Paulo, 2010

\begin{tabular}{|c|c|c|c|c|c|c|}
\hline $\begin{array}{l}\frac{8}{8} \\
\frac{0}{2} \\
\frac{1}{2} \\
\frac{1}{3}\end{array}$ & $\frac{\sqrt{2}}{\substack{0 \\
\frac{\pi}{0}}}$ & $\frac{n}{\pi}$ & 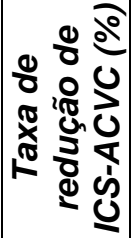 & 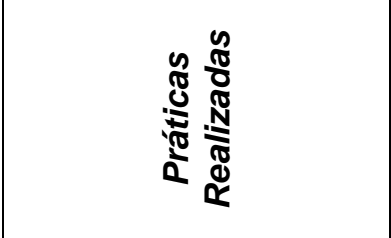 & 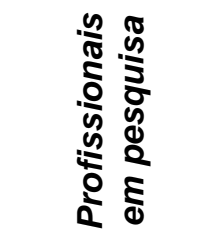 & $\begin{array}{l}5 \\
5 \\
0 \\
0 \\
1\end{array}$ \\
\hline $\mathrm{E} 1^{(15)}$ & $\begin{array}{c}\text { Venkatram S, } \\
\text { Rachmale S, } \\
\text { Kanna B. }\end{array}$ & EUA & $85 \%$ & $\begin{array}{l}\text { Lavagem das Mãos antes } \\
\text { e após inserção do cateter } \\
\text { e manipulação, uso de } \\
\text { barreira máxima na } \\
\text { inserção (campo estéril, } \\
\text { luva estéril, touca, avental } \\
\text { estéril, máscara), preparo } \\
\text { da pele com clorexidina, } \\
\text { remoção de cateter } \\
\text { desnecessário e uso de } \\
\text { biopatch }\end{array}$ & $\begin{array}{l}\text { Enfermeiros e } \\
\text { Médicos }\end{array}$ & Médica \\
\hline E2 ${ }^{(93)}$ & $\begin{array}{c}\text { Pronovost PJ, } \\
\text { Goeschel CA, } \\
\text { Colantuori E, } \\
\text { Watson S, } \\
\text { Lubomski LH, } \\
\text { Berenholtz S } \\
\text { et al. }\end{array}$ & EUA & $70,1 \%$ & $\begin{array}{l}\text { Lavagem das mãos antes } \\
\text { e após inserção do cateter } \\
\text { e manipulação, uso de } \\
\text { barreira máxima na } \\
\text { inserção (campo estéril, } \\
\text { luva estéril, touca, avental } \\
\text { estéril, máscara), limpeza } \\
\text { da pele com clorexidina, } \\
\text { remoção de cateter } \\
\text { desnecessário }\end{array}$ & $\begin{array}{c}\text { Equipe } \\
\text { multidisciplinar }\end{array}$ & $\begin{array}{l}\text { Médico- } \\
\text { cirúrgico }\end{array}$ \\
\hline E3 ${ }^{(112)}$ & $\begin{array}{l}\text { Barsuk JH, } \\
\text { Cohen ER, } \\
\text { Feinglass J, } \\
\text { McGahie WC, } \\
\text { Wayne DB. }\end{array}$ & EUA & $84,5 \%$ & $\begin{array}{l}\text { Higienização das mãos, } \\
\text { uso de barreira máxima } \\
\text { na inserção (campo } \\
\text { estéril, luva estéril, touca, } \\
\text { avental estéril, máscara), } \\
\text { limpeza da pele com } \\
\text { clorexidina, remoção de } \\
\text { cateter desnecessário }\end{array}$ & $\begin{array}{l}\text { Médicos } \\
\text { residentes }\end{array}$ & Médica \\
\hline$E 4^{(113)}$ & $\begin{array}{c}\text { Zingg W, Imhof } \\
\text { A, Maggiorini } \\
\text { M, Stocker R, } \\
\text { Keller E, Ruef } \\
\text { C. }\end{array}$ & Alemanha & $70 \%$ & $\begin{array}{l}\text { Higienização das mãos e } \\
\text { cuidados no preparo de } \\
\text { soluções intravasculares }\end{array}$ & $\begin{array}{l}\text { Enfermeiros e } \\
\text { Médicos }\end{array}$ & $\begin{array}{l}\text { Médico- } \\
\text { cirúrgico }\end{array}$ \\
\hline E5 ${ }^{(87)}$ & $\begin{array}{l}\text { Margel MA, } \\
\text { Madalone J, } \\
\text { Gwardschalads } \\
\text { e C, Longo K, } \\
\text { Hemmer D, } \\
\text { Haas J, } \\
\text { et al }\end{array}$ & $\begin{array}{c}\text { Não } \\
\text { Consta }\end{array}$ & $82,4 \%$ & $\begin{array}{c}\text { Protocolo de } \\
\text { recomendações quanto à } \\
\text { inserção e manutenção do } \\
\text { CVC usando o National } \\
\text { Healthcare Safety } \\
\text { Network (NHSN) }\end{array}$ & $\begin{array}{l}\text { Enfermeiros e } \\
\text { Médicos }\end{array}$ & Trauma \\
\hline
\end{tabular}

Continua... 
Conclusão Quadro 2

\begin{tabular}{|c|c|c|c|c|c|c|}
\hline $\begin{array}{l}\frac{0}{8} \\
0 \\
\frac{0}{0} \\
\frac{1}{5} \\
\frac{5}{3}\end{array}$ & 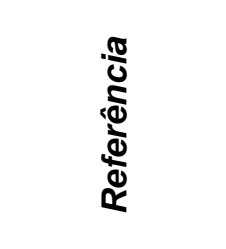 & $\frac{\pi}{\pi}$ & 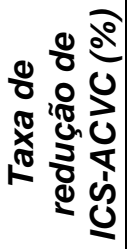 & 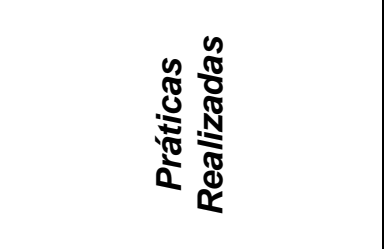 & 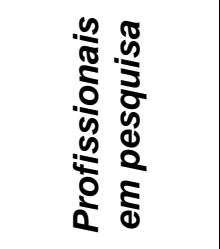 & $\begin{array}{l}5 \\
5 \\
0 \\
0 \\
0 \\
1\end{array}$ \\
\hline E6 ${ }^{(114)}$ & $\begin{array}{l}\text { Santana SL, } \\
\text { Furtado GHC, } \\
\text { Wey SB, } \\
\text { Medeiros EAS. }\end{array}$ & Brasil & $42,5 \%$ & $\begin{array}{c}\text { Programa educacional } \\
\text { dividido em: teste com } \\
\text { equipe de saúde sobre } \\
\text { conhecimento pré e pós- } \\
\text { intervenção, distribuição } \\
\text { de folhetos informativos } \\
\text { em locais estratégicos e } \\
\text { palestras sobre controle } \\
\text { de ICS-ACVC }\end{array}$ & $\begin{array}{c}\text { Equipe } \\
\text { Multidisciplinar }\end{array}$ & $\begin{array}{l}\text { Médico- } \\
\text { cirúrgico }\end{array}$ \\
\hline E7 ${ }^{(115)}$ & $\begin{array}{l}\text { MacCalla S, } \\
\text { Downing-Janos } \\
\text { T, Ellsworth K, } \\
\text { Allinger P, } \\
\text { Kirkpatrick K, } \\
\text { Zaicek S. }\end{array}$ & $\begin{array}{c}\text { Não } \\
\text { Consta }\end{array}$ & $50,5 \%$ & $\begin{array}{l}\text { Uso de barreira máxima } \\
\text { na inserção (campo } \\
\text { estéril, luva estéril, touca, } \\
\text { avental estéril, máscara), } \\
\text { higiene das mãos, cateter } \\
\text { impregnado e uso de } \\
\text { biopatch }\end{array}$ & $\begin{array}{l}\text { Enfermeiros e } \\
\text { Médicos }\end{array}$ & $\begin{array}{l}\text { Médico- } \\
\text { cirúrgico }\end{array}$ \\
\hline E8 ${ }^{(50)}$ & $\begin{array}{l}\text { Lobo RD, Levin } \\
\text { AS, Gomes } \\
\text { LMB, Cursino } \\
\text { R, Park M, } \\
\text { Figueiredo VB, } \\
\text { et al. }\end{array}$ & Brasil & $40 \%$ & $\begin{array}{c}\text { Orientações quanto as } \\
\text { práticas de inserção e } \\
\text { manipulação do CVC, } \\
\text { quando utilizar luvas e a } \\
\text { lavagem das mãos após } \\
\text { sua utilização }\end{array}$ & $\begin{array}{c}\text { Equipe } \\
\text { Multidisciplinar }\end{array}$ & Médica \\
\hline E9 ${ }^{(116)}$ & $\begin{array}{l}\text { Warren DK, } \\
\text { Zack JE, } \\
\text { Mayfield JL, } \\
\text { Chen A, } \\
\text { Prentice D, } \\
\text { Fraser VJ, } \\
\text { et al. }\end{array}$ & EUA & $58 \%$ & $\begin{array}{l}\text { Uso de barreira máxima } \\
\text { na inserção (campo } \\
\text { estéril, luva estéril, touca, } \\
\text { avental estéril, máscara), } \\
\text { uso de cateter } \\
\text { impregnado }\end{array}$ & $\begin{array}{c}\text { Equipe } \\
\text { Multidisciplinar }\end{array}$ & Médica \\
\hline $\mathrm{E} 10^{(90)}$ & $\begin{array}{l}\text { Coopersmith } \\
\text { CM, Zack JE, } \\
\text { Ward MR, } \\
\text { Sona CS, } \\
\text { Schallom ME, } \\
\text { Everett SJ, } \\
\text { et al. }\end{array}$ & EUA & $74 \%$ & $\begin{array}{l}\text { Adequada higiene das } \\
\text { mãos, Uso de barreira } \\
\text { máxima na inserção } \\
\text { (campo estéril, luva } \\
\text { estéril, touca, avental } \\
\text { estéril, máscara), tipo de } \\
\text { curativo na inserção de } \\
\text { CVC }\end{array}$ & $\begin{array}{c}\text { Equipe } \\
\text { Multidisciplinar }\end{array}$ & Cirúrgica \\
\hline $\mathrm{E} 11^{(117)}$ & $\begin{array}{l}\text { Warren DK, } \\
\text { Zack JE, } \\
\text { Cox MJ, Cohen } \\
\text { MM, Fraser VJ. }\end{array}$ & EUA & $57,1 \%$ & $\begin{array}{l}\text { Uso de cateter } \\
\text { impregnado }\end{array}$ & $\begin{array}{l}\text { Enfermeiros e } \\
\text { Médicos }\end{array}$ & $\begin{array}{l}\text { Médico- } \\
\text { cirúrgico }\end{array}$ \\
\hline $\mathrm{E} 12^{(75)}$ & $\begin{array}{l}\text { Rosenthal VD, } \\
\text { Guzman S, } \\
\text { Pezzotto SM, } \\
\text { Crnith CJ. }\end{array}$ & Argentina & $61,6 \%$ & $\begin{array}{l}\text { Higienização das mãos, } \\
\text { padronização do tipo de } \\
\text { curativo na inserção de } \\
\text { CVC }\end{array}$ & $\begin{array}{c}\text { Equipe } \\
\text { Multidisciplinar }\end{array}$ & $\begin{array}{l}\text { Médico- } \\
\text { cirúrgico }\end{array}$ \\
\hline $\mathrm{E} 13^{(118)}$ & $\begin{array}{l}\text { Coopersmith } \\
\text { CM, } \\
\text { Rebmann TL, } \\
\text { Zack JE, } \\
\text { Ward MR, } \\
\text { Corcoran RM, } \\
\text { Schallom ME, } \\
\text { et al }\end{array}$ & EUA & $65,7 \%$ & $\begin{array}{l}\text { Orientação quanto a } \\
\text { prática correta de } \\
\text { inserção e manutenção do } \\
\text { CVC e distribuição de } \\
\text { cartazes e folhetos } \\
\text { reforçando as } \\
\text { informações }\end{array}$ & Enfermeiros & Cirúrgica \\
\hline
\end{tabular}


A realização de um programa educativo visa construir conhecimento, embora seja esperado que os profissionais da área da saúde executem sempre as medidas de prevenção e controle de IrAS. A HM, uma das principais medidas de prevenção de infecção nosocomial, pode ser considerada um ato muito simples, contudo, a complexidade da sequência do atendimento faz com que a HM não ocorra dentro do fluxo de atendimento, mesmo que o ideal seja um comportamento automatizado para a HM, de acordo com cada situação de cuidado específico.

Além disso, a WHO (2009) refere que programas educacionais que visem a HM como único meio para a prevenção de infecção nosocomial geralmente não são sustentáveis ${ }^{(53)}$. A HM sofre influência apenas a curto prazo e, devido a este fato, os programas educativos devem abranger outras medidas de prevenção. Também há evidências claras de que o sucesso do programa pode ser afetado se as instalações físicas para proporcionar a HM não são adequadas ${ }^{(53)}$.

Entretanto, devemos lembrar que nosso estudo, assim como em todos os demais, avaliou atividades exercidas por adultos treinados e considerados aptos para exercer tais funções, no entanto, ensiná-los, mesmo que seja para realizar tarefas de forma correta, não é tão fácil como pensamos, pois: querem entender o porquê da necessidade de aprender certa coisa; gostam de aplicar seu conhecimento prévio no processo de aprendizagem; há interesse pela aprendizagem de coisas que possam ser aplicadas imediatamente; os processos de aprendizagem devem ser concentrados em problemas e não em conteúdos. Enfim, todos estes aspectos devem ser levados em consideração quando falamos no processo de ensino do adulto e fazem parte do princípio da andragogia ${ }^{(119)}$.

Mesmo assim, acredita-se que a implantação de um sistema de avaliação que monitore tais práticas poderá, além de reconhecer suas conformidades, identificar e correlacionar situações e condições que as favorecem e ou dificultam, de modo a desencadear políticas de gerenciamento e treinamento diretamente voltadas às situações e condições encontradas. 
Finalmente, pelos resultados obtidos, a nossa hipótese de que todas as avaliações não alcançariam a conformidade ideal de $80 \%$ foi parcialmente comprovada. Conforme visto, apenas um dos quatro indicadores avaliados apresentou conformidade superior à ideal (CSIP - 91,6\%). Os demais indicadores tiveram conformidade variando de $0 \%$ à $51,5 \%$.

Concordando com Cabral de Menezes (2009) ${ }^{(73)}$, a grande vantagem da avaliação realizada com indicadores de processo e técnica de OD devese à possibilidade de não somente identificar seus índices de conformidade em relação à melhor prática esperada, como também favorece, sobremaneira, reconhecimento das situações que contribuíram para os valores encontrados. 


\section{CONCLUSÕES}


Este estudo avaliou a conformidade de práticas de prevenção e controle da infecção da corrente sanguínea associada ao cateter venoso central por meio da aplicação de indicadores de processo (CSQI, CSIP, HMSEL, CSCM), possibilitando identificar seus índices de adesão entre os turnos de trabalho e as categorias profissionais.

A conformidade esperada de $80 \%$ foi alcançada apenas no Indicador que avaliou a prática de registro de indicação e tempo de permanência do CVC de curta permanência (Indicador CSIP). Os demais indicadores, apesar de não terem obtido conformidade geral esperada, alguns dos seus componentes superaram esse índice (inserção percutânea, uso de paramentação completa e de campo estéril ampliado no momento da instalação do CVC, uso de anti-séptico de veículo alcoólico para preparo da pele, troca de equipos e transdutores conforme recomendação e periodicidade da troca do curativo conforme recomendação), o que evidencia que várias recomendações estão bem estabelecidas.

No Indicador CSQI, apenas o componente que avaliou a presença do curativo oclusivo ao término da inserção apresentou conformidade nula $(0,0 \%)$, demonstrando a necessidade de atualização da equipe que realiza a inserção do CVC quanto aos curativos transparentes/impermeáveis que podem ser utilizados nesse momento.

Quanto ao Indicador CSCM, concluímos que apesar da equipe de enfermagem ter recebido treinamento para a realização do registro de troca do curativo e desinfecção de hubs e conectores com clorexidina alcoólica $0,5 \%$ antes da manipulação, não foi suficiente para incorporar essas práticas de forma correta. Isso nos leva a questionar se essas divergências ocorreram por ausência de conhecimento que fortaleça a importância do procedimento, alta demanda da carga de trabalho ocasionada pela redução do pessoal ou pacientes muito críticos, falta de material para a realização dessas práticas e supervisão insuficiente. Destacamos que para a prática de desinfecção de hubs e conectores com clorexidina alcoólica 0,5\% antes da manipulação, o turno da noite apresentou o menor índice de conformidade que nos demais períodos. 
$\mathrm{Na}$ aplicação do Indicador HMSEL, a não HM antes e após a troca do sistema de infusão foi o procedimento que mais comprometeu a conformidade geral dessa prática, em todos os quatro procedimentos observados. E, mais uma vez, o turno da noite foi que apresentou o menor índice de conformidade. Houve, inclusive, diferença estatisticamente significante entre os turnos de trabalho. Em seguida, as causas de não conformidade referiram-se a HM somente ANTES ou DEPOIS.

Em relação à categoria profissional, os auxiliares/técnicos de enfermagem apresentaram um maior número de oportunidades de observação que os enfermeiros, contudo, a conformidade de adesão geral para a prática de higiene das mãos foi muito inferior em comparação aos enfermeiros.

Com os resultados desse estudo, acreditamos ter identificado fatores relevantes para explicar a adesão ou não das práticas de prevenção e controle da ICS-ACVC, por meio da aplicação de indicadores de processo e da OD, apontando que mesmo com normas instituídas e consolidadas cientificamente, nem sempre são seguidas/realizadas corretamente.

É preciso destacar que a realização de intervenção educacional continuada tem sido comprovadamente eficaz na redução das taxas de infecção, pois desenvolve uma "cultura de prevenção" entre os profissionais da saúde e leva a uma redução sustentada das taxas de infecção. No entanto, tal intervenção não deve se resumir somente no conhecimento, uma vez que observamos, algumas vezes, realização de práticas ora corretas, ora incorretas, pelos mesmos profissionais. A busca das causas de não conformidade como excesso de trabalho e falta de material/produto também devem ser investigadas.

Acreditamos que esta pesquisa poderá contribuir para novas discussões a respeito da prática assistencial e colaborar na criação de estratégias educativas que visem à redução das taxas da ICS-ACVC. 
8 REFERÊNCIAS 
1. Focault M. Microfísica do poder. 5. ed. Rio de Janeiro: Graal. 1985.

2. Lacerda RA, Egry EY. As infecções hospitalares e sua relação com o desenvolvimento da assistência hospitalar: reflexões para análise de suas práticas atuais de controle. Rev. Latino-Am. de Enfermagem. Ribeirão Preto. 1997; 5(4): 13-23.

3. Brasil. Agencia Nacional de Vigilância Sanitária (Anvisa). Infecção relacionada à assistência à saúde (IrAS). Módulo I - Legislação e criação de um programa d prevenção e controle de infecção hospitalar. São Paulo, 2004.

4. Andrade GM. Infecção hospitalar: mitos e verdades, velhos hábitos, novas atitudes. Brasília Med. 2002; 39 (1/4): 57-59.

5. Fernandes AT, Furtado JJD, Porfírio FMV, Cavalcante NJF. Infecção hospitalar da corrente sanguínea. In: Fernandes AT, editor. Infecção hospitalar e suas interfaces na área da saúde. São Paulo: Atheneu; 2000. V. 1. p. 580-601.

6. Verdier R, Parer S, Jean-Pierre H, Dujols P, Picot MC. Impact of an infection control program in an intensive care unit in France. Infection Control and Hospital Epidemiology. 2006; 27 (1): 60-66.

7. Fernandes AT. O desafio da infecção hospitalar: a tecnologia invade um sistema em desequilíbrio. In: Fernandes AT, editor. Infecção hospitalar e suas interfaces na área da saúde. São Paulo: Atheneu; 2000. V. 1. p. 129-59.

8. Lacerda RA. Ambiente da sala de operações: fontes de contaminação e relação com infecção em centro cirúrgico. In: Lacerda RA (org). Controle de infecção em centro cirúrgico: fatos, mitos e controvérsias. São Paulo: Atheneu; 2003. p. 325-360. 
9. Brasil. Ministério da Saúde. Portaria n. 196 de 24 de junho de 1983. Dispõe sobre instruções para a prevenção e controle das infecções hospitalares. In: Brasil. Ministério da Saúde. Manual de controle de infecção hospitalar. Brasília, Centro de documentação do Ministério da Saúde. 1985. p. 101.

10. Lacerda RA, Joucla VMG, Egry EV. Infecções hospitalares no Brasil. Ações governamentais para o seu controle enquanto expressão de políticas sociais na área da saúde. Rev. Esc. Enf USP. 1996; 30 (1): 93-115.

11. Brasil. Ministério da Saúde. Portaria N ․ 930 de 27 de agosto de 1992. Estabelece normas para o controle da infecção hospitalar e revoga a Portaria n.196. Diário Oficial da União, Brasília, 4 set 1992, Seção 1. p. 12.279-81.

12. Brasil. Ministério da Saúde. Lei n. 9.431 de 6 de janeiro de 1997. Dispõe sobre a obrigatoriedade da manutenção de programa de controle de infecções hospitalares pelos hospitais do País. Diário Oficial da União, Brasília, 7 jan 1997, Seção 1.p.265.

13. Brasil. Ministério da Saúde. Portaria n. 2616, de 12 de maio de 1998. Dispõe sobre as diretrizes e normas para a prevenção e controle das infecções hospitalares. Diário Oficial da União, Brasília, 12 de maio de 1998. P. 232-36.

14. Giunta APN, Lacerda RA. Inspeção dos programas de controle de infecção hospitalar dos serviços de saúde pela vigilância sanitária: diagnóstico de situação. Rev esc. Enferm. USP. 2006; 40(1): 64-70.

15. Venkatram S, Rachmale S, Kanna B. Study of device use adjusted rates in health care-associated infections after implementation of "bundles" in a closed-model medical intensive care unit. Journal of Crtical Care. 2010; 25: e11-e18. 
16. Kelleghan RN, Salemi C, Padilla S, McCord M, Mermilliod G, Canola T, et al. An effective continuous quality improvement approach to the prevention of ventilator-associated pneumonia. Am J Infect Control. 1993; 21 (6): 322-30

17. Zuschneid I, Schwab F, Geffers C, Rüden H, Gastmeier P. Reducing central venous catheter-associated primary bloodstream infections in intensive care units is possible: data from the German Nosocomial infection Surveillance System. Infect Control Hosp Epidemiol. 2003; 24 (7): 501-505.

18. Safdar N, Maki DG. The pathogenesis of catheter-related bloodstream infection with noncuffed short-term central venous catheters. Intensive Care Med. 2004; 30: 62-67.

19. Centers for Disease Control and Prevention. Guidelines for the Prevention of Intravascular Catheter-Related Infections. MMWR. 2002; 51(No.RR-10): 1-36.

20. Marschall J, Mermel L A, Classen D, Arias K M, Podgorny K, Anderson $\mathrm{D} J$ et al. Strategies to Prevent Central Line-Associated Bloodstream Infections in Acute Care Hospitals - Supplement Article: SHEA/IDSA Practice Recommendation. Infection Control and Hospital Epidemiology. 2008; 29 (10).

21. Diretrizes Práticas para Terapia Intravenosa. Infusion Nurses Society Brasil. 2008.

22. Pittet D, Mourouga P, Perneger TV, members of the Infection Control Program. Compliance with handwashing in a teaching hospital. Ann Intern Med. 1999; 130: 126-30.

23. Yokoe DS, Classen D. Improving patient safety through infection control: a new healthcare imperative. Infect Control hosp Epidemiol. 2008; 29: S3-S11. 
24. Pronovost $P$, Needham D, Berenholtz S, Sinopoli D, Chu H, Cosgrove $S$, et al. An intervention to decrease catheter-related bloodstream infections in the ICU. N engl J Med. 2006; 355: 2725-32.

25. Jarvis WR. Infection control and changing health-care delivery systems. Emerg. Infect, Dis. 2001; 7: 170-3.

26. Poveda VB, Galvão CM, Santos CB. Fatores predisponentes à infecção do sítio cirúrgico em gastrectomia. Acta Paulista de Enfermagem. 2005; 18 (1): 31-8.

27. São Paulo (Estado). Secretaria da Saúde. Divisão de Infecção Hospitalar. Centro de Vigilância Epidemiológica. Manual de avaliação da qualidade de práticas de controle de infecção hospitalar. São Paulo; 2006.

28. Fernandes AT, Ribeiro Filho N. Infecção do acesso vascular. In: Fernandes AT, editor. Infecção Hospitalar e suas interfaces na área da saúde. São Paulo: Atheneu; 2000. V.1. p 556-79.

29. Phillips LD. Manual de terapia intravenosa. 2 ed. Porto Alegre: Artmed; 2001. p. 551.

30. Vendramini P. Cateter central de inserção periférica para acesso venoso em crianças: utilização segundo enfermeiros de hospitais do município de São Paulo [Tese]. São Paulo (SP): Universidade Federal de São Paulo; 2004.

31. O'Grady NP, Alexander M, Burns LA, Dellinger EP, Garland J, Heard SO, et al. Guidelines for the prevention of intravascular catheter-related infections. Draft. 2010. Disponível em: http://wwwn.cdc.gov/public comments/ guidelines-for-the- prevention- of-intravascular- catheterrelated-infections/2038.ashx

32. Widmer AF. Related infections. In: Wenzel RP. Prevention and control of nosocomial infections. $2^{\text {nd }}$ ed. Baltimore: Willians \& Wilkins; 1993: $p$. 556-79. 
33. Ferreira AS, Fernandes AT, Fernandes MOV, Vatimo MFF, Hosaka EM. Infecção do acesso vascular. In: Lacerda RA, coordenadora. Controle de infecção em centro cirúrgico: fatos, mitos e controvérsias. São Paulo: Atheneu; 2003. p. 115-33.

34. Gnass SA, Barboza L, Bilicich D, Angeloro P, Treiyer, W, Grenóvero, et al. Prevention of central venous catheter-related bloodstream infections using non-technologic strategies. Infect Control Hosp Epidemiol. 2004; 25: 675-677.

35. Maki DG, Kluger DM, Crnich CJ. The risk of bloodstream infection in adults with different intravascular devices: a systematic review of 200 published prospective studies. Mayo Clin Proc. 2006; 81(9): 1159-1171.

36. Horan TC, Andrus M, Dudeck MA. CDC/NHSN surveillance definition of health care-associated infection and criteria for specific types of infections in the acute care setting. Am J Infect Control. 2008; 36: 309-32.

37. Burton DC, Edwards JR, Horan TC, Jernigan JA, Fridkin SK. Methicillinresistant Staphylococcus aureus central line-associated bloodstream infections in US intensive care units, 1997-2007. JAMA 2009; 301:727-36.

38. Chen HS, Wang FD, Lin M, Lin YC, Huang LJ, Liu CY. Risk factors for central venous catheter-related infections in general surgery. J Micobiol Immunol Infect. 2006; 39: 231-6.

39. Sadoyma G, Diogo Filho A, Gontijo Filho PP. Central venous catheterrelated bloodstream infection caused by Staphilococcus aureus: microbiology and risk factors. Braz J Infect Dis. 2006; 10 (2): 100-6.

40. Crnich CJ, Maki DG. Infections caused by intravascular devices: epidemiology, pathogenesis, diagnosis, prevention, and treatment. In: APIC Text of Infection Control and Epidemiology. Vol 1. 2nd ed. Washington, DC: Association for Professionals in Infection Control and Epidemiology. 2005; 24: 21-24. 
41. Mermel LA. Review - Prevention of intravascular catheter-related infections. Ann Inern Med 2000; 132 (5): 391-402.

42. Brasil. Ministério do Trabalho e emprego. Portaria $n^{\circ} 485$, de 11 de novembro de 2005. Aprova a norma regulamentadora $n^{\circ} 32$ sobre a Segurança e Saúde do Trabalhador em Estabelecimentos de Saúde.

43. Menyhay S Z, Maki DG. Preventing central venous catheter-associated bloodstream infections: Development of an antiseptic barrier cap for needleless connectors. Am J Infect Control. 2008; 36 (10): 74-77.

44. Dezfulian C, Lavelle J, Nallamothu BK, Kaufman SR, Saint S. Rates of infection for single-lumen versus multilumen central venous catheters: a meta-analysis. Crit Care Med. 2003; 31: 2385-2390.

45. Sirvent JM, Vidaur L, García M, Ortiz P, Batlle J, Motjé M, et al. Colonization of the medial lumen is a risk factor for catheter-related bloodstream infection. Intensive Care Med. 2006; 32: 1404-1408.

46. Carrara, D. Influência do sistema fechado de infusão venosa sem agulha na incidência das infecções de corrente sanguínea em crianças operadas no InCor HC-FMUSP [Tese]. Faculdade de Medicina da Universidade de São Paulo; 2005.

47. Corona A, Raimond F. Prevention nosocomial infection in the ICU setting. Minerva Anestesiol. 2004; 70: 329-37.

48. Edwards JR, Peterson KD, Andrus ML, Dudeck MA, Pollock DA, Horan TC et al. National Healthcare Safety Network (NHSN) - Report, data summary for 2006 through 2007, issued November 2008. Am J Infect Control. 2008; 36: 609-26.

49. Rosenthal VD, Maki DG, Mehta A, Alvarez-Moreno C, Leblebicioglu $H$, Higuera $F$ et al. International Nosocomial Infection Control Consortium report, data summary for 2002-2007, issued January 2008. Am J Infect Control. 2008; 36: 627-37. 
50. Lobo RD, Levin AS, Gomes LMB, Cursino R, Park M, Figueiredo VB, et al. Impact of an educational program and policy changes on decreasing catheter-associated bloodstream infections in a medical intensive care unit in Brazil. Am J Infect Control. 2005; 33: 83-7.

51. Mermel LA, Allon M, Bouza E, Craven DE, Flynn P, O'Grady NP. Clinical Practice Guidelines for the Diagnosis and Management of Intravascular Catheter-Related Infection: 2009 Update by the Infectious Diseases Society of America. IDSA Guidelines for Intravascular Catheter-Related Infection. 2009; 49: 1-45.

52. Goede MR, Coopersmith CM. Catheter-related bloodstream infection. Surg Clin N Am. 2009; 89: 463-474.

53. WHO (WORLD HEALTH ORGANIZATION). The WHO Guidelines on Hand Hygiene in health Care. First Global Patient Safety Challenge. Clean care is safer care. Geneva: WHO Press. 2009. 262p.

54. Lam BCC, Lee J, Lau YL. Hand Hygiene Practices in a Neonatal Intensive Care Unit: A Multimodal Intervention and Impact on Nosocomial Infection. Pediatrics. 2004; 114: 565-571.

55. Centers for Disease Control and Prevention. Guideline for Hand Hygiene in Health-Care Settings: Recommendations of the Healthcare Infection Control Practices Advisory Committee and the HICPAC/SHEA/APIC/ IDSA Hand Hygiene Task Force. MMWR 2002; 51(No. RR-16):1-52.

56. Canada Communicable Disease Report. Hand washing, cleaning, disinfection and sterilization in health care. 1998; 24 (8): 1-55.

57. Ferraz EM, Ferraz AAB. Infecção em cirurgia: aspectos históricos. In: Ferraz EM. Infecção em Cirurgia. São Paulo: Medsi. 1991: p. 1-6.

58. Albert RK, Condie F. Hand-washing patterns in medical intensive-care units. N Engl J Med. 1981; 304: 1465-1466. 
59. Galpern D, Guerrero A, Tu A, Fahoum B, Wise L. Effectiveness of a central line bundle campaign on line-associated infections in the intensive care unit. Surgery. 2008; 144 (4): 492-5.

60. Rotter M. Hand washing and hand disinfection. In: Mayhall CG, ed. Hospital epidemiology and infection control. 2nd ed. Philadelphia, PA: Lippincott Williams \& Wilkins; 1999.

61. Winnefeld M, Richard MA, Drancourt M, Grobb JJ. Skin tolerance and effectiveness of two hand decontamination procedures in every-day hospital use. Br J Dermatol. 2000; 143: 546-50.

62. Larson EL, Aiello AE, Bastyr J, et al. Assessment of two hand hygiene regimens for intensive care unit personnel. Crit Care Med. 2001; 29: 944-51.

63. Eyer S, Brummitt C, Crossley K, Siegel R, Cerra F. Catheter-related sepsis: prospective, randomized study of three methods of long-term catheter maintenance. Crit Care Med. 1990; 18: 1073-9.

64. Erbay A, Ergonul O, Stoddard GJ, Samore MH. Recurrent catheterrelated bloodstream infections: risk factors and outcome. International Journal of Infectious Diseases. 2006; 10: 396-400.

65. Olson ME, Lam K, Bodey GP, King EG, Costerton JW. Evaluation of strategies for central venous catheter replacement. Crit Care Med. 1992; 20: 797-804.

66. Sub Comissão de Controle de Infecção Hospitalar - InCor/HC-FMUSP. Recomendações para controle de infecção hospitalar associada à passagem, uso e manutenção de cateteres intravasculares. São Paulo, $4^{\circ}$ Ed: 20 de março de 2003.

67. Brasil. Ministério da Saúde. Resolução RDC ํㅜ 45, de 12 de março de 2003. Dispõe sobre o Regulamento Técnico de Boas Práticas de Utilização das Soluções Parenterais (SP) em Serviços de Saúde. 
68. Polit DF, Beck CT, Hungler BP. Compreensão do delineamento da pesquisa quantitativa. In: Hungler BP, Beck CT, Polit DF. Fundamentos de pesquisa em enfermagem: métodos, avaliação e utilização. $5^{\mathrm{a}}$ Ed. Porto Alegre: Artmed; 2004. p. 163-98.

69. Novaes HMD. Avaliação de programas, services e tecnologias emsaúde. Ver Saúde Pública. 2000; 34(5): 547-59.

70. Rosner B. Fundamentals of biostatistics. $6^{\mathrm{a}}$ ed. Belmont: Thomson Brooks; 2006.

71. Torres MM, Andrade D, Santos CB. Punção venosa periférica: avaliação de desempenho dos profissionais de enfermagem. Rev Latino-am Enfermagem. 2005; 13(3): 299-304.

72. Nonino EAPM. Avaliação da qualidade dos procedimentos de enfermagem - banho e curativo - segundo o grau de dependência assistencial dos pacientes internados em um Hospital Universitário [tese]. Ribeirão Preto: Escola de Enfermagem, Universidade de São Paulo; 2006.

73. Cabral de Menezes IRS. Avaliação da conformidade de práticas de prevenção e controle da pneumonia associada à ventilação mecânica em um hospital público de ensino [dissertação]. São Paulo: Escola de Enfermagem, Universidade de São Paulo; 2009.

74. Pittet D, Hugonnet S, Harbarth $S$, et al. Effectiveness of a hospital-wide programme to improve compliance with hand hygiene. Lancet. 2000; 356: 1307-1312.

75. Rosenthal VD, Guzman S, Safdar N. Reduction in nosocomial infection with improved hand hygiene in intensive care units of a tertiary care hospital in Argentina. Am J Infect Control. 2005; 33(7): 392-7. 
76. Sharir R, Teitler N, Lavi I, Raz R. High-level handwashing compliance in a community teaching hospital: a challenge that can be met. J Hosp Infect. 2001; 49(1): 55-8.

77. Zimakoff J, Stormark M, Larsen SO. Use of gloves and handwashing behaviour among health care workers in intensive care units. A multicentre investigation in four hospitals in Denmark and Norway. J Hosp Infect. 1993; 24(1): 63-7.

78. Hulley SB, Martin JN, Cummings SR. Planejando as medições: precisão e acurácia. In: Hulley SB, Cummings SR, Browner WS, Grady D, Hearst $\mathrm{N}$, Newman TB. Delineando a pesquisa clínica: uma abordagem epidemiológica. 2ª ed. Porto Alegre: Artmed; 2003. p. 55-66.

79. Newman T, Browner WS, Cunnings SR. Delineando estudos de testes médicos. In: Hulley SB, Cummings SR, Browner WS, Grady D, Hearst $\mathrm{N}$, Newman TB. Delineando a pesquisa clínica: uma abordagem epidemiológica. $2^{a}$ ed. Porto Alegre: Artmed; 2003. p. 203-44.

80. Polit DF, Beck CT, Hungler BP. Avaliação dos métodos de coleta de dados. In: Hungler BP, Beck CT, Polit DF. Fundamentos de pesquisa em enfermagem: métodos, avaliação e utilização. 5a ed. Porto Alegre: Artmed; 2004. p. 247-84.

81. Shoukri MM. Measures of interobserver agreement. Boca Raton. 2004.

82. Randon Sequence Generator. [citado 2009 agosto 01]. Disponível em: http://www.random.org/sequence

83. Haas JP, Larson EL. Measurement of compliance with hand hygiene. J Hosp Infect. 2007; 66(1): 6-14.

84. Eckmanns T, Bessert J, Behnke $M$ et al. Compliance with antiseptic hand rub use in intensive care units:the hawthorne effect. Infect Control Hosp Epidemiol. 2006; 27: 931-934. 
85. Vallés J, Fernández I, Alcaraz D, Chacon E, Cazorla A, Canals M et al. Prospective randomized Trial of 3 antiseptic solutions for prevention of catheter colonization in an intensive care unit for adult patients. Infect Control Hosp Epidemiol. 2008; 29: 847-853.

86. Maki DG, Ringer M, Alvarado CJ. Prospective, randomized trial of povidone-iodine, alcohol, and chlorhexidine for prevention of infection associated with central venous and arterial catheters. Lancet. 1991; 338: 339-43.

87. Magerl MA, Madalona J, Gwardschaladse C, Longo K, Hemmer D, Hass $\mathrm{J}$, et al. A regional trauma intensive care unit (ICU) thirty-one month experience in decreasing central venous catheter-bloodstream infections (CVC-BSI). Americam Journal of Infection Control. 2009; 37 (5): E38-39.

88. Templeton A, Schelegel M, Fleisch F et al. Multilumen central venous catheters increase risk for catheter-related bloodstream infection: prospective surveillance study. Infection. 2008; 36: 322-27.

89. Nagashima G, Kikuchi T, Tsuyuzaki $\mathrm{H}$ et al. To reduce catheter-related bloodstream infections: is the subclavian route better than the jugular route for central venous catheterization? J Infect Chemother. 2006; 12(6): 363-65.

90. Coopersmith CM, Zack JE, Ward MR, Sona CS, Schallom ME, Everett SJ, et al. The impact of bedside behavior on catheter-related bacteremia in the intensive care unit. Arch Surg. 2004; 139: 131-36.

91. Kritchevsky SB, Braun BI, Kusek L, Wong ES, Solomon SL, Parry MF et al. The impact of Hospital Practice on Central Venous CatheterAssociated Bloodstream Infection Rates at the Patient and Unit Level: A Multicenter Study. American Journal of Medical Quality. 2008; 23 (1): 24-38. 
92. Walz JM, Memtsoudis SG, Heard SO. Analytic Reviews: Prevention of central venous catheter bloodstream infections. J Intensive Care Med. 2010; 25: 131-38.

93. Pronovost PJ, Goeschel CA, Colantuoni E, Watsom S, Lubomski LH, Berenholtz SM, et al. Sustaining reductions in catheter related bloodstream infections in Michigan intensive care units: observational study. BMJ. 2010; 340: c309-14.

94. Timsit JF, Schwebel C, Bouadma L, Geffroy A, Garrouste-Orgeas M, Pease $S$, et al. Chlorhexidine-impregnated sponges and less frequent dressing changes for prevention of catheter-related infections in critically ill adults: a randomized controlled trial. JAMA. 2009; 301(12): 1231-41.

95. Setz VG, Innocenzo MD. Avaliação da qualidade dos registros de enfermagem no prontuário por meio da auditoria. Acta Paul Enferm. 2009; 22(3): 313-7.

96. Cunha SMB, Barros ALBL. Análise da implementação da Sistematização da Assistência de Enfermagem, segundo o Modelo Conceitual de Horta. Rev Bras Enferm. 2005; 58(5): 568-72.

97. Reppetto MA, Souza MF. Avaliação da realização e do registro da Sistematização da Assistência de enfermagem (SAE) em um hospital universitário. Rev Bras Enferm. 2005; 58(3): 325-9.

98. Menyhay SZ, Maki DG. Disinfection of needleless catheter connectors and access ports with alcohol may not prevent microbial entry: promise of a novel antiseptic-barrier cap. Infect Control Hosp Epidemiol. 2006; 27: $23-7$.

99. Casey AL, Worthington T, Lambert PA, Quinn D, Faroqui MH, Elliott TS. A randomized, prospective clinical trial to assess the potential infection risk associated with the Posi Flow needleless connector. J Hosp Infect. 2003; 54: 288-93. 
100. Simmons S, Bryson C, Porter S. "Scrub the hub": cleaning duration and reduction in bacterial load on central venous catheters. Crit Care Nurs Q. $2011 ; 34$ (1): 31-5.

101. Souza FC, Santana HT. Higienização das mãos. In: Agência Nacional de Vigilância Sanitária (ANVISA). Manual de prevenção de infecções associadas a procedimentos estéticos. Brasíllia: ANVISA; 2009.

102. Cicaline S, Palmiere F, Petrosillo N. Clinical review: new tecnologies for prevention of intravascular catheter-related infections. Crit Care. 2004; 8: 157-62.

103. Golan Y, Doron S, Griffith J, El Gamal H, Tanios M, Blunt K, et al. The impact of gown-use requirement on hand hygiene compliance. Clin Infect Dis. 2006; 42(3): 370-6.

104. Karabey S, Ay P, Derbentli S, Nakipoglu Y, Esen F. Handwashing frequencies in an intensive care unit. J Hosp InFect. 2002; 50(1): 36-41.

105. Ricart M, Lorente C, Diaz E, Kollef MH, Rello J. Nursing adherence with evidence-based guidelines for preventing ventilator-associated pneumonia. Crit Care Med. 2003; 31(11):2693-6.

106. Lacerda RA. Riscos de infecção ocupacional por exposição a substâncias orgânicas e medidas de precauções. In: Lacerda RA, coordenadora. Controle de infecção em centro cirúrgico: fatos, mitos e controvérsias. São Paulo: Atheneu São Paulo; 2003b. p. 469-92.

107. Gilbert K, Stafford C, Crosby K, Fleming E, Gaynes R. Does hand hygiene compliance among health care workers change when patients are in contact preceution rooms in ICU?. Am J Infect Control. 2010; 38: 515-7.

108. Patarakul K, Tan-Khum A, Kanha S, Padungpean D, Jaichaiyapum $O O$. Cross- sectional survey of hand-hygiene compliance and attitudes of health care workers and visitors in the intensive care units at King Chulalongkorn Memorial Hospital. J med Assoc Thai. 2005; 88 (suppl 4): S287-93. 
109. Erasmus V, Brouwer W, Van Beeck EF, Oenema A, Daha TJ, Richardus $\mathrm{JH}$, et al. A qualitative exploration of reasons for poor hand hygiene among hospital workers: lack of positive role models and of convincingevidence that hand hygiene prevents cross-infection. Infect Control Hosp epidemiol. 2009; 30: 415-19.

110. Pittet D, Sax H, Hugonnet S, Harbarth S. Cost implications of successful hand hygiene promotion. Infect Control Hosp Epidemiol. 2004; 25 (3): 264-6.

111. Jardim JM, Lacerda RA.Intervenção educacional na redução da taxa de infecção da corrente sanguínea em Unidade de Terapia Intensiva adulto: revisão integrativa [Monografia]. São Paulo: Escola de Enfermagem da Universidade de São Paulo; 2010.

112. Barsuk JH, Cohen ER, Feinglass J, McGahie WC, Wayne DB. Use of simulation-based education to reduce catheter-related bloodstream infections. Arch Intern Med. 2009; 169 (15): 1420-1423.

113. Zingg W, Imhof A, Maggiorini M, Stocker R, Keller E, Ruef C. Impact of a prevention strategy targeting hand hygiene and catheter care on the incidence of catheter-related bloodstream infections. Crit care Med. 2009; 37 (7).

114. Santana SL, Furtado GHC, Wey SB, Medeiros EAS. Impact of an educational program on the incidence of central line-associated bloodstream infection in 2 medical-surgical intensive care units in Brazil. Infect Control Hosp Epidemiol. 2008; 29: 1171-1173.

115. MacCalla S, Downing-Janos T, Ellsworth K, Allinger P, Kirkpatrick K, Zaicek S. Central line-associated blood-stream infections in the ICU: the struggle to achieve and the effort to maintain zero. American journal of Infection Control. 2008; 37 (5): E41. 
116. Warren DK, Zack JE, Mayfield JL, Chen A, Prentice D, Fraser VJ et al. The effect of an education program on the incidence of central venous catheter-associated bloodstream infection in a Medical ICU. Chest. 2004; 126: 1612-1618.

117. Warren DK, Zack JE, Cox MJ, Cohen MM, Fraser VJ. An educational intervention to prevent catheter-associated bloodstream infections in a nonteaching, community medical center. Crit care med. 2003; 31: 19591963.

118. Coopersmith CM, Rebmann TL, Zack JE, Ward MR, Corcoran RM, Schallom ME et al. Effect of an education program on decreasing catheter-related bloodstream infections in the surgical intensive care unit. Crit care Med. 2002; 30: 59-64.

119. Lage, OC. Preparo para alta pós-cirúrgica: resultados da açäo andragógica observados durante visita domiciliar. [Dissertação]. São Paulo: Universidade de São Paulo-Escola de Enfermagem; 2002. 
9 APÊNDICES 


\section{APÊNDICE A - Construto operacional do Indicador CSCM: Avaliação da adesão aos cuidados e manutenção do curativo do cateter venoso central de curta permanência e seus dispositivos conforme recomendações da instituição durante sua utilização.}

Descrição: Após a inserção do cateter, este deve ter sua inserção coberta com curativo estéril que será substituído em intervalos regulares ou de acordo com a necessidade. Eles podem ser feitos com gaze e cobertos com fita adesiva, filmes transparentes sem gaze ou semipermeáveis, e sua escolha deve levar em consideração o conforto para o paciente e o fácil manuseio para os profissionais da saúde ${ }^{(21,31)}$. Para cateteres centrais o tempo para substituição do filme transparente é de até 7 dias ou quando sua integridade estiver comprometida ${ }^{(21,31)}$. Quanto aos curativos com gaze estéril e fita adesiva, estes devem ser trocados pelo menos a cada 48 horas, ou quando apresentar-se sujo ou úmido, ou sua integridade estiver comprometida ${ }^{(21,31)}$. Na instituição em que a pesquisa foi realizada, a periodicidade de troca do curativo com gaze e fita adesiva é feita a cada 24 hs devido as características desta população.

A desinfecção dos conectores com clorexidina alcoólica $0,5 \%$ antes da manipulação é outro importante passo na prevenção de ICS, pois, em primeiro lugar, se a superfície septal não é devidamente desinfetada antes da utilização, o contaminante presente na superfície será forçado pela via intraluminal. Em segundo lugar, as câmaras internas (penetração diferencial septal), uma vez contaminadas são impossíveis de desinfetar. Outros quesitos importantes na manutenção do cateter venoso central são os equipos utilizados para infusão contínua de drogas vasoativas e outras soluções e a coluna de fluídos necessária para a manutenção da permeabilidade do sistema de monitorização de pressão venosa são a porta de entrada para os microrganismos. A troca destes sistemas conforme a recomendação da instituição ou do fabricante reduz significativamente sua contaminação. A periodicidade de troca dos equipos varia de 24 horas à 72 horas $e$ os transdutores não devem exceder 96 horas.

Com base nestes dados este construto irá monitorar: registro em prontuário da troca do curativo do CVC, periodicidade de troca do curativo conforme recomendação da instituição, realização de desinfecção do hub e conexões com clorexidina alcoólica $0,5 \%$ antes do acesso ao CVC e troca de equipos e transdutores conforme as rotinas da instituição. 


\section{Fundamentação Científica:}

- Menyhay S Z, Maki DG. Preventing central venous catheter-associated bloodstream infections: Development of an antiseptic barrier cap for needleless connectors. Am J Infect Control 2008;36 (10): 74-77.

- O'Grady NP, Alexander M, Burns LA,Dellinger EP, garland J, heard SO, et al. Guidelines for the prevention of intravascular catheter-related infections. Draft. $2010 . \quad$ Disponivel em: http://wwwn.cdc.gov/publiccomments/comments/guidelines-for-theprevention-of-intravascular-catheter-related-infections/2038.ashx.

- Brasil. Ministério do Trabalho e emprego. Portaria $n^{\circ} 485$, de 11 de novembro de 2005. Aprova a norma regulamentadora $n^{\circ} 32$ sobre a Segurança e Saúde do Trabalhador em Estabelecimentos de Saúde.

- Diretrizes Práticas para Terapia Intravenosa. Infusion Nurses Society Brasil. 2008.

- Sub Comissão de Controle de Infecção Hospitalar- InCor-HC-FMUSP. Recomendações para controle de infecção hospitalar associada à passagem, uso e manutenção de cateteres intravasculares. São Paulo, $4^{\circ}$ Ed: 20 de março de 2003.

\section{Categoria de evidência: A}

Tipo de avaliação: processo

Numerador do indicador: Oportunidades na qual o profissional teve para anotar a troca de curativo e realizar a troca do curativo conforme recomendação da instituição, desinfecção dos hubs e conectores com clorexidina alcoólica 0,5\% antes da manipulação e dos equipos e transdutores conforme recomendação da instituição.

Denominador do indicador: $\mathrm{N}^{\circ}$ total de pacientes avaliados sob as condições descritas no numerados. 


\section{Fórmula do Indicador:}

№ de oportunidades que o profissional teve para realizar a anotação de realização do curativo, troca do curativo, desinfecção dos hubs e conectores com álcool $70 \%$ antes da manipulação e troca de equipos e transdutores realizada conforme recomendação da instituição

$N^{\circ}$ total de pacientes avaliados sob as condições descritas no numerados

Valor ideal: $100 \%$

Fonte de informação: anotação de enfermagem e observação direta do curativo do CVC e do profissional de saúde realizando tais procedimentos.

\section{Critérios para avaliação:}

A) Desinfecção de hubs e conectores: considerar Atende (A) quando a desinfecção dos hubs e conectores com clorexidina alcoólica $0,5 \%$ for realizada antes da manipulação e acesso aos CVC.

B) Troca de equipos e transdutores: considerar Atende (A) quando troca dos equipos e transdutores for realizada conforme recomendação da instituição.

C) Registro de troca do curativo: considerar Atende (A) quando houver registro na anotação de enfermagem a troca do curativo da inserção do CVC.

D) Troca do curativo: considerar Atende (A) quando a periodicidade da troca do curativo da inserção do CVC for realizado conforme orientação da instituição.

Obs: A presença de situação Não Atende para $A, B, C$ ou $D$ deve ser avaliada como não conforme na conclusão da avaliação deste paciente.

Amostra para análise de conformidade: definida previamente, de forma a garantir representatividade 


\section{APÊNDICE B: Planilha para registro do indicador CSCM: Avaliação da adesão aos cuidados e manutenção do curativo do cateter venoso central de curta permanência e seus dispositivos conforme recomendações da instituição durante sua utilização.}

Setor:

Data:

Avaliador:

Avaliação $\mathrm{n}^{0}$

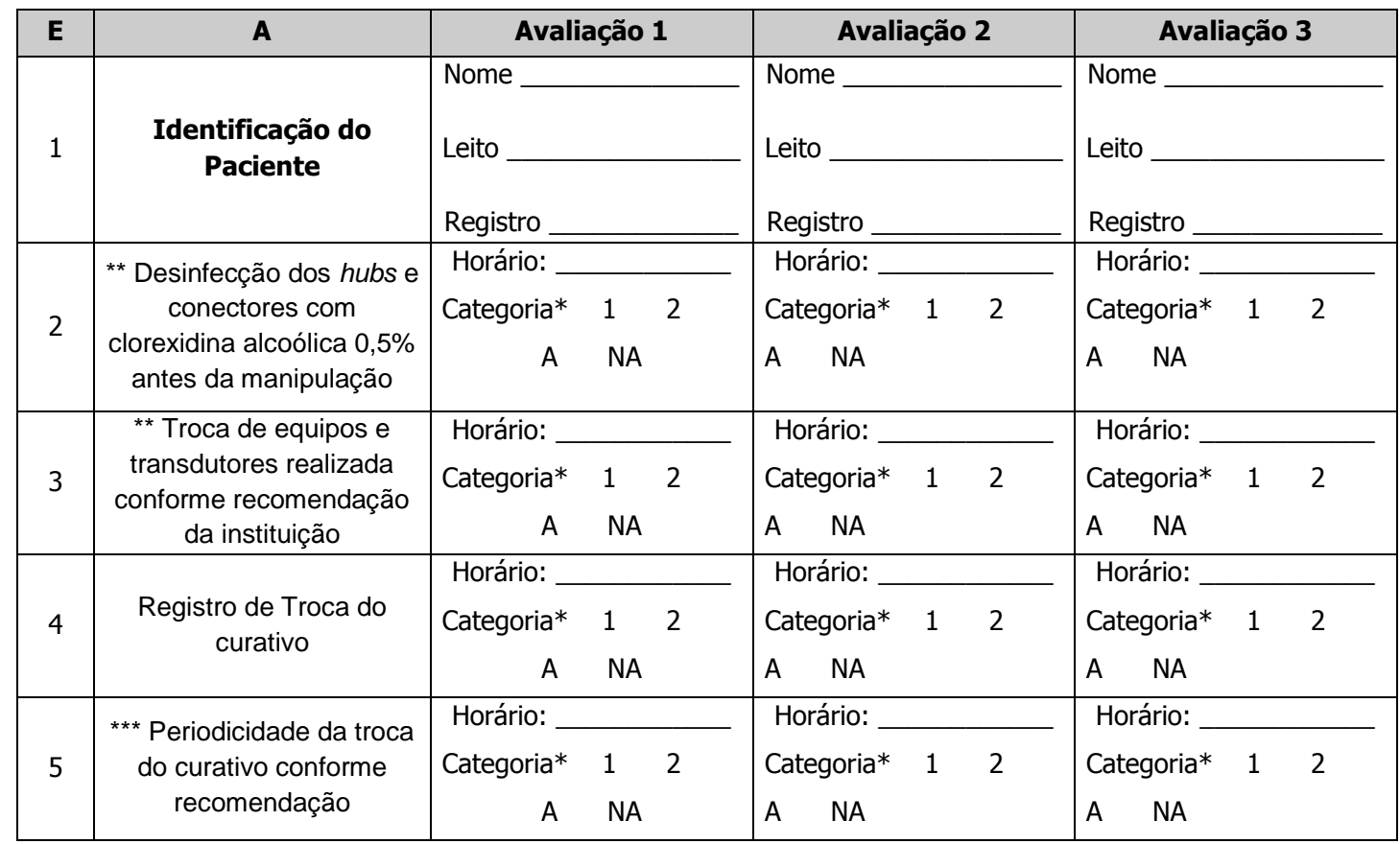

\section{(A) Atende; (NA) Não Atende}

*Categoria - refere-se à categoria profissional, sendo respectivamente: 1-Enfermeiro, 2-Técnico de Enfermagem.

** Considerar ATENDE quando o profissional realizar a desinfecção dos hubs e conectores com clorexidina alcoólica $0,5 \%$ antes da manipulação e a troca de equipos e transdutores é realizada conforme recomendação da instituição.

*** A periodicidade da troca do curativo refere-se:

- curativo com gaze e fita adesiva: troca a cada 24 hs;

- filme transparente: troca a cada 7 dias. 
10 ANEXOS 


\section{ANEXO A - Construto operacional do indicador CSIP: Avaliação dos Registros de Indicação e Tempo de Permanência do Cateter Vascular Central de Curta Permanência ${ }^{(27)}$}

Descrição: a utilização de cateter vascular central e o tempo de sua permanência são as principais causas de ocorrência de infecção da corrente sangüínea em pacientes atendidos em serviços de saúde. Portanto, a indicação criteriosa para a cateterização vascular e a limitação de sua permanência são práticas de melhor evidência para seu controle. Algumas situações clínicas são relatadas na literatura científica para a indicação do cateterismo vascular. No entanto, outras condições clínicas dos pacientes, critérios médicos individuais e protocolos institucionais inviabilizam a avaliação da adequação da indicação do cateter apenas em consonância com a literatura científica. Do mesmo modo, a avaliação de seu tempo de permanência, cujo prazo máximo adequado não é citado na literatura. Uma possibilidade para qualificar estas práticas, pelas instituições, é a definição de protocolos para orientar a indicação e a permanência do cateter vascular central adaptados às suas realidades de assistência. No entanto, a existência de protocolos não é suficiente para garantir que tais práticas sejam adequadamente realizadas, portanto uma avaliação eficaz deve analisar se os protocolos estão sendo respeitados. No momento atual, não são todos os hospitais que possuem protocolos específicos para indicação e permanência do cateter vascular central e, ainda existe a questão da possibilidade de ocorrência de situações clínicas e condutas individuais que justifiquem extrapolar as normas previamente estabelecidas.

Estas dificuldades não podem ser obstáculos para a avaliação da adequação ou conformidade destes procedimentos dada sua importância para o controle de infecção relacionada com a cateterização vascular. A determinação institucional para que os profissionais ao menos apresentem formalmente (registro em prontuário) suas justificativas para a indicação deste procedimento e sua manutenção seria um grande avanço qualitativo.

Considerando esta problemática, optou-se por considerar a existência de registro da justificativa para a realização da cateterização vascular central e a anotação contínua de seu tempo de permanência como indicadores de qualidade assistencial. Tal avaliação, se ainda não é a ideal, ao menos, constata a preocupação profissional ou institucional com a adequação desta prática. 
De outro modo, sugere-se que, durante as avaliações sucessivas, os conteúdos destes registros sejam conservados e tabulados, os quais permitirão análises comparativas de frequências de justificativas de indicação e de tempo de permanência, assim como fornecerão subsídios para a elaboração de um protocolo institucional.

\section{Fundamentação Científica}

- Guidelines for the Prevention of Intravascular Catheter- Related Infections - CDC, Pediatrics. 2002; 110 (5):1-24;

- Guidelines for Preventing Infections Associated with Indwelling Intravascular Access Devices - Division of

- Nosocomial and Occupational Infections - Health Canada. Canada Communicable Disease Report, 1997- Supplement- $23 S 8$.

\section{Categoria de evidência: $A$}

Tipo de Indicador: processo.

Numerador do indicador: cateteres vasculares centrais de curta permanência instalados em pacientes que apresentam registros de justificativa para sua indicação e

registro diário do seu tempo de permanência.

Denominador do indicador: cateteres vasculares centrais de curta permanência instalados, em pacientes, e avaliados.

\section{Fórmula do Indicador:}

No cateteres vasculares centrais de curta permanência instalados em pacientes em que há registros de justificativa para sua indicação e o registro diário do seu tempo de permanência

Total de cateteres vasculares centrais de curta permanência instalados e avaliados

OBS: a forma de construção da planilha de avaliação permite conhecer a conformidade isolada do registro tanto de indicação, quanto de justificativa do tempo de permanência do cateter, transformando, assim, em dois indicadores.

Valor ideal: $100 \%$

Fontes de Informação: prontuário dos pacientes submetidos ao cateterismo vascular central de curta permanência, registros médicos e/ou de enfermagem. 


\section{Critérios para avaliação:}

A) Indicação: considerar Atende (A) quando no prontuário do paciente submetido à cateterização vascular central de curta permanência houver registro de justificativa médica para a instalação deste dispositivo. Incluem situações clínicas como a condição hemodinâmica do paciente (presença de qualquer tipo de choque, com necessidade de aferição e monitoramento de pressão venosa central (PVC), infusão de drogas vasoativas, infusão de altos volumes de líquidos, sangue ou colóides), administração de soluções hipertônicas, administração de drogas citotóxicas, administração de Nutrição Parenteral Total - NPT (sem outro acesso vascular), necessidade de cateterização da artéria pulmonar, necessidade de hemofiltração e acesso venoso periférico difícil ou impossível (queimaduras extensas, imobilização ou amputação de membros superiores).

B) Tempo de permanência: considerar Atende (A) quando no prontuário do paciente submetido à cateterização vascular de curta permanência houver, pelo menos, registro dos dias de permanência do cateter nas anotações de enfermagem ou médicas (contagem do tempo de cateterização).

OBS: A presença da situação Não Atende para $A$ ou $B$ deve ser avaliada como não conforme na conclusão da avaliação deste paciente.

Amostra para análise de conformidade: conforme deliberação do grupo avaliador e/ou necessidade do serviço, a amostra pode ser uma coorte prospectiva (prontuários de pacientes internados que apresentam cateter vascular central de curta permanência instalados no momento de avaliação) ou retrospectiva (prontuários de pacientes que foram submetidos ao cateterismo vascular central com cateter de curta permanência) ou ambas. Esta amostra pode referir-se aos cateterismos realizados em todo o hospital ou em determinada unidade em um período de tempo. Sugestões de planos amostrais para conformidade de amostra são apresentadas no final deste manual.

OBS: Em avaliações sucessivas com objetivos de comparação, após introdução de medidas de melhoria de qualidade, a forma de obtenção da amostra deve ser sempre a mesma.

Planilha para avaliação: página seguinte. 
ANEXO B - Planilha para registro da avaliação do indicador CSIP: Avaliação do Registro de Indicação e Tempo de Permanência do Cateter Vascular Central de Curta Permanência

Período:

Setor:

Avaliador:

Avaliação $\mathrm{n}^{\circ}$.

Data: ......... ......../ ...........

\begin{tabular}{|l|c|c|c|c|c|c|}
\hline Evidência & \multicolumn{2}{|c|}{ A } & \multicolumn{2}{|c|}{ A } & \multicolumn{2}{|c|}{ Conclusão } \\
\hline \multirow{2}{*}{ Paciente } & \multicolumn{2}{|c|}{$\begin{array}{r}\text { Registro de } \\
\text { indicação do cateter }\end{array}$} & \multicolumn{2}{|c|}{$\begin{array}{r}\text { Registro do tempo } \\
\text { de permanência }\end{array}$} & \multicolumn{2}{|c|}{} \\
\cline { 2 - 7 } & A & NA & A & NA & Conforme & Não conforme \\
\hline 1 & & & & & & \\
\hline $\mathbf{2}$ & & & & & & \\
\hline 3 & & & & & & \\
\hline 4 & & & & & & \\
\hline Total & & & & & & \\
\hline
\end{tabular}

A - Atende NA - Não Atende 


\section{ANEXO C - Construto operacional do indicador CSQI: Avaliação da Qualidade da Inserção do Cateter Vascular Central ${ }^{(27)}$}

Descrição: Avalia a escolha da técnica de inserção do cateter vascular central por punção ou por corte (dissecção), monitora a utilização de paramentação completa, incluindo avental de manga longa, gorro, máscara, luvas estéreis e campo estéril ampliado, além da utilização de anti-séptico para preparo da pele do paciente e a oclusão da inserção.

A melhor avaliação para este indicador seria a observação direta dos momentos de realização do procedimento de cateterização vascular. No entanto, a demanda de tempo e de oportunidades necessárias para garantir uma amostra estatisticamente significativa pode inviabilizar esta avaliação na grande maioria das instituições, principalmente, devido à insuficiência de recursos humanos preparados. Esta dificuldade, porém, não pode constituir obstáculo para a avaliação da adequação ou conformidade destes procedimentos devido à sua importância no controle e prevenção da infecção da corrente sangüínea relacionada ao uso de cateterismo central. É possível realizar uma auditoria de processos através da utilização de registros em prontuário e entrevistas com os profissionais responsáveis pela realização do procedimento e de seus cuidados de manutenção. A utilização destas informações contribui, inclusive, para que as instituições melhorem progressivamente seus registros, de maneira que permitam as mais diversas formas de avaliação.

Deste modo, o presente indicador optou por avaliar tais procedimentos através da análise dos registros em prontuários e entrevistas, quando não for possível a observação direta. Tal avaliação, se não é ainda a ideal, ao menos constata preocupação profissional e ou institucional com a adequação desta prática.

OBS:

- Sob possibilidade e decisão do serviço de saúde, esta avaliação pode ser realizada pela observação direta (ideal), porém os critérios para avaliação deverão ser re-definidos.

- Os componentes selecionados para esta avaliação são aqueles de melhores evidências apresentados em diretrizes de recomendações. Isto não exclui, no entanto, a critério do serviço avaliador, a inclusão de outros componentes, tais como: troca de curativos, registro do local de inserção; troca do sistema de infusão, entre outros. 


\section{Fundamentação Científica}

- Guidelines for the Prevention of Intravascular Catheter- Related Infections - CDC, Pediatrics, 2002; 110 (5):1-24.

- Guidelines for Preventing Infections Associated with the Insertion and Maintenance of Central Venous Catheters (EPIC -UK). Journal of Hospital Infection, 2001; 47: S47-S67.

- Guidelines for Preventing Infections Associated with Indwelling Intravascular Access Devices Division of Nosocomial and Occupational Infections - Health Canada. Canada Communicable Disease Report, 1997 Supplement-23S8.

\section{Categoria de evidência: $A$}

Tipo de Indicador: processo.

Numerador do indicador: cateteres vasculares centrais de curta permanência com procedimentos adequados de inserção e manutenção.

Denominador do indicador: cateteres vasculares centrais de curta permanência avaliados quanto à qualidade dos procedimentos de inserção e manutenção.

\section{Fórmula do Indicador:}

№ total de cateteres vasculares centrais de curta permanência com procedimentos corretos de inserção

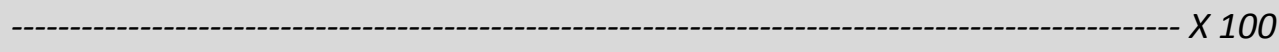

№ total de cateteres vasculares centrais de curta permanência avaliados

OBS: a forma de construção do indicador possibilita também a avaliação individual, tanto do registro da indicação, quanto do tempo de permanência.

Valor ideal: $100 \%$

\section{Fontes de Informação:}

A) Inserção percutânea: registro em prontuário sobre a localização do cateter (evolução médica ou de enfermagem) ou observação direta.

B) Paramentação completa: registro em prontuário ou informação fornecida, pelo enfermeiro responsável pela unidade onde o paciente está internado ou o profissional de enfermagem que acompanhou o procedimento, sobre a paramentação médica utilizada durante a instalação do cateter. 
C) Uso de campo estéril ampliado: registro em prontuário ou informação fornecida pelo enfermeiro responsável pela unidade onde o paciente está internado sobre a utilização de campo estéril ampliado no momento da instalação do cateter.

D) Anti-séptico de veículo alcoólico: registro em prontuário ou informação fornecida pelo enfermeiro responsável pela unidade onde o paciente está internado sobre o produto utilizado no preparo do campo de inserção do cateter.

E) Curativo oclusivo: registro em prontuário do tipo de conduta definido para manutenção da área de inserção do cateter ou observação direta.

OBS:

- Informações no prontuário é a forma ideal.

- A existência, no serviço de saúde, de protocolo implantado para este procedimento não justifica a ausência de registros no prontuário e sua avaliação. Ao contrário, a avaliação permitirá conhecer se este protocolo está sendo acatado.

\section{Critérios para avaliação:}

A) Inserção percutânea: Considerar Atende (A) se a informação coletada definir a presença de cateter de inserção percutânea.

B) Paramentação completa: Considerar Atende (A) se houver registro ou informação da utilização de barreira máxima de proteção pelo médico (gorro, máscara, avental estéril de manga comprida e luvas estéreis) no momento da instalação do cateter.

C) Uso de campo estéril ampliado: considerar Atende (A) quando a informação coletada confirma a utilização de campo estéril durante a realização da instalação do cateter vascular central.

D) Anti-séptico de veículo alcoólico: considerar Atende (A) quando o registro ou a informação coletada confirmar a utilização de anti-séptico veículo alcoólico.

E) Curativo oclusivo: considerar $\underline{\text { Atende }}$ (A) quando a informação coletada registrar a presença de curativo oclusivo do sítio de inserção do cateter com qualquer tipo de cobertura. 
OBS: Considerar Conforme quando todos os registros forem $\underline{\text { Atendidos. }} A$ presença de um Não Atende define a não conformidade para o cateter vascular sob avaliação.

Amostra para análise de conformidade: conforme deliberação do grupo avaliador e/ou necessidade do serviço, a amostra pode ser uma coorte prospectiva (prontuários de pacientes internados que apresentam cateter vascular central de curta permanência instalados no momento de avaliação) ou retrospectiva (prontuários de pacientes que foram submetidos ao cateterismo vascular central com cateter de curta permanência) ou ambas. Esta amostra pode referir-se aos cateterismos realizados em todo o hospital ou em determinada unidade em um período de tempo.

Sugestões de planos amostrais para conformidade de amostra são apresentadas no final deste manual.

OBS: Em avaliações sucessivas com objetivos de comparação, após introdução de medidas de melhoria de qualidade, a forma de obtenção da amostra e de avaliação deve ser sempre a mesma

Planilha para avaliação: página seguinte. 
ANEXO D - Planilha para registro da avaliação do indicador CSQI: Avaliação da Qualidade da Inserção e Manutenção do Cateter Vascular Central ${ }^{(27)}$

Período:

Setor:

Avaliador:

Amostra:

Avaliação $\mathrm{n}^{\circ}$

\begin{tabular}{|c|c|c|c|c|c|c|c|c|c|c|c|c|}
\hline \multirow{2}{*}{ CVC } & \multicolumn{2}{|c|}{$\begin{array}{l}\text { Inserção } \\
\text { Percutânea }\end{array}$} & \multicolumn{2}{|c|}{$\begin{array}{c}\text { Paramentação } \\
\text { Completa }\end{array}$} & \multicolumn{2}{|c|}{$\begin{array}{l}\text { Uso de } \\
\text { campo } \\
\text { estéril }\end{array}$} & \multicolumn{2}{|c|}{$\begin{array}{c}\text { Anti-séptico } \\
\text { de veículo } \\
\text { alcoólico }\end{array}$} & \multicolumn{2}{|c|}{$\begin{array}{l}\text { Curativo } \\
\text { oclusivo }\end{array}$} & \multicolumn{2}{|c|}{ Conclusão } \\
\hline & A & NA & A & NA & A & NA & A & NA & A & NA & Conf. & $\begin{array}{l}\text { Não } \\
\text { Conf. }\end{array}$ \\
\hline 1 & & & & & & & & & & & & \\
\hline 2 & & & & & & & & & & & & \\
\hline 3 & & & & & & & & & & & & \\
\hline $\mathbf{n}$ & & & & & & & & & & & & \\
\hline Total & & & & & & & & & & & & \\
\hline
\end{tabular}

CVC - cateter vascular central de curta permanência
A-Atende
NA - Não Atende

OBS: Considerar Conforme quando todos os registros forem Atendidos. A presença de um Não Atende define a não conformidade para o cateter vascular sob avaliação. 


\section{ANEXO E - Construto operacional do indicador HMSEL: avaliação da adesão à higiene das mãos ${ }^{(27)}$}

Descrição: Monitora e registra as ocasiões de adesão à higiene das mãos, nas oportunidades em que é necessária. Essa é uma prática unanimemente considerada como uma das principais ações de controle de infecção adquirida em serviços de saúde e internacionalmente recomendada nos seguintes casos: antes e após o contato direto com pacientes, após contato com materiais orgânicos e hospitalares contaminados, quando as mãos estiverem visivelmente sujas, após contato com membrana mucosa, com pele não íntegra, curativos e após a retirada das luvas, mesmo quando não estiverem visivelmente sujas. Dentro das recomendações, visando à redução de transmissão de microrganismos potencialmente patogênicos para pacientes e entre os próprios profissionais de saúde, inclui-se a higienização das mãos ao realizar um procedimento em uma área contaminada para outra no mesmo paciente. A descontaminação das mãos pode ser realizada com água e sabão com ou sem anti-sépticos ou, ainda, com solução alcoólica ${ }^{93}$. Outras recomendações importantes referem-se à higienização das mãos antes de hábitos higiênicos, bem como antes de se alimentar e após uso do toalete.

A avaliação pode ser aplicada em todas as unidades do hospital, em unidades previamente selecionadas (a critério do grupo avaliador) ou sempre que houver algum surto de infecção que possa estar diretamente relacionado à má prática da higiene das mãos (onfalite, conjuntivite, impetigo, infecções cutâneas, infecção de sítio cirúrgico e outros).

\section{Fundamentação científica:}

- CCDR. Infection Control Guidelines: hand washing, cleaning, disinfection and sterilization in health care. Health Canada. Can Commun Dis Rep. 1998, 24S8:1-55. Disponível em: <http://www.hc-sc.gc.ca/hph/lcdc>. Acesso em 24 mai 2009.

- Boyce JM, Pittet D. Guideline for hand hygiene in health-care settings: recommendations of the Healthcare Infection Control Practices Advisory Committee and the SHEA, APIC, IDSA Hand Hygiene Force Task. Infect Control Hosp Epidemiol. 2002, 23(S): 3-40. 
- Brasil. Ministério da Saúde. Portaria n 2.616, de 12 de maio de 1998. Dispõe sobre as diretrizes e normas para a prevenção e o controle das infecções hospitalares. Diário Oficial da União n 89, 12 de maio de 1998 p. 232-6.

- Guideline for Hand Hygiene in Health Care Settings: Recommendations of The Healthcare Infection Control Practices Advisory Committee and HICPAC/SHEA/APIC/IDSA hand Hygiene Task Force. Supplement 2002.

- Ministério da Saúde. Portaria no 2616, de 12 de maio de 1998 - publicada no D.O.U. no 89, 13 de maio de 1998 pg 133. Programa de Controle de Infecção Hospitalar.

\section{Categorias de evidências:}

- C: os componentes de avaliação (categoria profissional, situação de emergência, cateter venoso central, isolamento, ventilação mecânica e traqueostomia) não apresentam classificação específica nos guias de diretrizes estudadas, mas são importantes para auxiliar a interpretação dos resultados encontrados. A identificação da categoria profissional contribui para definir estratégias específicas, segundo o achado. As situações de emergência interferem na adesão à higiene das mãos. A presença de dispositivos invasivos (cateter venoso central, ventilação mecânica e traqueostomia) e/ou a condição infecciosa do paciente com necessidade de isolamento demonstra, indiretamente, a gravidade de cada paciente e determinam o volume de trabalho dos profissionais de saúde naquela unidade;

- A e B: Trato respiratório (aspiração traqueal, higiene oral, troca de cadarço, coleta secreção, troca de equipamento respiratório);

- A e B: Linhas vasculares (punção, troca do sistema de infusão, instalação de cateter vascular central, administração de medicamentos, troca ou realização de curativo, coleta de sangue);

- A e B: Trato urinário (instalação de sonda vesical, higiene íntima, coleta de urina para exame laboratorial, controle de diurese);

- A e B: Pele (banho no leito, curativos de incisão/inserção/escara, massagem de conforto, cuidados com estoma);

- A e B: Sondas digestivas, gástrica ou enteral: instalação ou retirada de sonda ou alimentação, controle de débito;

- A e B: Outros (mudança de decúbito, medicação intramuscular, transporte, exame físico). 
Tipo de avaliação: processo.

Numerador do indicador: oportunidades que o profissional de saúde teve para higienizar as mãos e efetivamente o fez (total de adesão à higiene das mãos entre as oportunidades selecionadas).

Denominador do indicador: oportunidades de higiene das mãos observadas.

\section{Fórmula do Indicador:}

№ total de oportunidades que o profissional de saúde teve para higienizar as mãos e efetivamente o fez ---

№ total de oportunidades de higiene das mãos observadas

Valor ideal: $100 \%$

Fontes de informação: conforme a planilha para registro:

- 1 a 6: Categoria profissional, situação de emergência, cateter venoso central, isolamento, ventilação mecânica e traqueostomia: observação direta ou prontuário do paciente.

- 7 a 12: Oportunidades descritas no cuidado com o trato respiratório, as linhas vasculares, o trato urinário, a pele, as sondas digestivas ou outros procedimentos: observação direta do profissional quanto à higiene das mãos antes e depois de qualquer uma das oportunidades descritas.

Critérios para avaliação: avaliação pontual ou por pequeno período. Definir qual ou quais unidades serão visitadas. Essa escolha deve ser feita de maneira sigilosa para que a equipe local haja de maneira natural. Preencher o cabeçalho do instrumento com as informações necessárias e dirigir-se à unidade. Cada coluna desse instrumento descreve uma categoria profissional que está sendo observada. $O$ instrumento foi criado de maneira que um observador possa simultaneamente observar e registrar informações referentes a várias oportunidades e a muitas categorias profissionais. Cada linha do instrumento refere-se a uma ou mais oportunidades observadas para um profissional. Caso haja observação de mais de uma categoria profissional, colocar em colunas distintas, pois cada um pode ter uma postura com relação à higiene das mãos. Quando um profissional está sendo observado, concentrar no preenchimento da linha (7 a 10) da oportunidade que está ocorrendo. 
- 1 a 6: Categoria profissional, situação de emergência, cateter venoso central, isolamento, ventilação mecânica e traqueostomia: Categoria profissional apenas uma constatação; demais itens (linha 2 a 6) - a resposta Sim vai demonstrar indiretamente a invasividade e gravidade dos pacientes.

- 7 a 12: Oportunidades descritas no cuidado com trato respiratório, linhas vasculares, trato urinário, pele, sondas digestivas ou outros procedimentos: registrar $\underline{\text { Sim ou Não, }}$ antes ou depois da oportunidade observada, classificandose como "Conforme" a observação positiva. Caso não tenha sido possível observar a oportunidade do início (higiene das mãos antes), deixar essa linha em branco. No final, a situação para essa oportunidade não será computada.

OBS:

a) Contar quantas oportunidades foram observadas no total, somando todos os itens preenchidos das linhas 7 a 12;

b) Contar quantas oportunidades para cada sítio específico (linhas 7 a 12) somando as colunas $x$ linhas preenchidas e subdividindo em ANTES $e$ DEPOIS;

c) Contar quantas oportunidades cuja resposta à aderência foi SIM, considerando que isso signifique conformidade;

d) $O$ indicador pode ser calculado de forma geral, utilizando-se todas as oportunidades observadas (denominador) e todas as respostas positivas (numerador) ou estudado por oportunidade (trato respiratório, linhas vasculares, etc) e/ou por categoria profissional e/ou por situação de emergência, etc;

e) Os períodos de observação devem ser selecionados de forma aleatória com o objetivo de assegurar o máximo de sigilo ao observador para que a coleta da informação seja a mais próxima da verdadeira prática;

f) Cada observador deve ser treinado para identificar a oportunidade e preencher o instrumento de forma discreta.

Amostra para análise de conformidade: deverá ser definida previamente, de forma a garantir representatividade da totalidade da realizada sob observação.

Planilha para avaliação: página seguinte. 


\section{ANEXO F - Planilha para registro do indicador HMSEL ${ }^{\star *}$ : avaliação da adesão à higiene das mãos ${ }^{(27)}$}

Setor:

Data:

Avaliador:

Avaliação $\mathrm{n}^{0}$

\begin{tabular}{|c|c|c|c|c|c|c|c|}
\hline $\mathbf{E}$ & $\mathbf{A}$ & \multicolumn{2}{|c|}{ Avaliação 1} & \multicolumn{2}{|c|}{ Avaliação 2} & \multicolumn{2}{|c|}{ Avaliação 3} \\
\hline 1 & $\begin{array}{c}\text { Identificação do } \\
\text { Paciente }\end{array}$ & $\begin{array}{l}\text { Nome } \\
\text { Leito } \\
\text { Registro }\end{array}$ & & $\begin{array}{l}\text { Nome } \\
\text { Leito } \\
\text { Registro }\end{array}$ & & $\begin{array}{l}\text { Nome } \\
\text { Leito } \\
\text { Registro }\end{array}$ & - \\
\hline 2 & $\begin{array}{c}\text { Cateter venoso central } \\
\text { Troca do sistema de } \\
\text { infusão }\end{array}$ & $\begin{array}{l}\text { Horário: } \\
\text { Antes } \square \operatorname{sim} \\
\text { Depois } \square \operatorname{sim} \\
\text { Categoria* } 1 \\
\text { Aluno } \square \text { sim }\end{array}$ & 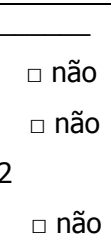 & $\begin{array}{l}\text { Horário: } \\
\text { Antes } \square \operatorname{sim} \\
\text { Depois } \square \operatorname{sim} \\
\text { Categoria* } 1 \\
\text { Aluno } \square \text { sim }\end{array}$ & 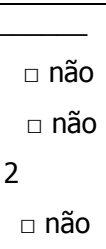 & $\begin{array}{l}\text { Horário: } \\
\text { Antes } \square \operatorname{sim} \\
\text { Depois } \square \operatorname{sim} \\
\text { Categoria* } 1 \\
\text { Aluno } \square \text { sim }\end{array}$ & 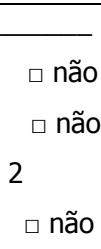 \\
\hline 3 & Coleta de Sangue & $\begin{array}{l}\text { Horário: } \\
\text { Antes } \square \operatorname{sim} \\
\text { Depois } \square \operatorname{sim} \\
\text { Categoria* } 1 \\
\text { Aluno } \square \text { sim }\end{array}$ & 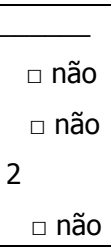 & $\begin{array}{l}\text { Horário: } \\
\text { Antes } \square \operatorname{sim} \\
\text { Depois } \square \operatorname{sim} \\
\text { Categoria* } 1 \\
\text { Aluno } \square \text { sim }\end{array}$ & 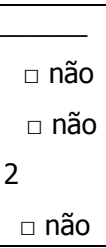 & $\begin{array}{l}\text { Horário: } \\
\text { Antes } \square \operatorname{sim} \\
\text { Depois } \square \operatorname{sim} \\
\text { Categoria* } 1 \\
\text { Aluno } \square \text { sim }\end{array}$ & 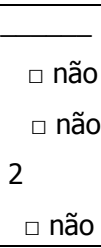 \\
\hline 4 & $\begin{array}{l}\text { Administração de } \\
\text { Medicamentos }\end{array}$ & $\begin{array}{l}\text { Horário: } \\
\text { Antes } \square \operatorname{sim} \\
\text { Depois } \square \operatorname{sim} \\
\text { Categoria* } 1 \\
\text { Aluno } \square \text { sim }\end{array}$ & $\begin{array}{l}\square \text { não } \\
\square \text { não } \\
2 \begin{array}{l}\square \text { não }\end{array}\end{array}$ & $\begin{array}{l}\text { Horário: } \\
\text { Antes } \square \operatorname{sim} \\
\text { Depois } \square \operatorname{sim} \\
\text { Categoria* } 1 \\
\text { Aluno } \square \text { sim }\end{array}$ & $\begin{array}{l}\square \text { não } \\
\square \text { não } \\
2 \begin{array}{l}\square \text { não }\end{array}\end{array}$ & $\begin{array}{l}\text { Horário: } \\
\text { Antes } \square \operatorname{sim} \\
\text { Depois } \square \operatorname{sim} \\
\text { Categoria* } 1 \\
\text { Aluno } \square \text { sim }\end{array}$ & 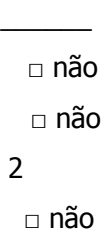 \\
\hline 5 & $\begin{array}{c}\text { Troca e realização de } \\
\text { curativo }\end{array}$ & $\begin{array}{l}\text { Horário: } \\
\text { Antes } \square \operatorname{sim} \\
\text { Depois } \square \operatorname{sim} \\
\text { Categoria* } 1 \\
\text { Aluno } \square \operatorname{sim}\end{array}$ & 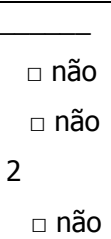 & $\begin{array}{l}\text { Horário: } \\
\text { Antes } \square \operatorname{sim} \\
\text { Depois } \square \operatorname{sim} \\
\text { Categoria* } 1 \\
\text { Aluno } \square \operatorname{sim}\end{array}$ & 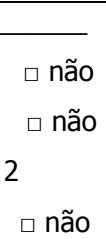 & $\begin{array}{l}\text { Horário: } \\
\text { Antes } \square \operatorname{sim} \\
\text { Depois } \square \operatorname{sim} \\
\text { Categoria* } 1 \\
\text { Aluno } \square \operatorname{sim}\end{array}$ & 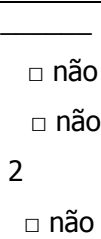 \\
\hline
\end{tabular}

\footnotetext{
*Categoria refere-se à categoria profissional, sendo respectivamente:

1- Enfermeiro

2- Técnico de Enfermagem
}

** Contém apenas as situações selecionadas para o desenvolvimento do presente estudo.

\section{Observações:}




\title{
ANEXO G
}

\section{hOSPITAL dAS Clínicas da fACULdAde de MEDICINA DA UNIVERSIDADE DE SÃO PAULO-HCFMUSP}

\author{
TERMO DE CONSENTIMENTO LIVRE E ESCLARECIDO
}

PROFISSIONAL

DADOS DE IDENTIFICAÇÃO DO SUJEITO DA PESQUISA OU RESPONSÁVEL LEGAL

1. NOME:

DOCUMENTO DE IDENTIDADE № : SEXO :.$M \square F \square$ DATA NASCIMENTO: № APTO:

ENDEREÇO: CIDADE

BAIRRO:

CEP: TELEFONE: DDD (...)

2.RESPONSÁVEL LEGAL

NATUREZA (grau de parentesco, tutor, curador etc.)

DOCUMENTO DE IDENTIDADE: SEXO: $M \square F \square$

DATA NASCIMENTO: № APTO:

ENDEREÇO: CIDADE:

BAIRRO:

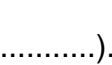

\section{DADOS SOBRE A PESQUISA}

1. TÍTULO DO PROTOCOLO DE PESQUISA: “Avaliação das Práticas de Prevenção e Controle de Infecção da Corrente Sanguínea associada ao Cateter Venoso Central de curta Permanência por Meio de Indicadores Clínicos"

PESQUISADOR : Enf Jaquelline Maria Jardim ${ }^{1}$, Enf Dra Marcia Cristina da Silva Magro ${ }^{2}$

CARGO/FUNÇÃO: .Enfermeira da Unidade de Terapia Intensiva Cirúrgica - InCor - HCFMUSP Mestranda do Programa em Pós-Graduação de Enfermagem na Saúde do Adulto da Escola de Enfermagem da USP ${ }^{1}$,

Enfermeira da Unidade de Terapia Intensiva Cirúrgica - InCor - HCFMUSP Doutora em Saúde do Adulto pela da Escola de Enfermagem da USP ${ }^{2}$.

INSCRIÇÃO CONSELHO REGIONAL DE ENFERMAGEM - SP - $126024^{1}$ '- $39432^{2}$.

UNIDADE DO HCFMUSP: Instituto do Coração. 
3. AVALIAÇÃO DO RISCO DA PESQUISA:

$\begin{array}{ll}\text { RISCO MÍNIMO } \mathbf{X} & \text { RISCO MÉDIO } \\ \text { RISCO BAIXO } \quad \square & \text { RISCO MAIOR }\end{array}$

(probabilidade de que o indivíduo sofra algum dano como consequêencia imediata ou tardia do estudo)

4.DURAÇÃO DA PESQUISA : 6 semanas para os participantes

Versão.2 de 30 de julho de 2010. 


\section{HOSPITAL DAS CLÍNICAS DA FACULDADE DE MEDICINA DA UNIVERSIDADE DE SÃO PAULO-HCFMUSP}

1 - Venho convidar o $\operatorname{Sr}($ a) para participar deste estudo que tem como objetivo avaliar se as práticas de prevenção e controle de infecção da corrente sanguínea (quando microorganismos atingem o sangue) associada ao cateter venoso central de curta permanência (cateter colocado em veia de grande calibre - jugular, subclávia e femoral) estão sendo seguidas corretamente;

2 - Os procedimentos avaliados na pesquisa estão relacionados com a prática de colocação do cateter venoso central antes da cirurgia cardíaca (inserção percutânea; uso de máscara, gorro, avental estéril, luvas estéreis; uso de campo estéril no momento da instalação do cateter; uso de anti-séptico de veículo alcoólico para preparo da pele do paciente; presença de curativo oclusivo após inserção do cateter) indicação deste cateter, tempo de permanência do cateter e se os profissionais estão lavando as mãos com sabonete degermante (anti-séptico) ou usando álcool gel nas mãos antes e após a troca de equipos, administração de medicamentos, troca e realização de curativo e coleta de sangue.

3 - A coleta dos dados da pesquisa se dará por meio de observação dos profissionais que colocam, cuidam e/ou mexem no cateter, além de análise de registros de prontuários, o que não irá alterar em nada na rotina dos profissionais da saúde e cuidados com o paciente;

4 - Não haverá desconfortos e riscos esperados nos procedimentos dos itens 2 e 3; 5 - Não há benefício direto para o participante por tratar-se de um estudo experimental com a hipótese de que os profissionais da saúde não tomam os devidos cuidados durante os procedimentos relacionados ao cateter venoso central, que vão desde sua colocação até os cuidados, como meio de evitar a infecção da corrente sanguínea (quando microorganismos atingem o sangue). Somente com estes resultados poderemos agir e corrigir os erros e com isso gerar os benefícios que serão futuros;

6 - Não haverá procedimentos alternativos para tal pesquisa;

7 - O Sr(a) terá acesso: em qualquer etapa do estudo, você terá acesso aos profissionais responsáveis pela pesquisa para esclarecimento de eventuais dúvidas. O principal investigador é a Enf Dra. Marcia Cristina da Silva Magro, que pode ser encontrado no endereço Av. Dr. Enéas de Carvalho Aguiar, 44, $4^{\circ}$ Andar Telefone(s) 3069-5654 ramais 5053, 5648, 5653. Se você tiver alguma 
consideração ou dúvida sobre a ética da pesquisa, entre em contato com o Comitê de Ética em Pesquisa (CEP) - Rua Ovídio Pires de Campos, 225 - 5a andar - tel: 3069-6442 ramais 16, 17, 18 ou 20, FAX: 3069-6442 ramal 26 - E-mail: cappesq@hcnet.usp.br

8 - É garantida a liberdade da retirada de consentimento a qualquer momento que queira deixar de participar do estudo, sem qualquer prejuízo à continuidade de seu tratamento na Instituição;

09 - Direito de confidencialidade - As informações obtidas serão analisadas em conjunto com outros pacientes, não sendo divulgada a identificação de nenhum paciente;

10 - Direito de ser mantido atualizado sobre os resultados parciais das pesquisas, quando em estudos abertos, ou de resultados que sejam do conhecimento dos pesquisadores;

11 - Despesas e compensações: não há despesas pessoais para o participante em qualquer fase do estudo, incluindo exames e consultas. Também não há remuneração financeira relacionada à sua participação. Se existir qualquer despesa adicional, ela será absorvida pelo orçamento da pesquisa.

12 - Compromisso do pesquisador de utilizar os dados e o material coletado somente para esta pesquisa.

Acredito ter sido suficientemente informado a respeito das informações que li ou que foram lidas para mim, descrevendo o estudo "Avaliação das Práticas de Prevenção e Controle de Infecção da Corrente Sanguínea associada ao Cateter Venoso Central de curta Permanência por Meio de Indicadores Clínicos" 


\section{HOSPITAL DAS CLÍNICAS DA FACULDADE DE MEDICINA DA UNIVERSIDADE DE SÃO PAULO-HCFMUSP}

Eu discuti com a Enf Dra. Marcia Cristina da Silva Magro sobre a minha decisão em participar nesse estudo. Ficaram claros para mim quais são os propósitos do estudo, os procedimentos a serem realizados, seus desconfortos e riscos, as garantias de confidencialidade e de esclarecimentos permanentes. Ficou claro também que minha participação não terá despesas e que tenho garantia do acesso a tratamento hospitalar quando necessário. Concordo voluntariamente em participar deste estudo e poderei retirar o meu consentimento a qualquer momento, antes ou durante o mesmo, sem penalidades ou prejuízo ou perda de qualquer benefício que eu possa ter adquirido, ou no meu atendimento neste Serviço.

Assinatura do paciente/representante legal

Data $1 / 1$

Assinatura da testemunha

Data 11

para casos de pacientes menores de 18 anos, analfabetos, semi-analfabetos ou portadores de deficiência auditiva ou visual.

(Somente para o responsável do projeto)

Declaro que obtive de forma apropriada e voluntária o Consentimento Livre e Esclarecido deste paciente ou representante legal para a participação neste estudo.

Data

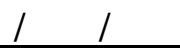




\section{ANEXO H}

\section{HOSPITAL DAS CLÍNICAS DA FACULDADE DE MEDICINA DA UNIVERSIDADE DE SÃO PAULO-HCFMUSP}

TERMO DE CONSENTIMENTO LIVRE E ESCLARECIDO

PACIENTE

DADOS DE IDENTIFICAÇÃO DO SUJEITO DA PESQUISA OU RESPONSÁVEL LEGAL

1. NOME:

DOCUMENTO DE IDENTIDADE № : SEXO : $M \square F \square$ DATA NASCIMENTO: .........................

ENDEREÇO: №. APTO:

BAIRRO: CIDADE

CEP: TELEFONE: DDD

2.RESPONSÁVEL LEGAL

NATUREZA (grau de parentesco, tutor, curador etc.)

DOCUMENTO DE IDENTIDADE: SEXO: $M \square F \square$

DATA NASCIMENTO: ..............

ENDEREÇO: № APTO:

BAIRRO: CIDADE:

CEP: TELEFONE: DDD

\section{DADOS SOBRE A PESQUISA}

1. TíTULO DO PROTOCOLO DE PESQUISA: "Avaliação das Práticas de Prevenção e Controle de Infecção da Corrente Sanguínea associada ao Cateter Venoso Central de curta Permanência por Meio de Indicadores Clínicos"

PESQUISADOR : Enf Jaquelline Maria Jardim ${ }^{1}$, Enf Dra Marcia Cristina da Silva Magro ${ }^{2}$ CARGO/FUNÇÃO: .Enfermeira da Unidade de Terapia Intensiva Cirúrgica - InCor - HCFMUSP Mestranda do Programa em Pós-Graduação de Enfermagem na Saúde do Adulto da Escola de Enfermagem da USP ${ }^{1}$,

Enfermeira da Unidade de Terapia Intensiva Cirúrgica - InCor - HCFMUSP Doutora em Saúde do Adulto pela da Escola de Enfermagem da USP ${ }^{2}$.

INSCRIÇÃO CONSELHO REGIONAL DE ENFERMAGEM - SP - $126024^{1}$ '- $39432^{2}$. UNIDADE DO HCFMUSP: Instituto do Coração. 
3. AVALIAÇÃO DO RISCO DA PESQUISA:

$\begin{array}{ll}\text { RISCO MÍNIMO } \mathbf{X} & \text { RISCO MÉDIO } \\ \text { RISCO BAIXO } \quad \square & \text { RISCO MAIOR }\end{array}$

(probabilidade de que o indivíduo sofra algum dano como consequêencia imediata ou tardia do estudo)

4.DURAÇÃO DA PESQUISA : 6 semanas para os participantes

Versão.1 de 30 de julho de 2010. 


\section{hOSPITAL DAS CLÍNICAS DA FACULdADE DE MEDICINA DA UNIVERSIDADE DE SÃO PAULO-HCFMUSP}

1 - A participação neste estudo é voluntária e tem como objetivo avaliar se as práticas de prevenção e controle de infecção da corrente sanguínea (quando bactérias atingem o sangue) associada ao cateter venoso central de curta permanência (cateter colocado em uma veia do pescoço ou da virilha para receber medicação durante e após a cirurgia) estão sendo seguidas corretamente;

2 - Os procedimentos avaliados na pesquisa estão relacionados com a prática de colocação do cateter na veia do pescoço ou virilha antes da cirurgia cardíaca, indicação deste cateter, tempo de permanência do cateter e se os profissionais estão lavando as mãos ou usando álcool gel nas mãos antes de cuidar ou mexer no cateter colocado em uma veia do pescoço ou da virilha;

3 - A coleta dos dados da pesquisa se dará por meio de observação dos profissionais que cuidam e/ou manipulam o cateter, além de análise de registros de prontuários, o que não irá alterar em nada na rotina dos profissionais da saúde e cuidados com o paciente;

4 - Não haverá desconfortos e riscos esperados nos procedimentos dos itens 2 e 3; 5 - Não há benefício direto para o participante por trata-se de um estudo experimental com a hipótese de que os profissionais da saúde não tomam os devidos cuidados durante os procedimentos relacionados ao cateter colocado na veia do pescoço ou da virilha, que vão desde sua colocação até a manutenção, como meio de evitar a infecção do sangue (quando bactérias atingem o sangue). Somente com estes resultados poderemos agir e corrigir os erros e com isso gerar os benefícios que serão futuros;

6 - Não haverá procedimentos alternativos para tal pesquisa;

7 - Garantia de acesso: em qualquer etapa do estudo, você terá acesso aos profissionais responsáveis pela pesquisa para esclarecimento de eventuais dúvidas. O principal investigador é a Enf Dra. Marcia Cristina da Silva Magro, que pode ser encontrado no endereço Av. Dr. Enéas de Carvalho Aguiar, 44, $4^{\circ}$ Andar Telefone(s) 3069-5654 ramais 5053, 5648, 5653. Se você tiver alguma consideração ou dúvida sobre a ética da pesquisa, entre em contato com o Comitê de Ética em Pesquisa (CEP) - Rua Ovídio Pires de Campos, 225 - 5ํandar - tel: 3069-6442 ramais 16, 17, 18 ou 20, FAX: 3069-6442 ramal 26 - E-mail: cappesq@hcnet.usp.br 
8 - É garantida a liberdade da retirada de consentimento a qualquer momento que queira deixar de participar do estudo, sem qualquer prejuízo à continuidade de seu tratamento na Instituição;

09 - Direito de confidencialidade - As informações obtidas serão analisadas em conjunto com outros pacientes, não sendo divulgada a identificação de nenhum paciente;

10 - Direito de ser mantido atualizado sobre os resultados parciais das pesquisas, quando em estudos abertos, ou de resultados que sejam do conhecimento dos pesquisadores;

11 - Despesas e compensações: não há despesas pessoais para o participante em qualquer fase do estudo, incluindo exames e consultas. Também não há remuneração financeira relacionada à sua participação. Se existir qualquer despesa adicional, ela será absorvida pelo orçamento da pesquisa. O paciente continuará tendo direito de assistência no ambulatório do Instituto do Coração-InCor no grupo em que está matriculado.

12 - Compromisso do pesquisador de utilizar os dados e o material coletado somente para esta pesquisa.

Acredito ter sido suficientemente informado a respeito das informações que li ou que foram lidas para mim, descrevendo o estudo "Avaliação das Práticas de Prevenção e Controle de Infecção da Corrente Sanguínea associada ao Cateter Venoso Central de curta Permanência por Meio de Indicadores Clínicos”. 


\section{HOSPITAL DAS CLÍNICAS DA FACULDADE DE MEDICINA DA UNIVERSIDADE DE SÃO PAULO-HCFMUSP}

Eu discuti com a Enf Dra. Marcia Cristina da Silva Magro sobre a minha decisão em participar nesse estudo. Ficaram claros para mim quais são os propósitos do estudo, os procedimentos a serem realizados, seus desconfortos e riscos, as garantias de confidencialidade e de esclarecimentos permanentes. Ficou claro também que minha participação não terá despesas e que tenho garantia do acesso a tratamento hospitalar quando necessário. Concordo voluntariamente em participar deste estudo e poderei retirar o meu consentimento a qualquer momento, antes ou durante o mesmo, sem penalidades ou prejuízo ou perda de qualquer benefício que eu possa ter adquirido, ou no meu atendimento neste Serviço.

Assinatura do paciente/representante legal

Data

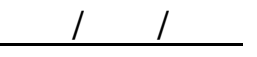

Assinatura da testemunha

Data

para casos de pacientes menores de 18 anos, analfabetos, semi-analfabetos ou portadores de deficiência auditiva ou visual.

\section{(Somente para o responsável do projeto)}

Declaro que obtive de forma apropriada e voluntária o Consentimento Livre e Esclarecido deste paciente ou representante legal para a participação neste estudo.

Data

11




\section{ANEXO}

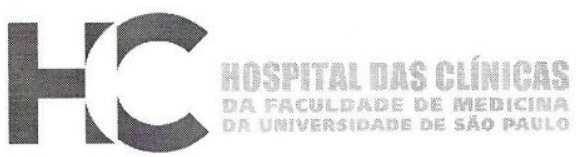

\section{APROVAÇÃO}

A Comissão de Ética para Análise de Projetos de Pesquisa CAPPesa da Diretoria Clínica do Hospital das Clínicas e da Faculdade de Medicina da Universidade de São Paulo, em sessão de 25/08/2010, APROVOU O Protocolo de Pesquisa $n^{\circ}$ 0382/10, intitulado: "AVALIAÇÃO DAS PRÁtICAS DE PREVENÇÃO E CONTROLE DE INFECÇÃO DA CORRENTE SANGUÍNEA ASSOCIADA A CATETER VENOSO CENTRAL DE CURTA PERMANÊNCIA POR MEIO DE INDICADORES CLÍNICOS." apresentado pela COMISSĀO CIENTíFICA DO INCOR, inclusive o Termo de Consentimento Livre e Esclarecido versão 2 de 30.07.10.

Cabe ao pesquisador elaborar e apresentar à CAPPesq, os relatórios parciais e final sobre a pesquisa (Resolução do Conselho Nacional de Saúde n 196, de 10/10/1996, inciso IX.2, letra "c").

Pesquisador (a) Responsável: Marcia Cristina Silva Magro

Pesquisador (a) Executante: Jaquelline Maria Jardim

CAPPesq, 26 de Agosto de 2010

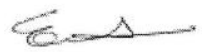

Prof. Dr. Eduardo Massad

Presidente da Comissão de Ética para Análise de Projetos de Pesquisa

COMISSÄO CIENTIFICA RECEBIDO

$27 / 08 / 10$

Comissão de Ética para Análise de Projetos de Pesquisa do HCFMUSP e da FMUSP Diretoria Clínica do Hospital das Clínicas da Faculdade de Medicina da Universidade de São Paulo Rua Ovídio Pires de Campos, 225, 5 andar - CEP 05403010 - São Paulo - SP Fone: 01130696442 Fax: 01130696492 e-mail: cappesq@hcnet.usp.br/ secretariacappesq2@hcnet.usp.br 